\title{
COMPARACIÓN DE HERRAMIENTAS SIG PARA LA EVALUACIÓN DE PROYECTOS DE INFRAESTRUCTURA DE TRANSPORTE EN EL ÁREA METROPOLITANA DE CONCEPCIÓN - CHILE
}

Tesis de Maestría

$$
\text { HELEN DE LA FUENTE }
$$

Presentada ante la Facultad de Ingeniería de la Universidad Nacional de La Plata como requisito para la obtención del grado académico de MAGÍSTER EN GEOMÁTICA

Dirección de Tesis:

Director: Dr. Juan Carrasco, Codirector: Agrimensor Leandro Soto Jurado de Tesis:

Dra. Alejandra Geraldi, Dra. Fernanda Gaspari y Mag. Claudia Infante

Fecha de la defensa oral y pública: 07 de Diciembre de 2021 


\section{ÍNDICE}

TABLA DE CONTENIDO

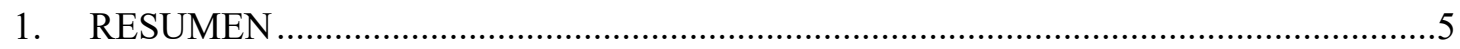

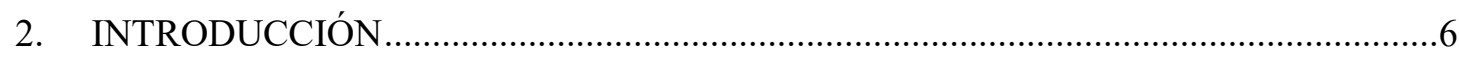

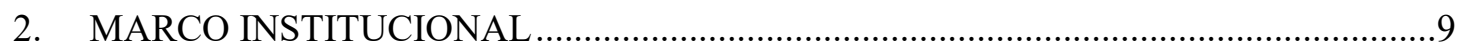

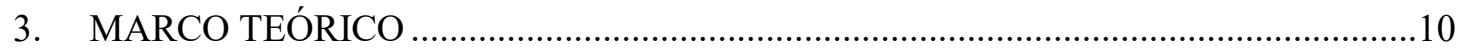

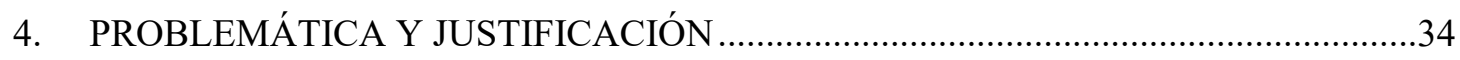

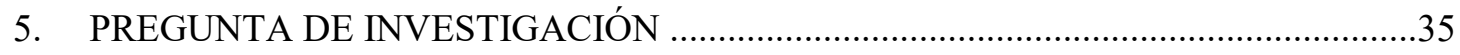

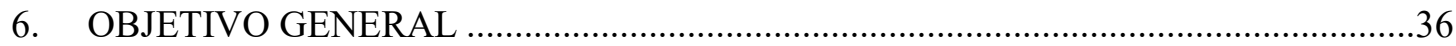

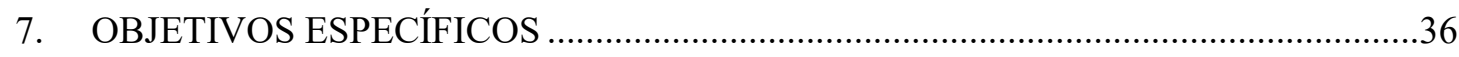

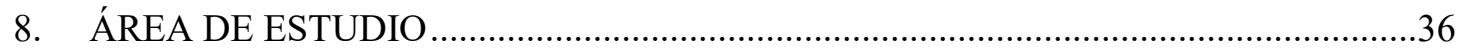

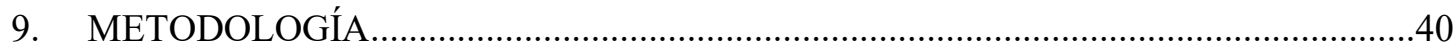

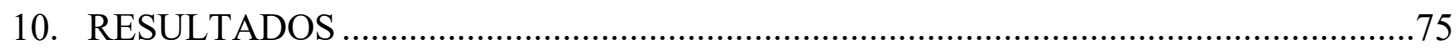

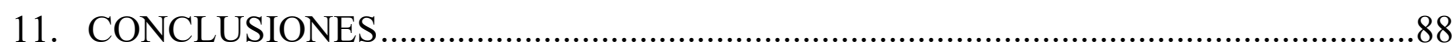

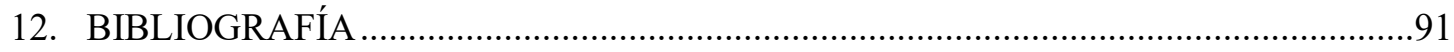




\section{ÍNDICE DE FIGURAS, TABLAS Y GRÁFICOS}

\section{FIGURAS:}

FIGURA 1: ETAPAS DE DESARROLLO DE UN PROYECTO DE TRANSPORTE ........................................... 14

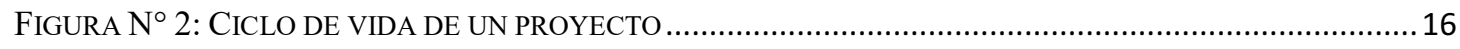

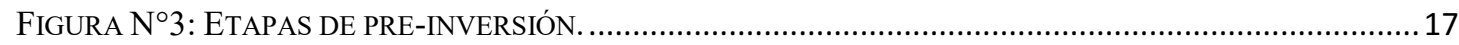

FIGURA $N^{\circ}$ 4: RESULTADO DEL PROCESO DE LOCALIZACIÓN-ASIGNACIÓN EN ARCGIS. ..........................22

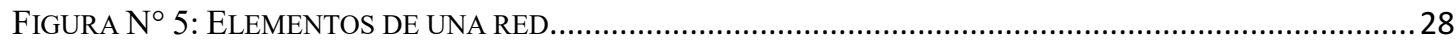

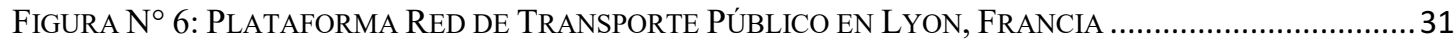

Figura $N^{\circ} 7$ : Plataforma RED DE TRANSPORTE EN COLONIA, ALEMANIA ...................................... 31

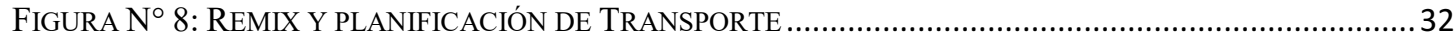

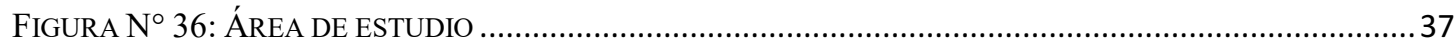

FIGURA N³7: DISTRIBUCIÓN DE VIAJES SEGÚN DESTINO MÁS FRECUENTE....................................... 40

FIGURA $N^{\circ}$ 9: ETAPAS DE LA METODOLOGÍA .............................................................................. 41

FIGURA N ${ }^{\circ}$ 10: LOCALIZACIÓN DE CENTROS DE SALUd EN EL ÁREA METROPOLITANA DE CONCEPCIÓN 45

FIGURA N ${ }^{\circ}$ 11: LOCALIZACIÓN DE LUGARES DE TRABAJO EN EL ÁREA METROPOLITANA DE CONCEPCIÓN

FigurA N ${ }^{\circ}$ 2: LOCALIZACIÓN DE ESTABLECIMIENTOS EDUCACIONALES EN EL ÁREA METROPOLITANA DE CONCEPCIÓN.

FIGURA N ${ }^{\circ}$ 13: LOCALIZACIÓN DE FERIAS LIBRES Y SUPERMERCADOS EN EL ÁREA METROPOLITANA DE

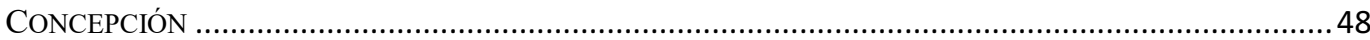

Figura N 14 : LOCALIZACIÓN DE ÁREAS VERDES EN EL ÁREA METROPOLITANA DE CONCEPCIÓN ........49

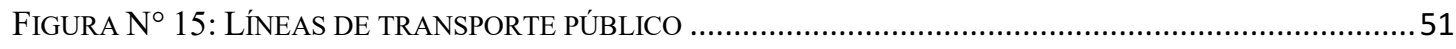

FIGURA $N^{\circ}$ 16: MODELACIÓN DEL PROBLEMA GEOGRÁFICO A RESOLVER ..........................................5 52

FIGURA N ${ }^{\circ}$ 17: MODELO CONCEPTUAL INICIAL DEL PROYECTO …........................................................ 53

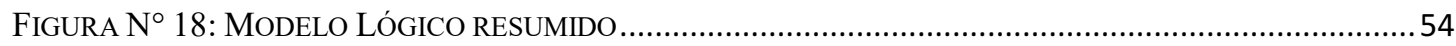

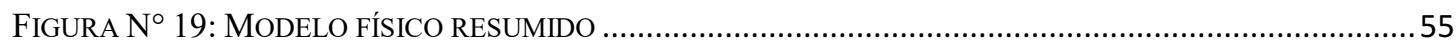

FIGURA N ${ }^{\circ} 20$ : SELECCIÓN DEL SISTEMA DE REFERENCIA UTM H18S.................................................5 57

FIGURA $N^{\circ} 21$ : SELECCIÓN SISTEMA DE REFERENCIA VERTICAL ........................................................... 58

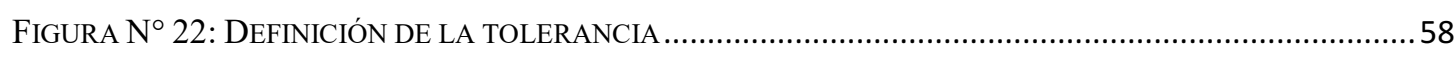

FIGURA N ${ }^{\circ}$ 23: ELEMENTOS DEL FEATURE DATASET PARA MODELACIÓN DE LA RED .............................5 59

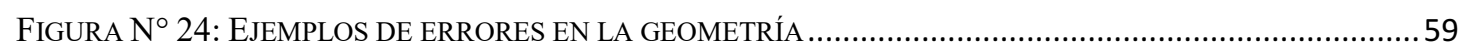

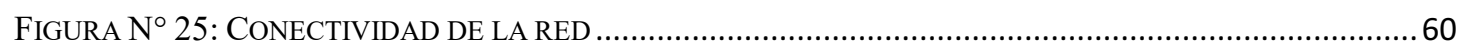

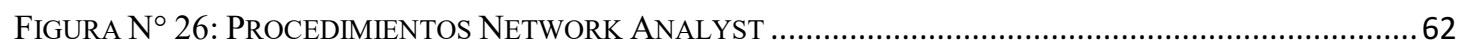

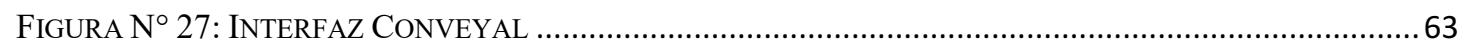

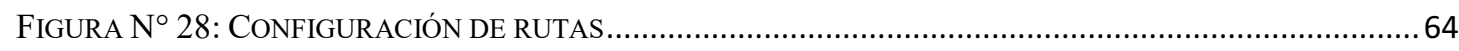

FIGURA N N $^{\circ}$ 29: VISUALIZACIÓN DE ISÓCRONAS EN CONVEYAL Y ESTADÍSTICAS ASOCIADAS...................65

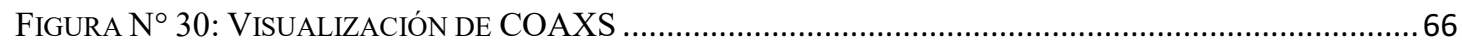

FigurA N ${ }^{\circ}$ 31: ProyeCtos DE CORREDORES DE TRANSPORTE PÚBLICO EN EL ÁrEA METROPOLITANA DE

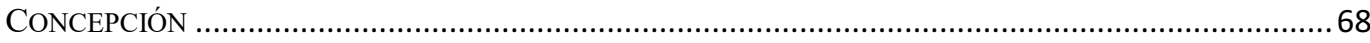

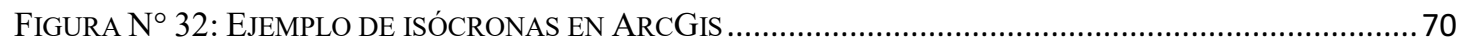

FIGURA $N^{\circ} 33$ : EJEMPLO DE RESULTADO EN COAXS ....................................................................... 70

FIGURA $N^{\circ} 34$ : SET DE FOTOGRAFÍAS DE LOS TALLERES DE TESTEO ..................................................... 74

FIGURA $N^{\circ} 35$ : EJEMPLOS DE UNA NUBE DE PALABRAS ............................................................. 74

FIGURA $N^{\circ}$ 38: COMPARACIÓN ENTRE ESCENARIO BASE Y FUTURO CON ARCGIS...................................80

FIGURA N ${ }^{\circ} 39$ : COMPARACIÓN DE ESCENARIO BASE Y FUTURO CON COAXS.........................................82

FIGURA N ${ }^{\circ}$ 40: RESULTADOS PARA EL ESCENARIO FUTURO. A Y D REPRESENTAN A CENTRO CíviCOS, B Y E ZONAS CON MENOR DENSIDAD POBLACIONAL Y C Y F ZONAS CON MAYOR DENSIDAD

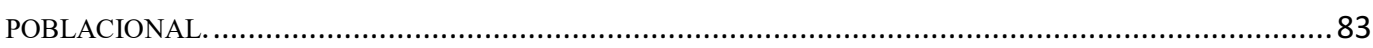

FIGURA N ${ }^{\circ} 41$ : NUBE DE PALABRAS A PARTIR DE LOS TALLERES ….................................................. 87 


\section{TABLAS:}

TABLA 1: ENFOQUES EVALUACIÓN SOCIAL DE PROYECTOS ................................................................ 15

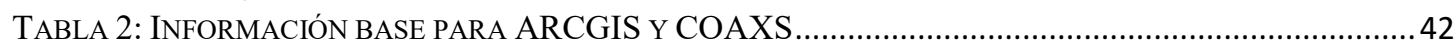

TABLA 3: INFORMACIÓN BASE PARA ARCGIS Y COAXS .............................................................. 43

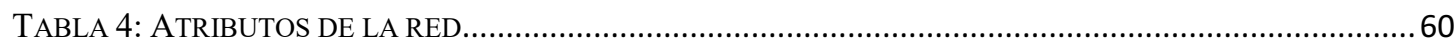

TABLA 5: VELOCIDAD DE OPERACIÓN EN EJES CON Y SIN CORREDORES DE TRANSPORTE PÚBLICO ..........67

TABLA 6: EVALUACIÓN DE LA CALIDAD INTERNA/EXTERNA DEL SOFTWARE ....................................... 72

TABLA 7: EVALUACIÓN DE LA CALIDAD DE USO DEL SOFTWARE ......................................................... 73

TABLA 8: ANTECEDENTES A NIVEL COMUNAL, ÁREA METROPOLITANA DE CONCEPCIÓN ........................38

TABLA 9: EVALUACIÓN DE LA CALIDAD DE LOS SOFTWARES ............................................................ 86

\section{GRÁFICOS:}

GRÁFICO 1: PORCENTAJES SEGÚN MODOS DE VIAJE 39

GRÁFICO 2: NÚMERO DE SERVICIOS ALCANZADOS ENTRE LA SITUACIÓN BASE Y LA SITUACIÓN FUTURA, SOFTWARE ARCGIS

GRÁFICO 3: NÚMERO DE SERVICIOS ALCANZADOS ENTRE LA SITUACIÓN BASE Y LA SITUACIÓN FUTURA, PLATAFORMA COAXS

GRÁFICO 4: DiSPERSIÓN DE RESULTADOS POR SOFTWARE PARA EL CASO DE CENTROS CÍVICOS.

GRÁFICO 5: DISPERSIÓN DE RESULTADOS POR SOFTWARE PARA EL CASO DE ZONAS CON MENOR Y MAYOR DENSIDAD POBLACIONAL 


\section{RESUMEN}

Los Sistemas de Información Geográfica abarcan variados ámbitos relacionados a la planificación del territorio, siendo el transporte urbano es uno de ellos. Dentro de los elementos analizados se considera el impacto en la construcción de una infraestructura de transporte en el Área Metropolitana de Concepción (Corredores de Transporte Público) según diversas comparaciones en dos plataformas que utilizan información georreferenciada.

La comparación se realiza por medio de análisis de redes en ambas plataformas permitiendo contrastar la accesibilidad desde ciertos puntos de la ciudad hacia servicios y equipamientos de los municipios involucrados. Los resultados indican la importancia de la calidad de los datos y su configuración para obtener cifras de salida más precisas y cercanas a la realidad. Por otro lado, se destaca la participación ciudadana como un componente importante a ser considerado en la planificación de las ciudades, por ende, estas nuevas herramientas facilitan la compresión de los impactos de proyectos urbanos de manera sencilla e innovadora. Finalmente, la opinión de los propios usuarios es un insumo valioso para el mejoramiento de los softwares el cual puede ser recogido a través de métricas normadas y estandarizadas. 


\section{INTRODUCCIÓN}

Los proyectos de infraestructura de transporte son una inversión que se justifica sobre la base del impacto que tienen en el desarrollo de los territorios que conectan (OCDE, 2002). En consecuencia, los habitantes o actores de cada territorio involucrado deben ser considerados en las etapas de desarrollo de los proyectos, a esto se le llama participación ciudadana, que en otras palabras es la inclusión activa de los ciudadanos locales en la planificación del territorio.

Así, la utilización de nuevas tecnologías y herramientas en los procesos de participación facilitan la comprensión de las personas, comunicando la información técnica de los proyectos de forma clara y precisa.

Actualmente, las plataformas Web basadas en Sistemas de Información Geográfica y que se relacionan a temas de transporte están orientadas a planificar un viaje a través de diferentes modos como caminata, transporte público y privado principalmente. Dentro de las más comunes, se encuentran las desarrolladas por Google Maps que permiten conocer el tiempo de viaje, transbordos y trazado de la ruta a seguir desde un punto a otro. Por otra parte, una menor cantidad de plataformas muestran directamente la accesibilidad como las oportunidades para acceder a ciertos equipamientos a través del transporte público. Un ejemplo de ello es la aplicación ISO4APP ${ }^{1}$, la cual genera polígonos de isolíneas que representan el área accesible desde un punto de origen a partir de un tiempo o distancia especificada.

Debido a que en América Latina el 56\% de los viajes se realiza en transporte público (BID, 2017) es importante considerar este factor como un elemento clave en la movilidad urbana. Por lo mismo, y dado que los métodos tradicionales de evaluación social de proyectos de vialidad

\footnotetext{
${ }^{1}$ http://www.iso4app.net aplicación italiana pagada
} 
urbana en Chile no incorporan en sus estudios el análisis espacial de proyectos, es necesario estudiar la accesibilidad a través de Plataformas de Sistemas de Información Geográfica como pieza fundamental en el impacto de los proyectos de infraestructura de transporte. Es más, la metodología utilizada en el contexto del Sistema Nacional de Inversiones evalúa los proyectos a través del enfoque costo - beneficio y no incluye el análisis de accesibilidad en ninguna parte del proceso.

Contrario a esta metodología convencional se encuentra la plataforma CoAXs, desarrollada por Massachusetts Institute of Technology (MIT), su particularidad se centra principalmente en ser una herramienta que facilita la participación, es decir, permite a las personas probar nuevos escenarios de transporte interactuando con la plataforma en tiempo real. Los usuarios pueden comprender espacialmente los posibles impactos de un futuro proyecto y observar los cambios por ejemplo en las velocidades o frecuencias del bus, las diferencias en acceso a trabajos, a comercio, servicios de salud entre otros.

Pero la plataforma CoAXs se diferencia totalmente de las plataformas de Sistemas de Información Geográfica tradicionales, ya que estas últimas imponen mayores desafíos geoestadísticos como por ejemplo el análisis de patrones espaciales, de distribución espacial o de redes por mencionar algunos métodos.

A pesar de que los enfoques de los Sistemas de Información Geográfica y CoAXs son distintos, ambos contribuyen a entender el concepto de accesibilidad desde puntos de vista complementarios, siendo un aporte para la planificación del transporte público y de la ciudad.

Por esta razón, la implementación de la herramienta CoAXs estudiada en esta tesis es una oportunidad tanto para usuarios del transporte público como para los tomadores de decisiones, con el fin de observar los impactos de nuevas infraestructuras en la ciudad, expresados en este caso, en indicadores de accesibilidad a distintas oportunidades como equipamientos, servicios o lugares de interés. 
Del mismo modo, resulta interesante comparar este tipo de plataformas web con herramientas convencionales de los Sistemas de Información Geográfica, ya que esto permitirá determinar el grado de aproximación a la realidad de cada una.

A continuación, se presenta dicha Tesis estructurada en 13 capítulos, los cuales describen el contexto de la investigación, sus principales resultados y posteriores conclusiones. 


\section{MARCO INSTITUCIONAL}

El desarrollo de esta tesis forma parte del programa de investigación subvencionado por los MISTI Global Seed Funds del Massachusetts Institute of Technology (MIT) y que tiene por objetivo el intercambio de conocimiento entre investigadores, profesores y estudiantes entre Universidades de distintos lugares del mundo.

En el periodo 2016/2017, fueron adjudicados dichos fondos para investigar en torno a la temática: "Participatory Design for Sustainable Public Transportation Planning: Applications in Different Socio-cultural Contexts". Dentro de este programa de investigación se inserta el desarrollo de la herramienta Collaborative Accesibility-Based stakeholder engagement for Public Transportation Planning (CoAXs) cuyo objetivo es colaborar y explorar la resolución creativa de problemas relacionados a la planificación de sistemas de transporte público, a través de una plataforma interactiva que permite a los usuarios probar nuevos escenarios de transporte; examinar los efectos de los cambios, como en las velocidades o frecuencias del bus; y visualizar el impacto de estos cambios en diferentes lugares de una región, los cuales se muestran en un mapa por medio de una interfaz sencilla.

Actualmente COAXS ha sido implementado en ciudades como Atlanta, Boston, New Orleans, Londres, San Francisco y Santiago, siendo Concepción incluida en este estudio. 


\section{MARCO TEÓRICO}

\section{Planificación del transporte}

La planificación del transporte toma cada vez más importancia debido al crecimiento progresivo de la urbanización y el aumento del consumo de suelo (Banco Mundial, 2020) provocando cambios significativos en la tasa de motorización, por tanto, es imprescindible promover otros modos de transporte más sostenible como el transporte público. Esto concuerda totalmente con los objetivos del Desarrollo Sostenible de las Naciones Unidas al año 2030, siendo la preocupación primordial la urbanización en las ciudades y cómo esto implica mejorar la capacidad de planificación y una gestión más participativa, integrada y sostenible de los asentamientos humanos de los países (PNUD, 2018).

De acuerdo a esta premisa, es necesario conocer y diagnosticar la situación actual y futura de las ciudades en relación a los servicios que puede ofrecer, las personas que tendrán acceso y como la construcción de nuevos proyectos de infraestructura de transporte público podrían aportar a mejorar las condiciones de las zonas más desfavorecidas, para esto es clave la participación ciudadana ya que los ciudadanos se sienten alejados de la toma de decisiones en materia de transporte público (Morales, 2013).

El concepto transversal de esta tesis en términos de transporte se relaciona directamente con la accesibilidad, pero también se torna interesante si dicha noción se considera en el desarrollo de un proyecto de infraestructura.

- Accesibilidad

La accesibilidad establece una estrecha relación con la cercanía o proximidad de las personas a un lugar en específico en el que se encuentra un equipamiento, servicio u otro lugar en el cual pueda satisfacer sus intereses. Esta perspectiva, desde la cual es posible analizar el concepto de accesibilidad, es la vertiente espacial, y que ha generado una mayor 
cantidad de posibilidades de medición, adquiriendo una gran importancia ya que es altamente susceptible de ser estudiada mediante los Sistemas de Información Geográfica.

Además del punto de vista espacial, la accesibilidad tiene un enfoque temporal el cual es entendido en función del tiempo, es decir, el tiempo que las personas emplean para acceder a determinados lugares. Desde el enfoque económico también es posible analizar la accesibilidad, estudiando los costos (individuales y colectivos) en que deben incurrir las personas para acceder y satisfacer sus intereses (Ramírez, 2006).

En cuanto al análisis de accesibilidad a equipamientos, objeto de análisis en este estudio, estos dependen de su dispersión en el territorio, es decir, la configuración espacial de la oferta y demanda ya que si los equipamientos están distribuidos de manera irregular esto determina fuertemente la forma de acceder a ellos (Bosque Sendra \& Moreno, 2004).

Existen tres medidas de accesibilidad respecto a la localización de equipamientos:

Disponibilidad de equipamientos dentro de un alcance espacial, en el cual existen una diversidad de indicadores, como población cubierta y no cubierta por un servicio de un radio de influencia, enfoque utilizado por Gutiérrez \& García 2002a, con el fin de medir la accesibilidad peatonal a una red sanitaria. El alcance espacial puede medirse en términos de distancia euclidiana, Manhattan o por medio de una red. Otros indicadores de disponibilidad de equipamientos son: cociente entre oferta y demanda dentro un alcance espacial prefijado, distancia total recorrida por la población demandante para utilizar un centro más cercano.

Accesibilidad considerando el tamaño de la oferta y costes de viaje, o también conocidos como modelos gravitatorios o de interacción espacial, que plantean la relación inversa entre atracción y la distancia que separa la oferta y demanda.

Accesibilidad considerando la distancia y atributos variados de los centros de oferta, corresponde un grupo de medidas de accesibilidad muy utilizado en la 
localización de centros de servicios y evalúan la utilidad relativa que el usuario obtendría acudiendo a una instalación determinada.

Para Moreno Jiménez (2000) quien concuerda con Jones (1979), la accesibilidad está relacionada con la oportunidad que posee una persona, situada en una localización dada, de llevar a cabo una actividad o conjunto de las mismas. En este caso, la accesibilidad es en función de la movilidad de un individuo o tipo de personas, de la localización de las oportunidades respecto al punto de partida del individuo, de los períodos en los que dichas personas puede realizarlas y del horario en que esa actividad está disponible. Por tanto, la accesibilidad se relaciona no con el comportamiento, sino con la oportunidad o potencial provisto por el transporte y el sistema de usos del suelo de que diferentes tipos de personas lleven a cabo actividad.

Páez et al., (2012) al igual que Moreno Jiménez (2000), plantea que la accesibilidad también tiene relación con el potencial para alcanzar o conseguir oportunidades que se distribuyen en el espacio. Estas oportunidades son elementos que ofrecen un servicio cuya localización es fija pero también debe considerarse la facilidad con la que un lugar atractivo (desde un punto de vista económico) alcanza a otros lugares (Bavoux et al., 2009).

En países en vías de desarrollo, el concepto de accesibilidad y su potencial como herramienta de evaluación de impactos económicos y sociales aún es un tema poco abordado (Gutiérrez, J. 2016) aunque siendo valorado progresivamente, pasando de un concepto simplemente topológico, a la aplicación en diferentes campos haciendo que se valoraren los beneficios más allá de los aspectos directamente relacionados con la movilidad (Oviedo \& Bocarejo, 2011).

En general, los análisis de accesibilidad miden la facilidad que ofrece una red vial o en general cualquier modo de transporte. El beneficio potencial de una infraestructura puede ser evaluado en función de las posibilidades de comunicación existentes entre diferentes zonas geográficas, sobre todo si considera un sistema de transporte eficiente, adecuadamente gestionado y operado 
implicando mejores índices de calidad de vida en las regiones e incentivando el crecimiento económico" (Escobar, D. et.al,. 2013).

En temáticas como la planificación del transporte, la planificación urbana y geografía, la accesibilidad juega un papel importante en la formulación de políticas (Geurs, K. \& Van Wee, B., 2004) dejando atrás la tradicional concepción del espacio al momento de construir infraestructuras, dicho de otra manera, la visión tradicional considera el espacio como un continuo donde los tiempos de acceso aumentaba gradualmente con la distancia. Pero en la actualidad, el transporte y movilidad por autopistas y vías estructurantes han producido una contracción del espacio al reducir las distancias en tiempo. Esta nueva tendencia ha generado heterogeneidades en el espacio, así, los nodos de unión de las principales vías suelen corresponder con las aglomeraciones urbanas, espacios beneficiarios del nuevo orden espacial, al quedar conectados entre sí de forma rápida y eficiente. Por consiguiente, las nuevas infraestructuras de transporte, esenciales para el desarrollo socioeconómico y la articulación e integración de municipios y espacios, pueden modificar la accesibilidad y la dinámica de la población influyendo en el desarrollo regional.

En síntesis, existe una estrecha relación entre accesibilidad y la construcción de infraestructuras de transporte, estudiada principalmente por los indicadores, herramienta potente para planificadores. El cálculo de indicadores permite, entre otras cosas, comparar planes alternativos de transporte, evaluar su contribución al equilibrio territorial y analizar el impacto y consecuencias de cada actuación prevista. En cuanto a la presentación de resultados, es necesario que sean de forma gráfica ya que de esta manera serán fácilmente asequible para todos. Los indicadores de accesibilidad permitirán explicar las posibilidades de interacción entre los distintos puntos de un territorio, pero teniendo en consideración que más infraestructuras de transporte no significa necesariamente más accesibilidad (Jaramillo, J., 2006). 
- Desarrollo de un proyecto de transporte y participación ciudadana

Según Sinha \& Labi (2007), el "Proceso de Desarrollo de Proyectos de Transporte (PDP)" se define como la secuencia de actividades relacionadas con la planificación, el diseño, construcción, gestión, operación y evaluación de una instalación de transporte. Estos procesos de desarrollo son un esfuerzo a nivel de proyecto que generalmente pertenece a un plan de transporte de una ciudad. El proceso para desarrollar proyectos de transporte varía de una agencia/empresa a otra, debido a los diferentes requisitos y condiciones locales. El proceso de desarrollo del proyecto es complejo e intensivo en recursos porque implica la consideración de cuestiones sociales, económicas, ambientales, culturales y de políticas públicas. Sin embargo, el esfuerzo general del PDP facilita en gran medida adoptando buenas prácticas. Un proceso de este tipo a menudo involucra todos los niveles de gobierno. Un PDP comprende varios pasos: una revisión del plan, particularmente hoy se relaciona con el proyecto en cuestión, planificación de ubicación y selección del sitio, diseño de ingeniería, construcción, operación y preservación (Figura $\mathrm{N}^{\circ} 1$ ).

Figura $\mathrm{N}^{\circ} 1$ : Etapas de desarrollo de un proyecto de transporte

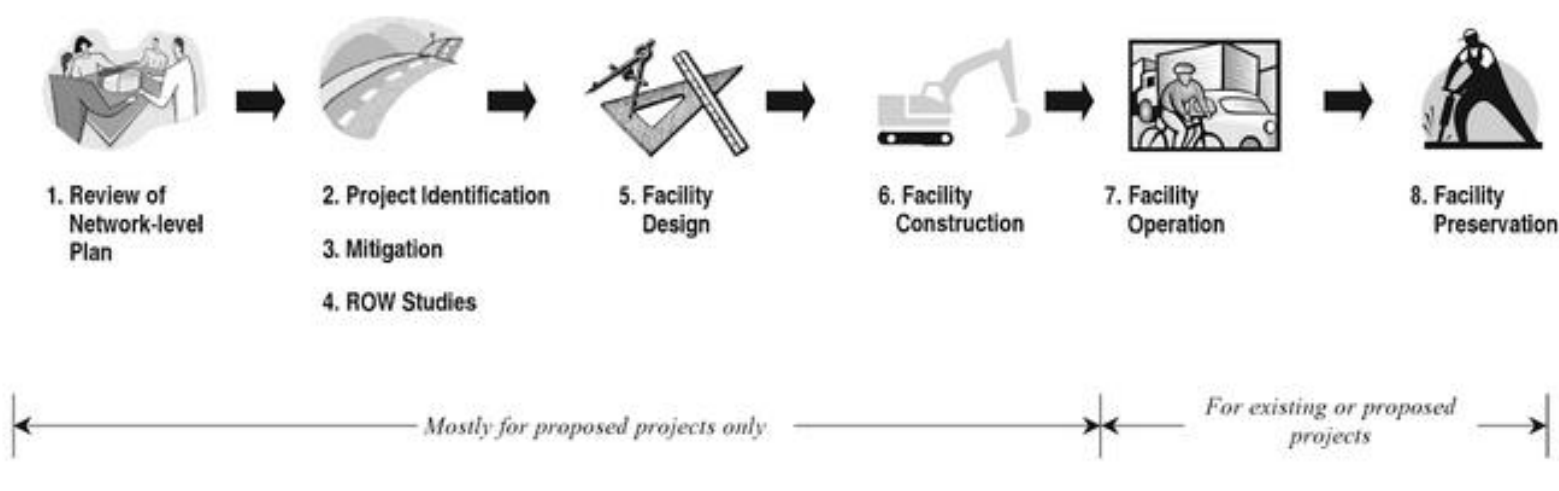

Fuente: Sinha \& Labi, 2007.

Pero en este enfoque no se considera la participación ciudadana en ninguna de sus fases, al igual que en la metodología de Evaluación Social de Proyectos adoptada por el Ministerio de Transporte en Chile. Esta metodología formula y evalúa proyectos de vialidad bajo el enfoque 
de costo-beneficio o costo-eficiencia (Tabla $\mathrm{N}^{\circ} 1$ ), de manera de seleccionar la alternativa tecnológica óptima según la realidad de cada localidad y territorio.

Tabla Nº1: Enfoques Evaluación Social de Proyectos

\begin{tabular}{|l|l|}
\hline Enfoque & Características \\
\hline Costo - Beneficio & Se pueden identificar, medir y valorar los costos y beneficios \\
& del proyecto \\
\hline Costo - eficiencia & Se pueden identificar, medir y valorar los costos; los beneficios \\
& pueden identificarse, a veces medirse, pero no pueden ser \\
& valorados \\
\hline
\end{tabular}

Fuente: MIDEPLAN, 2015.

En Chile, el desarrollo de metodologías para el análisis y evaluación social de proyectos de mejoramiento de los sistemas de transporte representa una línea de trabajo permanente del Programa de Vialidad y Transporte Urbano, y por lo mismo, en el año 1998 se creó el Manual de Diseño y Evaluación Social de Proyectos de Vialidad Urbana (MESPIVU), con una última actualización del año 2013, que recogió el estado del arte en materias de análisis, formulación y evaluación social de proyectos de vialidad urbana. El MESPIVU aborda la evaluación de estos proyectos en la etapa de prefactibilidad, guiando y apoyando los procesos de formulación, análisis y evaluación de proyectos de transporte en el ámbito urbano y forma parte importante de los documentos del Sistema Nacional de Inversiones (SECTRA, 2013).

El Sistema Nacional de Inversiones norma y rige todos aquellos procesos de inversión pública en Chile, es decir, a través de esto se demuestra concretamente que un proyecto es socialmente rentable y que los beneficios son mayores a los costos.

En cuanto a los beneficios de los proyectos relacionados al transporte urbano, en especial a la vialidad urbana, sea intermedia o estructurante, son aquellos asociados al sistema de transporte vehicular (transporte público o transporte privado) como el ahorro de tiempos de viaje y el 
ahorro de costos operacionales vehiculares, todo en valor presente neto durante el horizonte de evaluación del proyecto (MDS, 2016). Mientras que los costos se miden en unidades físicas expresadas en indicadores económicos de los recursos utilizados, el cual generalmente tiene largos plazos de retorno.

Un caso contrario sucede con los proyectos de vialidad local, ya que no se enmarcan en el enfoque clásico de ahorros de tiempos y costos de viaje y tienen más sentido en el contexto de un estándar mínimo para dar el servicio de accesibilidad y movilidad a las personas de un sector, reduciendo además las externalidades negativas (ruidos molestos, polvo en suspensión, mal estado de los caminos). Estos proyectos se tratan bajo el marco de pavimentos participativos pues son pavimentos nuevos en calles y pasajes de sectores residenciales en sectores de escasos recursos. Para lograr esto, se necesita la activa participación y aporte de los propios vecinos y de las municipalidades.

Si bien las etapas de realización o ciclo de vida de un proyecto (Figura $\mathrm{N}^{\circ} 2$ ) y en específico en la etapa re pre-inversión (Figura $\mathrm{N}^{\circ} 3$ ) consisten en la transformación de ideas en soluciones concretas, estas siempre comienzan con la identificación de un problema y por lo mismo la participación ciudadana debe ir orientada a este primer nivel y no a la evaluación post realización del proyecto.

La evaluación social de proyectos considera que los recursos son escasos y es necesario asignarlos de manera eficiente, lo que implica formular y evaluar bien cualquier iniciativa de inversión considerando también a aquellos proyectos que entreguen bienestar social.

Figura $\mathrm{N}^{\circ}$ 2: Ciclo de vida de un proyecto

Fuente: Elaboración propia. 

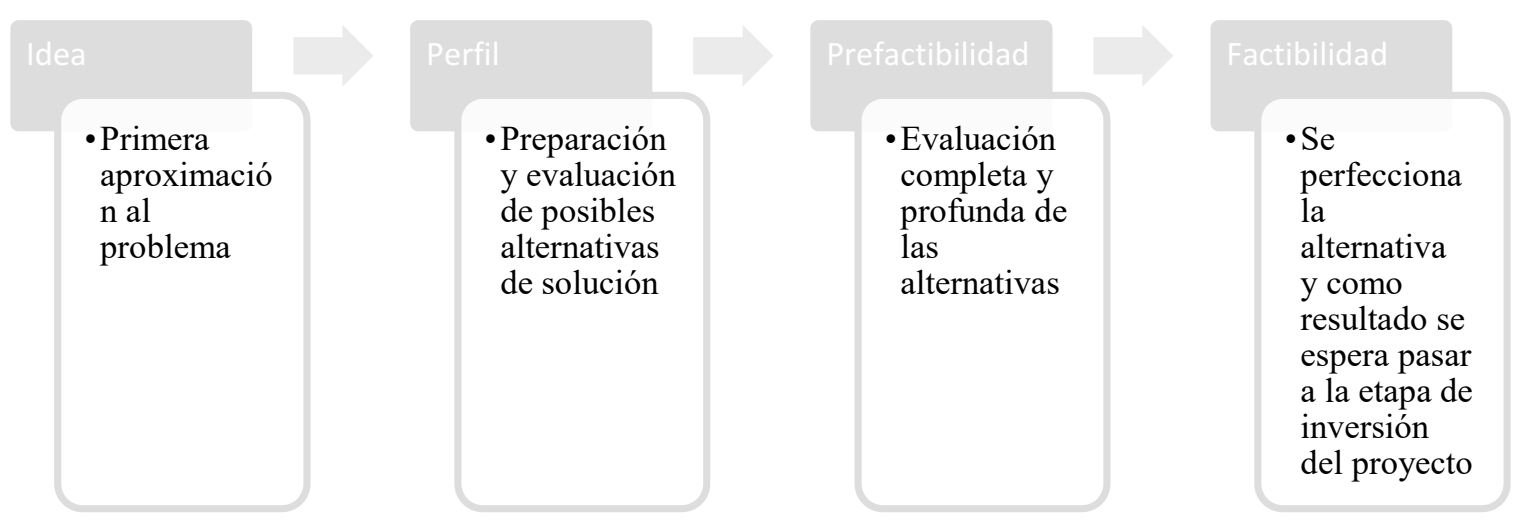

Fuente: CEPAL, 2009.

Sin duda incluir la participación ciudadana en el ciclo de vida de un proyecto es de suma importancia, principalmente en la fase de pre-inversión como en la evaluación post proyecto, esto porque el transporte y la calidad de vida tienen una estrecha relación cumpliendo la función de integrar lo económico y las estructuras sociales de las comunidades; mejorar el acceso a la educación, la salud y servicios sociales, lo que a menudo se ve limitado por las deficiencias el sistema de transporte (Baedeker et al., 2013). Los impactos de los proyectos de transporte tienen diversos efectos en diferentes grupos, por lo tanto, la identificación precisa de estos impactos adquiere una gran importancia (Karst et al., 2009).

En la literatura existen diversos registros sobre formas de realizar participación ciudadana entendiendo que, en su definición más práctica, es la inclusión activa de ciudadanos locales y partes interesadas en el proceso de planificación de la movilidad urbana (Baedeker S. B. \& Lindenau, M., 2013). La Corporación de Estudios Sociales y Educación (2001) define la participación de manera más detallada como la redistribución del poder para proporcionar a los ciudadanos, especialmente aquellos que no pueden involucrarse en asuntos políticos y económicos, en los procesos de toma de decisiones y así tomar parte en futuros proyectos. 
Para Arnstein, (1969) y Hart, (1992), la participación se representa con una simple figura de escalera simbólica. La figura de la escalera muestra los niveles de participación de abajo hacia arriba los que se describen a continuación:

- Participación manipulada: es cuando la población es utilizada para realizar acciones que no entienden y que responden totalmente a intereses ajenos a los suyos.

- Participación decorativa: se realiza cuando se incorpora a la población sólo como un accesorio, es decir, para decorar o animar determinada actividad.

- Participación simbólica: se realizan acciones donde la participación de la población es sólo aparente.

- Participación de asignados, pero informados: es cuando aún se dispone de la población para que participe en una determinada actividad, sin embargo se le informa en qué consiste la misma. A pesar de ser limitada, es el primer nivel de participación real.

- Participación con información y consulta: Es el segundo nivel de participación real. En él, los agentes externos de desarrollo informan y consultan a la población sobre su probable participación. En base a ello, la población decide.

- Participación en ideas de agentes externas de desarrollo compartidas con la población: La acción es pensada por agentes externos de desarrollo, pero es compartida con la población. Supone que ellos se incorporan en pensar y aportar respecto a la acción a realizar

- Participación en acciones pensadas y ejecutadas por la propia población: la acción se gesta en la propia población y es ejecutada por ellos. No hay relación con agentes externos de desarrollo.

- Participación en acciones pensadas por la propia población y que han sido compartidas con agentes externos de desarrollo: la acción es pensada por la población, pero a diferencia del escalón anterior, es compartida con agentes externos de desarrollo. Es el nivel superior que contempla la llamada Escalera de la Participación. 
En contraste con los enfoques tradicionales para la planificación del transporte mencionados anteriormente y continuando con la línea de la participación ciudadana, el nuevo concepto hace hincapié en la participación de los ciudadanos y de los grupos de interés, mediante la coordinación de políticas entre los sectores (transporte, urbanismo, medio ambiente, desarrollo económico, política social, salud, seguridad, etc.) y entre los niveles de las autoridades locales y otras autoridades vecinas.

Por esto y a modo de ejemplo, un enfoque participativo en un Plan de Movilidad Urbana Sostenible se centra en las personas y en la satisfacción de sus necesidades básicas de movilidad. La planificación participativa es un requisito previo para que los ciudadanos y los grupos de interés se hagan cargo del plan en específico y también de las políticas que en él se promueven (Wefering, F. et al., 2014).

Una instancia similar y aislada son los diagnósticos participativos que son diálogos ciudadanos realizados en grupos de trabajo y concluyen con una propuesta y principios por parte de la ciudadanía que debieran ser considerados en la Política Nacional de Transporte (MTT, 2013).

\section{○ Sistemas de Información Geográfica}

Si bien su origen se remonta a la década de los $60^{\prime}$ en el Canadian Geographic Information System (CGIS) con funciones netamente forestales, hoy en día existen variadas definiciones para un Sistema de Información Geográfica (SIG), algunos autores como Sarría (2001) lo describen en base a su utilidad como sistemas informáticos orientados a la gestión de datos espaciales que constituyen la herramienta informática más adecuada y extendida para la investigación y el trabajo profesional en Ciencias de la Tierra y Ambientales.

Definiciones más clásicas lo definen como una aplicación de las tecnologías de la información en el manejo y análisis de la información espacial a través de ordenadores personales y estaciones de trabajo (Guerra \& Fernando, 2009) 
En cuanto al rol que han tenido los SIG en la ciencia geográfica, se discuten principalmente dos enfoques, el primero como un sistema para el manejo de bases de datos espaciales y el segundo como un sistema de apoyo a la toma de decisiones. Según Gutiérrez Puebla et. al (2009), hoy en día estos enfoques no son contrarios, enmarcándose los programas y procedimientos dentro de los sistemas de información geográfica diseñados tanto para manejar volúmenes de datos espaciales como para el apoyo a la toma de decisiones en diferentes ámbitos de uso.

En ese sentido, uno de los campos de mayor desarrollo es el avance de los SIG en los Sistemas de Ayuda a la Decisión Espacial (SADE) para la localización de equipamientos (Buzai \& Baxendale, 2008). En términos prácticos, un SADE incorpora las funcionalidades de un SIG como el manejo espacial de los datos y el despliegue cartográfico, así como la capacidad de integrar modelos matemáticos analíticos, dentro de una interfase flexible capaz de estructurar los datos y realizar informes (Ahola et al, 2007; Goodchild, 1999 en López et al. 2008).

Dentro de los SADE se encuentran los modelos de localización-asignación, los cuales resultan por la preocupación de establecer procedimientos numéricos que permitan explicar y predecir las localizaciones de los fenómenos humanos sobre el territorio o generar métodos que permitan encontrar lo que se considera la más adecuada localización de un fenómeno (Bosque Sendra, 2004). Su metodología principal es evaluar las localizaciones actuales de diversos servicios en función de la distribución de la demanda, creando escenarios que logren una distribución espacial más eficiente o equitativa.

En cuanto a casos de aplicación, Bosque Sendra (2006) desarrolló un modelo de localización de instalaciones no deseables el cual involucra dos aspectos: la necesidad de construir estas instalaciones por el servicio que ofrecen a la población pero por otra parte, considera el problema de las molestias y externalidades negativas que generan en sus inmediaciones. Por tanto, la localización óptima de este tipo de equipamientos o servicios debería situarse a la mayor lejanía posible de la población residente y potencialmente afectada, y además, la mayor cercanía posible a los productores y usuarios de la instalación. 
Otro ejemplo de modelo de localización-asignación es el presentado por Buzai, G. (2011), quien lo aplica a servicios públicos urbanos, en específico a Centros de Atención Primaria de Salud en la ciudad de Luján, Argentina. Su conclusión principal es que el análisis espacial automatizado contribuye con bases teóricas y metodológicas a los diferentes procesos para la toma de decisiones en temas de planificación urbana, permitiendo disminuir las desigualdades socioespaciales de la población.

Basado en Bosque Sendra (2004), un problema de localización comienza con una serie de principios entre ellos destacan:

1. Una instalación material específica o actividad humana generará flujos de otros elementos.

2. Los elementos existentes influyen en la posición más adecuada de una instalación, es decir, estos elementos inciden en la aparición de flujos espaciales y se les denomina factores de localización

3. Los sistemas e infraestructura permiten diversos desplazamientos o traslados sobre el espacio (Bosque Sendra, 1999), dicho de otra forma, las redes son un elemento clave ya que a través de ellas se mueven los flujos a en el territorio.

Operacionalmente, existen varios softwares capaces de aplicar un SADE, en el caso de ArcGis (Análisis de ubicación - asignación) ofrece siete tipos de problemas a resolver tales como:

-Minimizar la impedancia: minimiza la suma de todos los costes ponderados entre los puntos de demanda y las instalaciones de la solución.

-Maximizar la cobertura: las instalaciones se ubican de modo que el máximo número de puntos de demanda se asignen a instalaciones de la solución situadas dentro de la tolerancia de impedancia

-Maximizar la cobertura capacitada: elige las instalaciones de modo que toda o la mayor parte de la demanda se puede servir sin exceder la capacidad de ninguna instalación. 
-Minimizar las instalaciones: minimizar instalaciones es igual que Maximizar cobertura, con la excepción del número de instalaciones que se van a ubicar, determinado en este caso por el solucionador.

-Maximizar la asistencia: las instalaciones se eligen de modo que se asigne el máximo peso de demanda posible a las instalaciones asumiendo que el peso de la demanda se reduce en relación con la distancia entre la instalación y el punto de demanda.

-Maximizar la cuota de mercado: se elige un número concreto de instalaciones de modo que la demanda asignada se maximice en presencia de competidores. El objetivo es captar la máxima cuota de mercado posible con un número dado de instalaciones que se especifique.

-Cuota de mercado objetivo: cuota de mercado objetivo elige el número mínimo de instalaciones necesarias para captar un porcentaje concreto de la cuota de mercado en presencia de competidores.

A modo de ejemplo, la visualización del resultado sería similar a la Figura $\mathrm{N}^{\circ} 4$, donde se busca la mejor ubicación de las instalaciones y además asigna puntos de demanda a dichas instalaciones (ArcGis, 2021).

Figura $N^{\circ} 4$ : Resultado del proceso de localización-asignación en ArcGis.

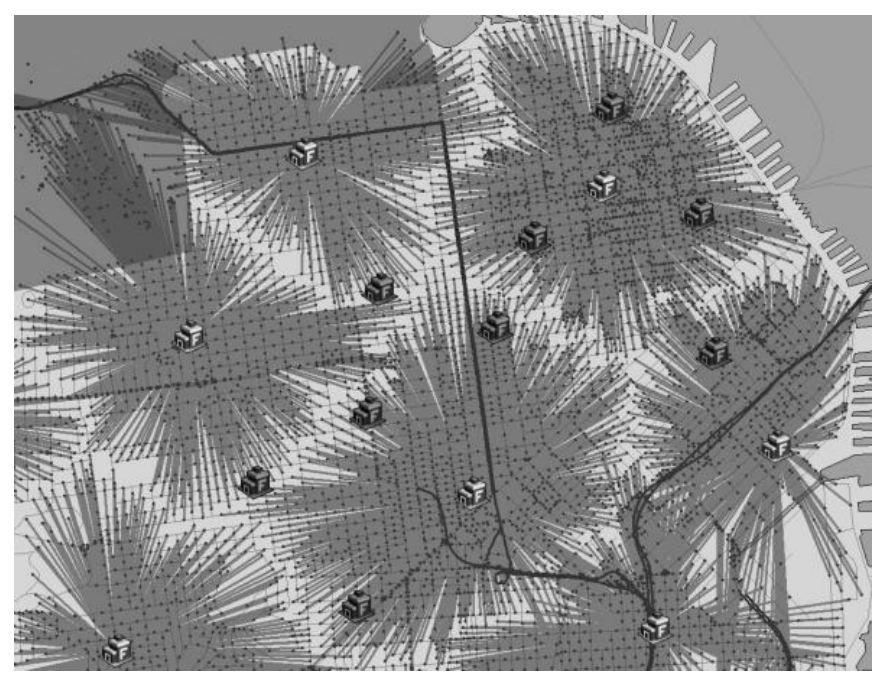

Fuente: https://desktop.arcgis.com/es/arcmap/latest/extensions/network-analyst/location-allocation.htm 
- Modelos y estructura de datos espaciales

Para llevar a cabo cualquier modelamiento de la realidad o resolver una problemática a través de los Sistemas de Información Geográfica, es necesario contar con una amplia base de datos ya sea espacial o no espacial

Para datos espaciales existen dos tipos de modelos: vectorial y ráster, los que a su vez poseen diferentes estructuras. Cada modelo se describe a continuación:

- Modelo de datos vectorial

El modelo de datos vectorial es representado por objetos geométricos simples o entidades espaciales como puntos, líneas y polígonos. Para su representación, un polígono requerirá contar con un número de vértices, los cuales poseen coordenadas y una posición relativa con respecto a los bordes adyacentes de otras entidades (Shekhar \& Xiong, 2008).

El punto representa un objeto sin dimensión y sólo está asociado a una posición en el espacio.

Las líneas, simbolizan la longitud de un objeto por lo tanto son representaciones de una sola dimensión (Moliner, 2005).

Los datos vectoriales son acompañados de una tabla de atributos, la cual contiene un identificador o ID de cada objeto, el tipo de entidad y valores asociados que caracterizan cada objeto.

- Modelo de datos ráster

El modelo ráster es representando por celdas o píxeles. Es decir, una superficie es dividida en filas y columnas formando una estructura de cuadrícula regular. Cada celda debe ser de forma rectangular, pero no necesariamente cuadrada.

Cada celda contiene un valor de atributo y la ubicación espacial de cada celda está implícitamente contenida dentro del ordenamiento de la matriz, a diferencia de una estructura vectorial que almacena la topología explícitamente. Las áreas que contienen el mismo valor de 
atributo se reconocen como tales, sin embargo, las estructuras ráster no pueden identificar los límites de dichas áreas como polígonos (Ellis, 2001).

- Estructura de datos espaciales

Para datos vectoriales existen dos tipos de estructuras: con topología y sin topología. Los datos vectoriales con topología poseen una relación espacial explícita, permitiendo realizar funciones del análisis espacial con datos geográficos. Dentro de las relaciones espaciales más comunes se encuentran:

- Conectividad: en el caso de las líneas, estas deben conectarse a través de nodos. Esto se conoce como la estructura Arco-Nodo ${ }^{2}$, el cual se detallará en el siguiente apartado.

- Adyacencia: esta relación se observa en polígonos y son adyacentes si comparten una línea de límite en común.

- Contención: es cuando un polígono puede contener a otro como una isla.

Los datos vectoriales sin topología no tienen relaciones espaciales explícitas y esto permite que las entidades puedan ocupar el mismo espacio geográfico, al contrario de la estructura anterior donde no puede existir duplicación de entidades.

La topología se puede almacenar como parte de la representación del mapa (en las tablas de la base de datos) o se puede construir a partir de las coordenadas de cada entidad (Malczewski, 1999).

Para los datos ráster existe otro tipo de estructura: simple y compleja, ambos con relaciones implícitas entre las celdas. La estructura simple es aquel formato en que la matriz es monobanda, es decir, trabaja con atributos binarios. La estructura compleja contiene múltiples matrices o multibandas, comúnmente utilizadas en teledetección (Morales, 2013).

\footnotetext{
${ }^{2}$ Arco: Sucesión de segmentos rectos entre dos nodos y Nodos: Cada vértice en el que se cruzan 3 o más arcos, o el vértice terminal de un arco
} 
- Análisis espacial

Es el tema transversal que va desde la formulación del problema hasta su resolución. El análisis espacial constituye una serie de procesos matemáticos y análisis estadísticos aplicados a los datos distribuidos en este caso sobre el espacio geográfico. Cuando se enfoca en los Sistemas de Información Geográfica, en adelante SIG, este se considera como su núcleo ya que posibilita trabajar con las relaciones espaciales de las entidades contenidas en cada capa temática de la base de datos geográfica (Buzai \& Baxendale, 2015).

En el ámbito de la geografía cuantitativa, el análisis espacial ha contado con dos marcadas líneas de definición, relacionadas con entender los procesos espaciales, la primera se realiza directamente como en el caso del modelamiento espacial, estos modelos matemáticos se basan en teorías de como los individuos escogen diferentes alternativas espaciales (Sistemas de ayuda a la decisión espacial) y la segunda, se aplica indirectamente, es decir se analiza espacialmente patrones de puntos donde se puede inferir un proceso espacial (Fotheringham, et al., 2007) .

- Análisis espacial a través de redes y cálculo de rutas de desplazamiento

En las últimas décadas la Geografía del Transporte ha estudiado las redes de transporte y movilidad. Asimismo, sus líneas de investigación han evolucionado de acuerdo a los cambios históricos del transporte, pasando desde un enfoque centrado en el transporte ferroviario a un interés por el transporte urbano. Ya a partir de 1960, luego del aumento del número de trabajos, el transporte en las ciudades y los problemas de tráfico son cada vez más intensos, generando un interés por la geografía y otras ciencias a fin de encontrar soluciones (Torrego, 1986).

Actualmente, los problemas de transporte no tienen que ver con la construcción de grandes obras de infraestructura, sino que su objetivo principal es analizar la oferta y demanda a diferentes escalas territoriales. La demanda es la "movilidad", que supera al concepto de desplazamiento ya que involucra causalidades y consecuencias relacionadas al propio desplazamiento, enlazando actividades y motivaciones que llevan al individuo a desplazarse (Richman 1983 en Escalona 1989). 
De acuerdo a estas nuevas tendencias, la geografía del transporte ha realizado diferentes estudios que utilizan redes para encontrar rutas óptimas de desplazamiento, jugando un papel importante las variables de tiempo y distancia.

Algunos autores concuerdan en que tiempo y distancia se percibe como una sola variable, ambas con una connotación espacial, en otras palabras, las distancias dejan de medirse en longitud para pasar a medirse en tiempo, debido a que en una ciudad ya no importa la separación física de dos lugares, sino que el tiempo que tarda el desplazamiento (García Palomares, 2008).

A modo de ejemplo, en el trabajo de Parras y Gómez (2015) en la ciudad de Resistencia (Argentina), se ha estudiado el componente temporal del transporte público y se construyeron escenarios ideales para lograr la eficiencia del servicio. Los resultados indican que existen grandes desequilibrios territoriales en relación a la variable espacio-tiempo, dados principalmente por la expansión urbana siendo necesario incorporar la percepción de la población en cuanto a estos mismos tiempos de viaje.

Dentro de las metodologías utilizadas para la creación de escenarios se encuentra el modelo de rutas óptimas. En los SIG existen variadas formas de obtenerlo, uno de ellos es a través de datos de ráster, este análisis se realiza mediante el cálculo de valores acumulativos de los diferentes píxeles de una capa ráster. Dicha capa representa la dificultad o coste de un desplazamiento en un territorio, de esta forma el software selecciona la ruta que une dos puntos y donde el valor acumulado de las celdas es menor (López, 2005).

Con datos vectoriales se utiliza como base la red vial, la cual debe contener atributos como sentido de las vías, velocidad máxima permitida según el modo de transporte ya sea caminata, bicicleta, transporte privado o transporte público, cruces semaforizados, paradas de autobuses y otros atributos que puedan afectar el modelo de ruta óptima (Serna-Uran et al, 2016). La creación de este dataset (network dataset) permite modelar la red de transporte y a su vez generar la ruta óptima según puntos de inicio u origen y fin o destino. Luego en el SIG la 
herramienta permite encontrar la mejor ruta según parámetros, como los definidos anteriormente, pero además la ruta óptima puede ser escogida según (Moreno, 2007):

1. Trayecto más corto en distancia: se basa en la localización geográfica y es la opción de un trazado directo entre el origen y el destino. Se ignora la impedancia ${ }^{3}$ pero proporciona posibles ejes que podrían reforzarse para unir diferentes puntos.

2. Trayecto más corto en tiempo: considera la impedancia y se hace necesario incluir la intermodalidad para aproximarse a la realidad.

\section{- Estructura Arco-Nodo}

Para elaborar un network dataset y realizar un correcto análisis espacial con redes se debe trabajar sobre la estructura de datos "Arco - Nodo". Esto significa que las redes de transporte se consideran como grafos ${ }^{4}$ donde los núcleos o intersecciones de caminos son nodos o vértices (Figura $\mathrm{N}^{\circ} 5$ ), los segmentos de vías de comunicación que los unen son arcos o aristas y los conjuntos de segmentos o arcos que unen nodos son tramos. A su vez, la mayor o menor complejidad de los grafos se relaciona con las propiedades del medio físico y el grado de desarrollo económico de las sociedades a la que corresponden. Así, el estudio de las redes de transporte constituye uno de los mejores indicadores para obtener características de la sociedad concordando con la visión de geógrafos como Lefevre y Plassard sobre el papel del transporte como elemento fundamental en la producción del espacio y organización del territorio.

\footnotetext{
${ }^{3}$ La impedancia se define como el costo que representa el desplazamiento a lo largo de un arco o ruta (Ávila, 1996)

${ }^{4}$ Término matemático para designar un conjunto de puntos unidos entre sí por segmentos o arcos de curva. Representa un proceso o relación funcional. (Zárate \& Rubio, 2010).
} 
Figura $\mathrm{N}^{\circ}$ 5: Elementos de una red

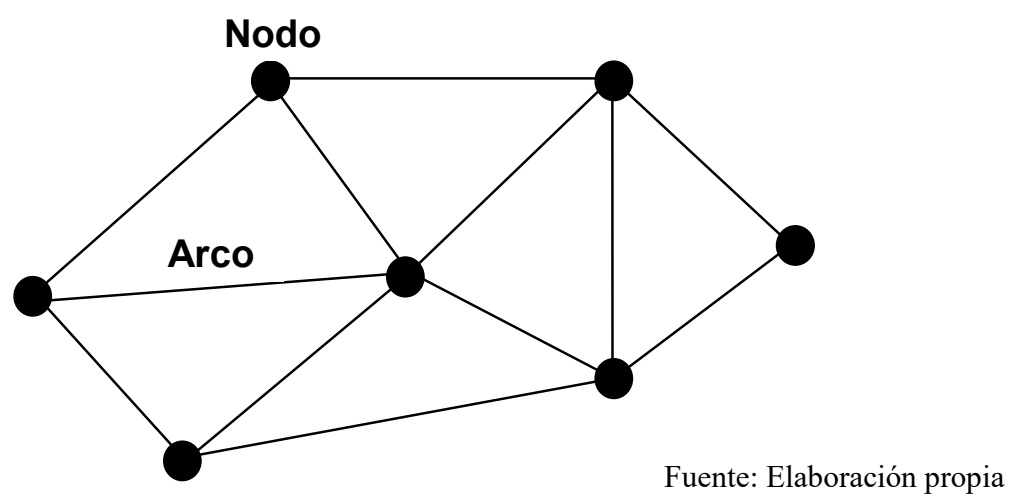

Tiempo de viaje en transporte público.

A diferencia de otros modos como el automóvil privado, el transporte público posee rutas predefinidas y horarios que dependen de la hora del día (punta mañana, punta tarde, etc.) y del día de la semana, pudiendo dichos tiempos estar sujetos además a modificaciones. Deficiencias típicas en los modelos de accesibilidad están asociadas al tiempo de viaje lo que a su vez está relacionado directamente con las velocidades (Lei \& Church., 2010).

En muchas ocasiones, debido a la falta de información detallada del cronograma de cada línea de bus, las velocidades de viaje promedio normalmente se asignan a toda la ruta, ignorando las diferencias entre las diferentes partes de la ruta (Liu y Zhu, 2004; Moniruzzaman y Páez, 2012; O'Sullivan et al., 2000; Peipins et al., 2011).

Por otra parte, y desde el punto de vista del usuario, los tiempos de espera para realizar combinaciones o tiempo que se pierde al cruzar calles o esperar en los semáforos debería ser considerado. Algunas aproximaciones se obtienen a través de la densidad de intersecciones (Nodos/km de vialidad), mayor número de intersecciones significaría una mayor cantidad de tiempo (Vaccaro, 2011).

Los softwares de SIG estándar escasamente proporcionan herramientas y datos adecuados para el desplazamiento multimodal ${ }^{5}$ son elementos clave para determinar tiempos en los servicios

\footnotetext{
${ }^{5}$ Es el desplazamiento a través de una red conformada por diferentes modos de transporte como: por carretera, ferroviario, peatonal, etc. (Vera et al. 2010).
} 
de transporte público (Martin et al., 2008). Sin embargo, el reciente desarrollo de formatos de datos como los GTFS (General Transit Feed Specification) ha abierto nuevas oportunidades y servicios de planificación debido a que son datos abiertos e interoperables. El potencial de estos formatos de datos se orientan principalmente a servicios web y más recientemente con fines de investigación (Eluru et al., 2012; Jäppinen et al., 2013; Lei \& Church, 2010).

- Plataformas sobre transporte y formas de difusión de resultados

Este tipo de plataformas de mapas se popularizaron a mediados de la década de los 90', cuando la difusión masiva de datos en internet hizo que se comenzara a pensar en formas de compartir información geográfica, tanto dentro de una organización como con el público en general. Así, sus primeros pasos comenzaron a través de publicación de imágenes estáticas de mapas y luego a versiones más actualizadas de estas plataformas. Los mapas web se convirtieron en una oportunidad para ejercitar las técnicas cartográficas y elaborar mapas más atractivos surgiendo los llamados Web Map 2.0, como los servicios ofrecidos por Google o Microsoft entre otros. Posteriormente, a medida que los navegadores web aumentaron a comienzos de la década del 2000, aumentaron las posibilidades de mayor interactividad de estas plataformas debido a la adopción generalizada de dispositivos inteligentes (Sterling, 2017).

La proliferación masiva de información geográfica favoreció que surgieran las Infraestructuras de Datos Espaciales (IDE), que según Bernabé-Poveda \& López (2012): “...es una infraestructura que permite compartir, intercambiar, combinar, analizar y acceder a los datos geográficos de forma estándar e interoperable. Esta infraestructura no es más que el conjunto de recursos cartográficos disponibles en la red, sobre la que los datos mismos serán más útiles al formar parte de un todo más completo".

Dicha definición incluye dos conceptos importantes: información estándar e interoperable. La información es estándar en el sentido de que cumple con una normativa o reglas generales, esto ayuda a solucionar y gestionar los componentes de la misma manera, independiente de la temática de la información, para ello existen la normativa ISO 19100 u otras como en Open 
Geospatial Consortium. En cambio, información interoperable significa que es posible intercambiar información y utilizarla sin importar el sistema utilizado. Una solución sencilla sería que todos desarrollaran o adquirieran un único sistema información, de este modo no habría problemas al intercambiar (exportar), integrar (importar) o buscar información. Sin embargo, esto no es la realidad, y es necesario que todos los sistemas adquiridos o desarrollados manejen los mismos estándares. La adopción de estándares comunes puede proveer niveles óptimos de interoperabilidad (Gómez, 2007).

Las IDE contribuyen a la democratización de la información geográfica, ya que todos los usuarios ya sean o no especialista puedan utilizar en la web la información geográfica del modo más eficaz posible. Por lo mismo, una IDE necesita de un marco de políticas, disposiciones institucionales, tecnologías, datos y personas que hacen posible el compartir y usar la información de modo más eficaz (Bernabé \& López, 2012).

En Chile se destaca IDE CHILE ${ }^{6,}$ brinda servicios de mapas y coloca a disposición información geográfica de carácter público para dar un soporte a la toma de decisiones; también iniciativas locales desarrolladas desde el ámbito académico como Gesitran BíoBío ${ }^{7}$, plataforma tecnológica que recopila, administra y procesa información del sistema de transporte y uso de suelo del Gran Concepción.

Sobre planificación de viajes en transporte público existen variadas plataformas en el mundo, dentro de ellas se encuentra la red de transporte público de Lyon, Francia (TCL) ${ }^{8}$, la cual ayuda a recorrer toda el área metropolitana de la ciudad (Figura $\mathrm{N}^{\circ} 6$ ). Es un sistema de transporte que incorpora diferentes modos como metro, tranvía, funicular y más 130 líneas de autobús. Otro

\footnotetext{
${ }^{6} \mathrm{http}: / /$ www.ide.cl/

${ }^{7} \mathrm{http}: / /$ www.gesitranbiobio.cl/

${ }^{8}$ http://www.tcl.fr/es
} 
ejemplo es el Kölner Verkehrs-Betriebe $\mathrm{AG}^{9}$, plataforma que agrupa a todas las empresas de transporte de Colonia, Alemania (Figura $\mathrm{N}^{\circ}$ ) ). En su sistema integra el uso de la bicicleta a través de la compra del ticket y además fomenta la utilización del auto compartido realizando descuentos a través de la suscripción.

Figura $N^{\circ}$ 6: Plataforma Red de Transporte Público en Lyon, Francia

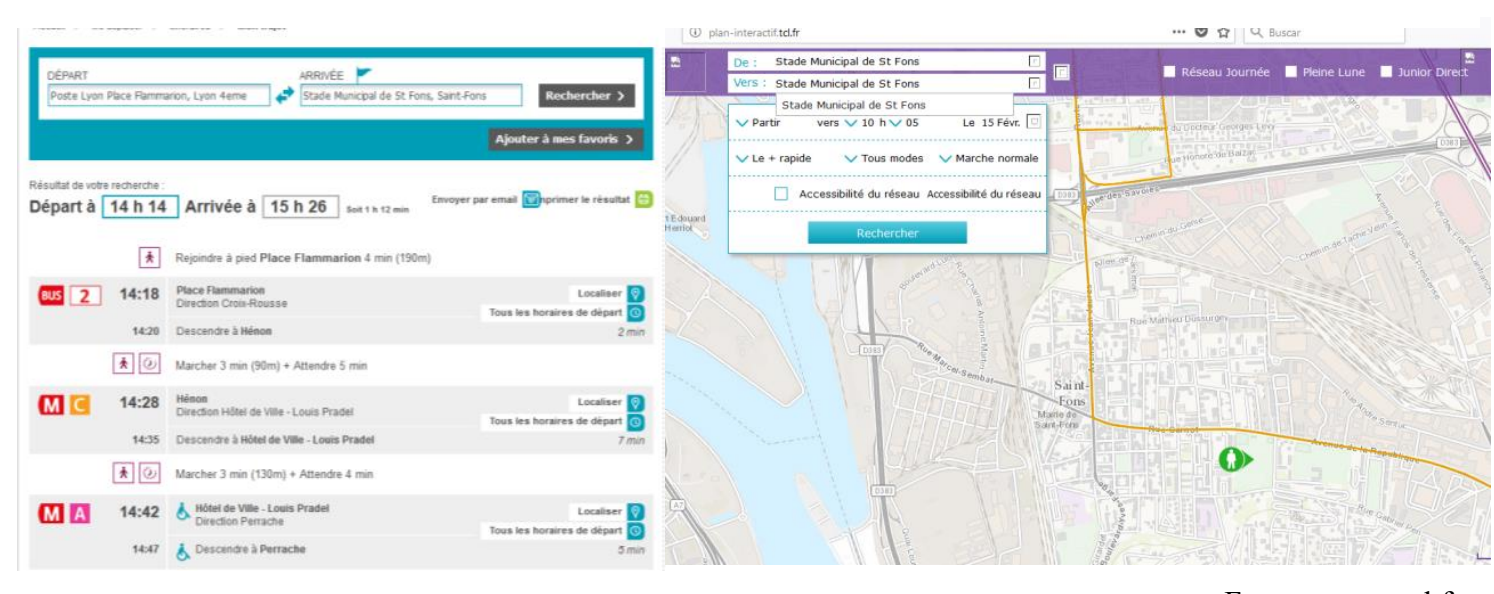

Fuente: www.tcl.fr

Figura $\mathrm{N}^{\circ}$ 7: Plataforma Red de Transporte en Colonia, Alemania

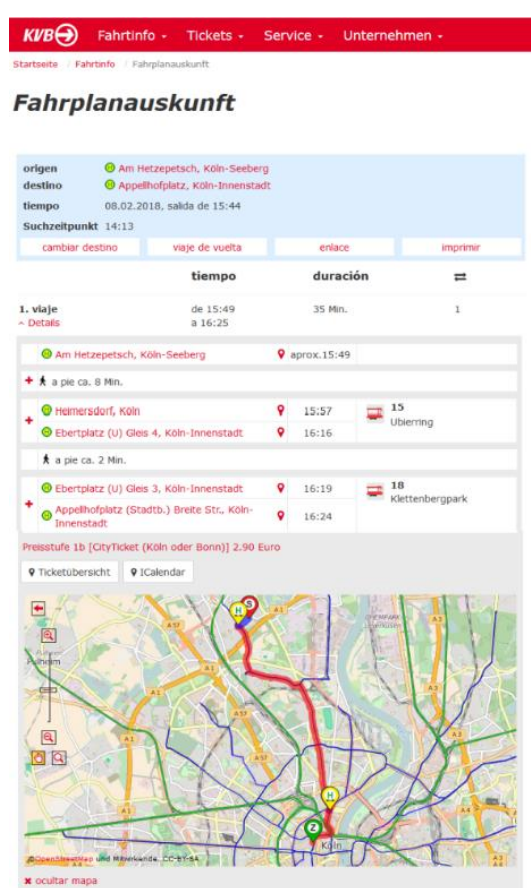

${ }^{9}$ https://www.kvb.koeln/ 
En relación a plataformas que colaboran en la planificación del transporte "Remix" es una de ellas, creada en Estados Unidos, esta aplicación web permite la planificación del transporte público permitiendo a técnicos o planificadores dibujar rutas en el mapa y visualizar en tiempo real diferentes escenarios observando los impactos a través de isócronas, tal como se muestra en la siguiente figura. Esta plataforma se basa principalmente en información proporcionada por los GTFS.

Figura $\mathrm{N}^{\circ}$ 8: Remix y planificación de Transporte

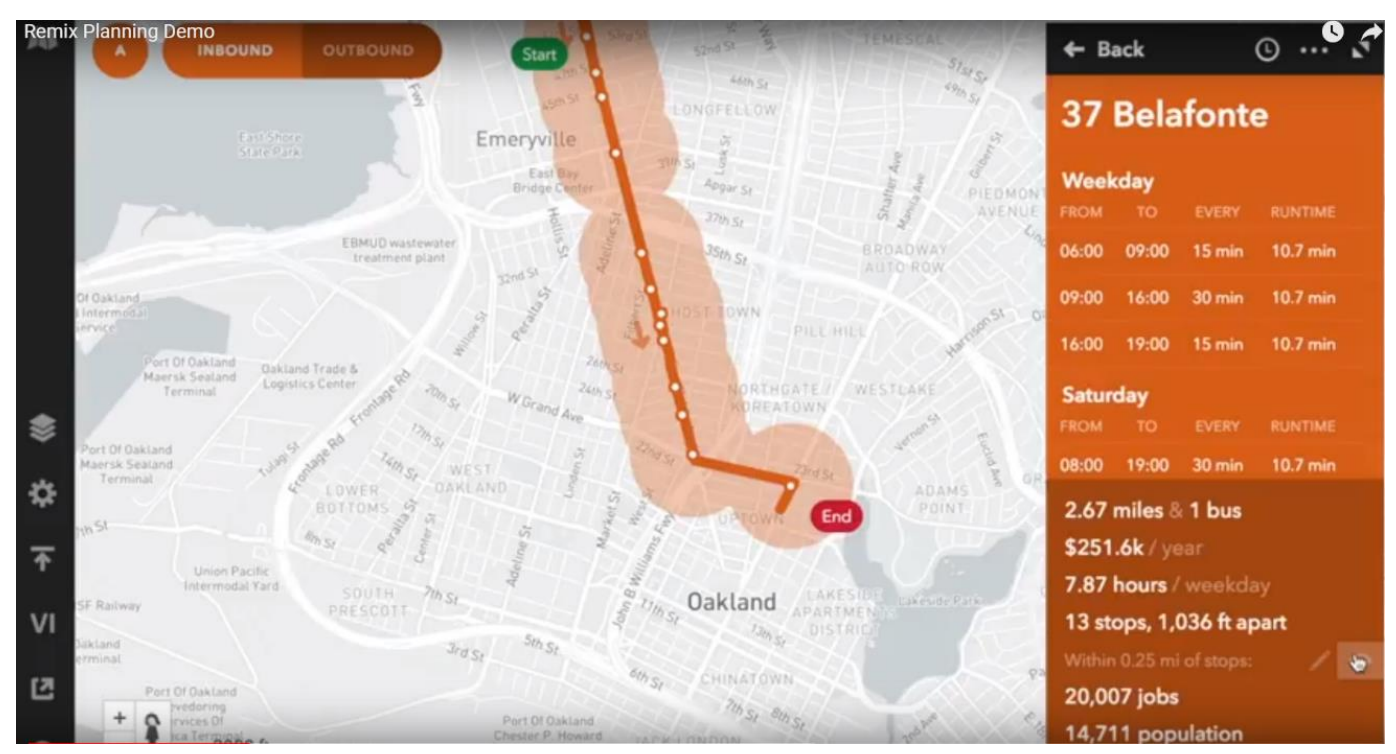

Fuente: www.remix.com.

Ciertamente, el desarrollo de mapas web facilita la incorporación de herramientas que permite suministrar datos geoespaciales, facilitando el acceso de los usuarios a los datos desde cualquier lugar (que tenga acceso a la red) y sin límites de horario (Opazo, et al. 2014), informando a la comunidad sobre la accesibilidad a distintos servicios en su entorno. Desde el punto de vista académico y a pesar de la existencia de consistentes estudios científicos que profundizan en la importancia accesibilidad territorial del trasporte público en la planificación urbana, es dificultoso mostrar los resultados y generalmente no se permite una interacción con 
la información geoespacial, esto propicia el desconocimiento y la falta de participación ciudadana en proyectos de infraestructura de transporte los cuales una vez construidos influyen de manera significativa en la accesibilidad de las personas.

- Tipos de Software

Dada la rápida evolución tecnológica en los últimos años, han surgido diferentes movimientos en torno a la creación, distribución y propiedad de los softwares que en muchas ocasiones se desconoce.

Para comenzar, el término de software libre (Free software) se refiere a las libertades esenciales del usuario, es decir, la libertad de utilizarlo, ejecutarlo, estudiarlo y modificarlo o de distribuir copias con o sin modificaciones (Stallman, 2011).

En cambio, en software de código libre (Open Source) no tiene porqué implicar libertad, sino que sólo hay disponibilidad de acceso al código fuente, esto en su definición estrictamente literal. Sin embargo, los programas de código abierto ofrecen a los usuarios la posibilidad de mejorarlos con el sólo hecho de estar disponible el código fuente, previa restricciones sobre su uso o modificación.

Algunos organismos como la GNU (Sistema Operativo Free Software) afirman que a pesar de interpretar al código libre como un término más débil y flexible que el de software libre ambos movimientos reconocen el mismo conjunto de licencias y mantienen principios equivalentes.

Históricamente, el inicio de estos dos movimientos comienza en el año 1998 cuando una parte de la comunidad del software libre se bifurcó y originó una campaña para promover el Open Source (código abierto). Si bien, ambas expresiones describen casi la misma categoría de software representan puntos de vista basados en valores fundamentalmente diferentes. El código abierto es una metodología de programación en términos de cómo mejorar el software, en sentido meramente práctico, el software libre es un movimiento social y un imperativo ético, que es la libertad de los usuarios, esta modalidad es empleada en CoAXs. 
Por lo general, casi todo el software de código abierto es software libre, con algunas excepciones.

En el caso del software privativo, estos se identifican como todo aquel software que no es libre en otras palabras se prohíbe su uso, redistribución o modificación, se requiere que se solicite permiso, o tiene tantas restricciones en donde no se puede utilizar libremente, en esta categoría se incluye el software ArcGis utilizado para el trabajo en redes de esta tesis.

\section{PROBLEMÁTICA Y JUSTIFICACIÓN}

Las tendencias tecnológicas actuales convergen cada vez más hacia sistemas móviles, sensores, información en tiempo real y la participación activa de los ciudadanos (Ballari et al., 2014). De este modo, la herramienta CoAXs concuerda con esta línea creando un mapa interactivo de medidas de accesibilidad ${ }^{10}$, el cual fomenta la colaboración de diversos actores en la planificación del sistema de transporte de la ciudad, ayudando a los participantes o usuarios a considerar impactos más allá de sus propios viajes y ahorros de tiempos de forma individual (Stewart \& Zegras, 2016).

Desde el punto de vista de los usuarios, la creación de este tipo de plataformas de mapas web permite dar a conocer y convertir en accesible la información espacial que habitualmente está disponible sólo para profesionales con expertise, quienes utilizan softwares especializados para el procesamiento y visualización de los datos. Esta realidad comienza a cambiar progresivamente con la mayor difusión de estas plataformas, así un tomador de decisiones o

\footnotetext{
${ }^{10}$ Se define accesibilidad como la oportunidad que posee una persona, situada en una localización específica, de llevar a cabo una actividad o conjunto de las mismas en función principalmente del tiempo y distancia (Ramírez, 2008).
} 
cualquier habitante de la ciudad interesado puede conocer las problemáticas e impactos de los proyectos de transporte.

Pero por otra parte y basándose en la teoría de sistemas, la mayoría de las plataformas WebSIG funcionan bajo el modelo de caja negra el cual presenta entradas, procesos y salidas. Las entradas son los datos a ingresar, los que posteriormente son procesados y finalmente se entrega el producto final, el problema es que se desconoce la forma en que se modificaron o transformaron los datos. Justamente es importante evitar este modelo o de lo contrario documentar cada una de las operaciones aplicadas para entender y mejorar los resultados obtenidos. Por esta razón, esta tesis propone analizar los resultados entregados por la herramienta CoAXs, que es un sistema ya implementado en lenguaje Java, en contraste con métodos convencionales desarrollados en Sistemas de Información Geográfica y el trabajo en redes, permitiendo la configuración de diferentes factores que influyen en el análisis de accesibilidad.

La comparación entre estas dos plataformas, contribuye al análisis de fortalezas y debilidades en función del uso para el cual se quiera emplear.

Finalmente, el resultado de esta tesis es una contribución en el proceso de participación ciudadana en proyectos de infraestructura vial ya que involucra la comprensión e interacción directa del participante a través de diferentes tecnologías dejando atrás la forma expositiva y meramente informativa en que se realizan las jornadas participativas.

\section{PREGUNTA DE INVESTIGACIÓN}

- En la comprensión de impactos de proyectos de infraestructura de transporte, ¿Cuáles son las ventajas y desventajas de realizar dichos análisis en ArcGis desktop frente al realizado en la plataforma CoAXs? 


\section{OBJETIVO GENERAL}

Comparar escenarios de accesibilidad provenientes ArcGis desktop y la plataforma CoAXs con la finalidad de simular los impactos de proyectos de transporte público en el Área Metropolitana de Concepción.

\section{OBJETIVOS ESPECÍFICOS}

- Identificar recursos y variables de entrada a considerar en el ArcGis desktop y en CoAXs.

- Medir los cambios en la accesibilidad en la situación con y sin proyecto en ambas plataformas.

- Proponer una metodología para la evaluación de la calidad desde el punto de vista del usuario, del software ArcGis y CoAXs.

- Analizar los resultados obtenidos del trabajo en redes en un Sistema de Información Geográfica y la plataforma Web-SIG CoAXs.

\section{8. ÁREA DE ESTUDIO}

El Área Metropolitana de Concepción la componen nueve comunas: Concepción (centro principal), Talcahuano, Hualpén, San Pedro de la Paz, Penco, Tomé, Chiguayante, Coronel y Lota, localizadas en la Provincia de Concepción, Región del Bío Bío, zona Centro-Sur de 
Chile entre los $36^{\circ} 35^{\prime}$ y $37^{\circ} 00^{\prime}$ de Latitud Sur y los $72^{\circ} 45^{\prime}$ a $73^{\circ} 15^{\prime}$ de Longitud Oeste.

Figura $\mathrm{N}^{\circ}$ 9: Área de estudio

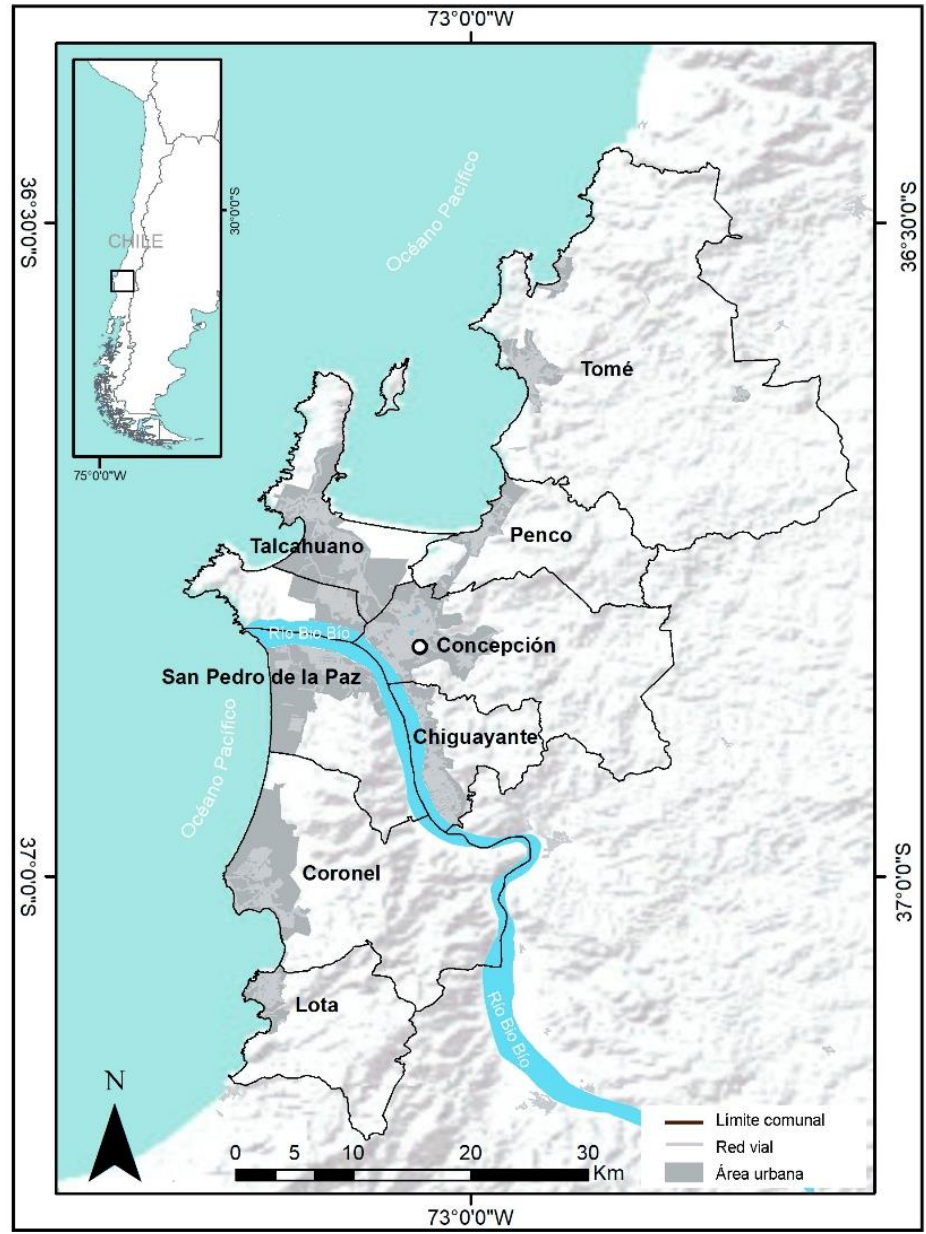

Fuente: Elaboración propia.

El área de análisis tiene una superficie total de 2.830,40 $\mathrm{km} 2$ y representa un 7,63\% de la superficie regional. Según el Censo de Población y Vivienda del año 2017, cuenta con una población de 892.006 habitantes, equivalentes el 44\% de la población de la región del Bío-Bío. 
Cada una de estas comunas presenta características propias, algunas de ellas se describen en el cuadro $\mathrm{N}^{\circ} 2$.

Tabla $\mathrm{N}^{\circ}$ 2: Antecedentes a nivel comunal, Área Metropolitana de Concepción

\begin{tabular}{|c|c|c|c|c|}
\hline Comuna & Población & Superficie & Porcentaje & Distancia en \\
\hline & Censo 2017 & $\begin{array}{l}\text { comunal } \\
(\mathrm{Km} 2)\end{array}$ & $\begin{array}{l}\text { Superficie } \\
\text { Urbana }\end{array}$ & $\begin{array}{l}\text { km al centro } \\
\text { principal }\end{array}$ \\
\hline Concepción & 223.574 & 218,91 & $19,5 \%$ & 0 \\
\hline Coronel & 116.262 & 278,05 & $14,7 \%$ & 31 \\
\hline Chiguayante & 85.938 & 74,94 & $25,2 \%$ & 17 \\
\hline Hualpén & 91.773 & 50,38 & $32,9 \%$ & 9,3 \\
\hline Lota & 43.535 & 114,63 & $8,0 \%$ & 38,7 \\
\hline Penco & 47.367 & 107,76 & $12,5 \%$ & 13 \\
\hline San Pedro de la Paz & 131.808 & 112,57 & $35,2 \%$ & 8 \\
\hline Talcahuano & 151.749 & 95,39 & $51,9 \%$ & 15,6 \\
\hline Tomé & 54.946 & 495,13 & $3,1 \%$ & 30 \\
\hline
\end{tabular}

Los centros de Concepción y Talcahuano destacan como los principales articuladores urbanos de este espacio dedicado principalmente a actividades secundarias y terciarias, como lo demuestran los indicadores económicos extraídos del Servicio de Impuestos Internos para el año 2013. Así, un 33\% de las empresas corresponden a la rama Comercio mientras que un $15,2 \%$ son actividades inmobiliarias, empresariales y de alquiler; luego predominan actividades industriales y de construcción con alrededor de un $8 \%$. 
En términos de transporte y basados en la Encuesta Origen Destino (SECTRA, 2017), en el Área Metropolitana de Concepción se realizan 2.976 .668 viajes diarios y los modos más utilizados son el transporte público con $36 \%$ y el transporte privado con $35 \%$ (Gráfico $\mathrm{N}^{\circ} 1$ ).

Gráfico $\mathrm{N}^{\circ}$ 1: Porcentajes según modos de viaje

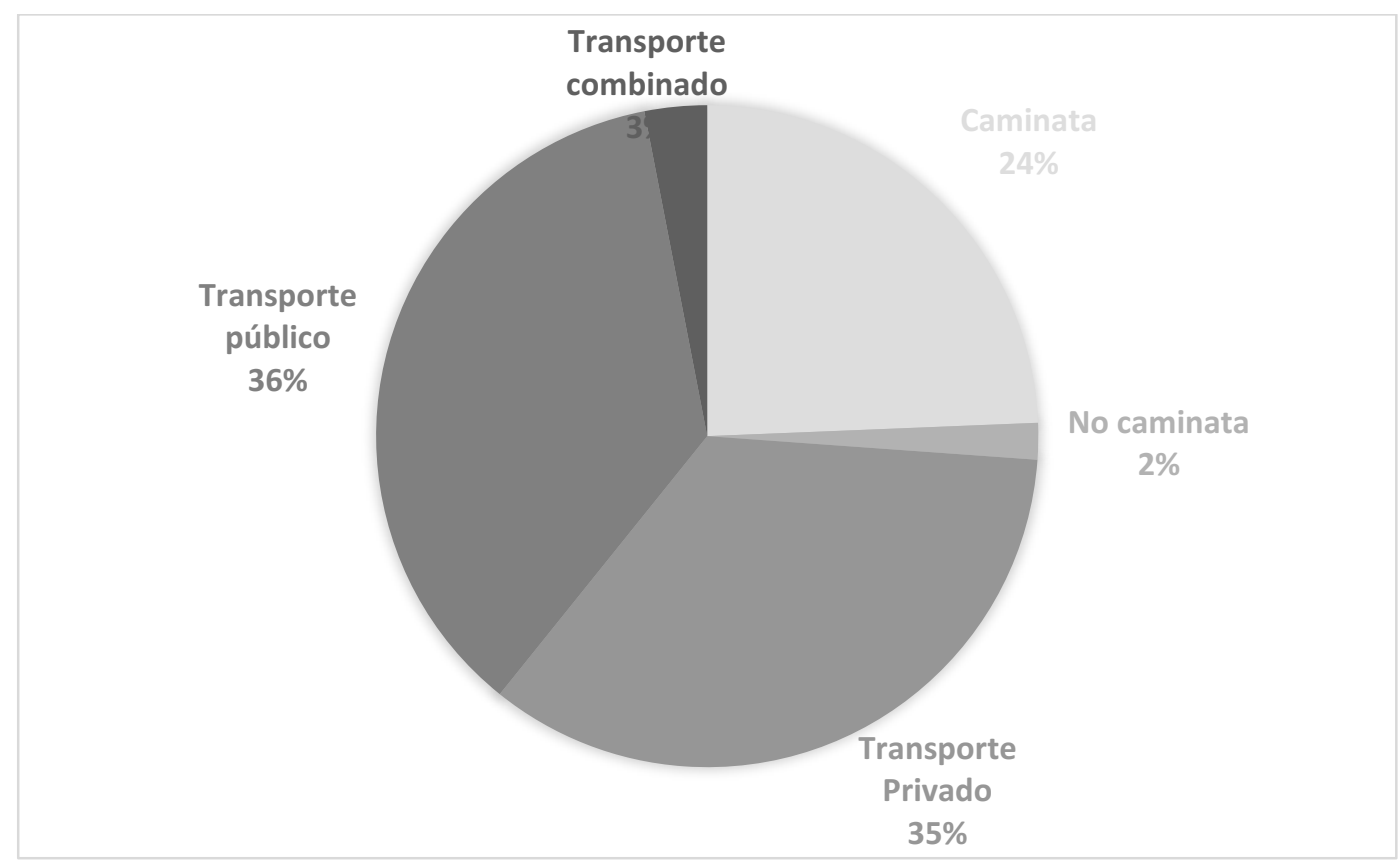

Fuente: Encuesta Origen Destino, 2017.

En cuanto al tiempo destinado para viajar un $48,6 \%$ de las personas que viven en el AMC viajan más de una hora al día para llegar a su trabajo y las comunas de destinos más frecuentes son hacia la comuna de Concepción y Talcahuano, dado principalmente por el patrón de centro periferia, donde Concepción es el principal núcleo articulador (Figura $\mathrm{N}^{\circ} 10$ ). 
Figura $\mathrm{N}^{\circ} 10$ : Distribución de viajes según destino más frecuente

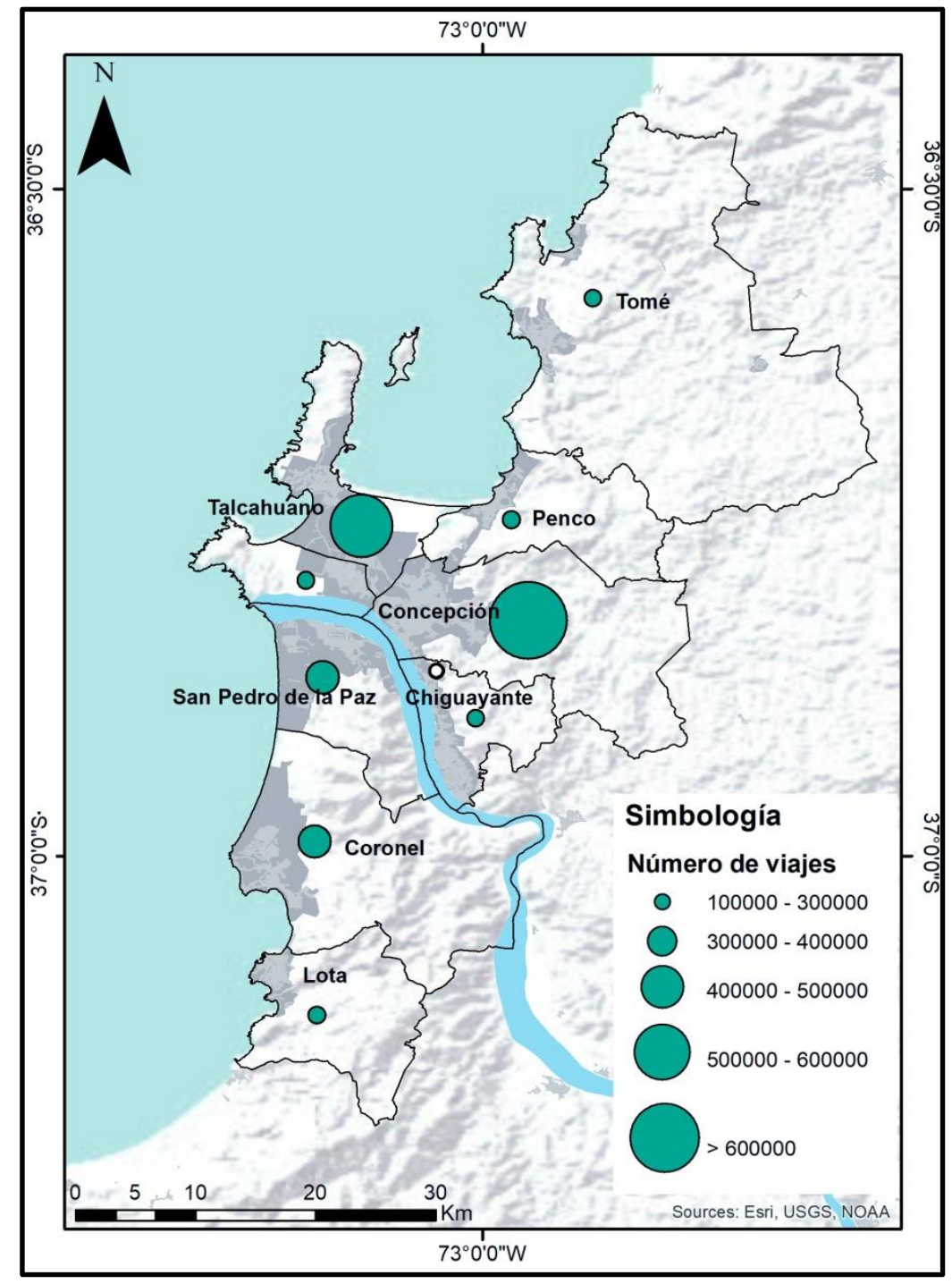

Fuente: Encuesta Origen Destino, 2017.

\section{METODOLOGÍA}

La metodología de trabajo consiste en cinco etapas principales que tienen relación al modelamiento del problema en un Sistema de Información Geográfica, detalladas en la Figura $\mathrm{N}^{\circ}$ 9. El primer paso comienza desde un análisis previo, luego la recopilación de información hasta el proceso final de análisis y comparación de ambos sistemas. 


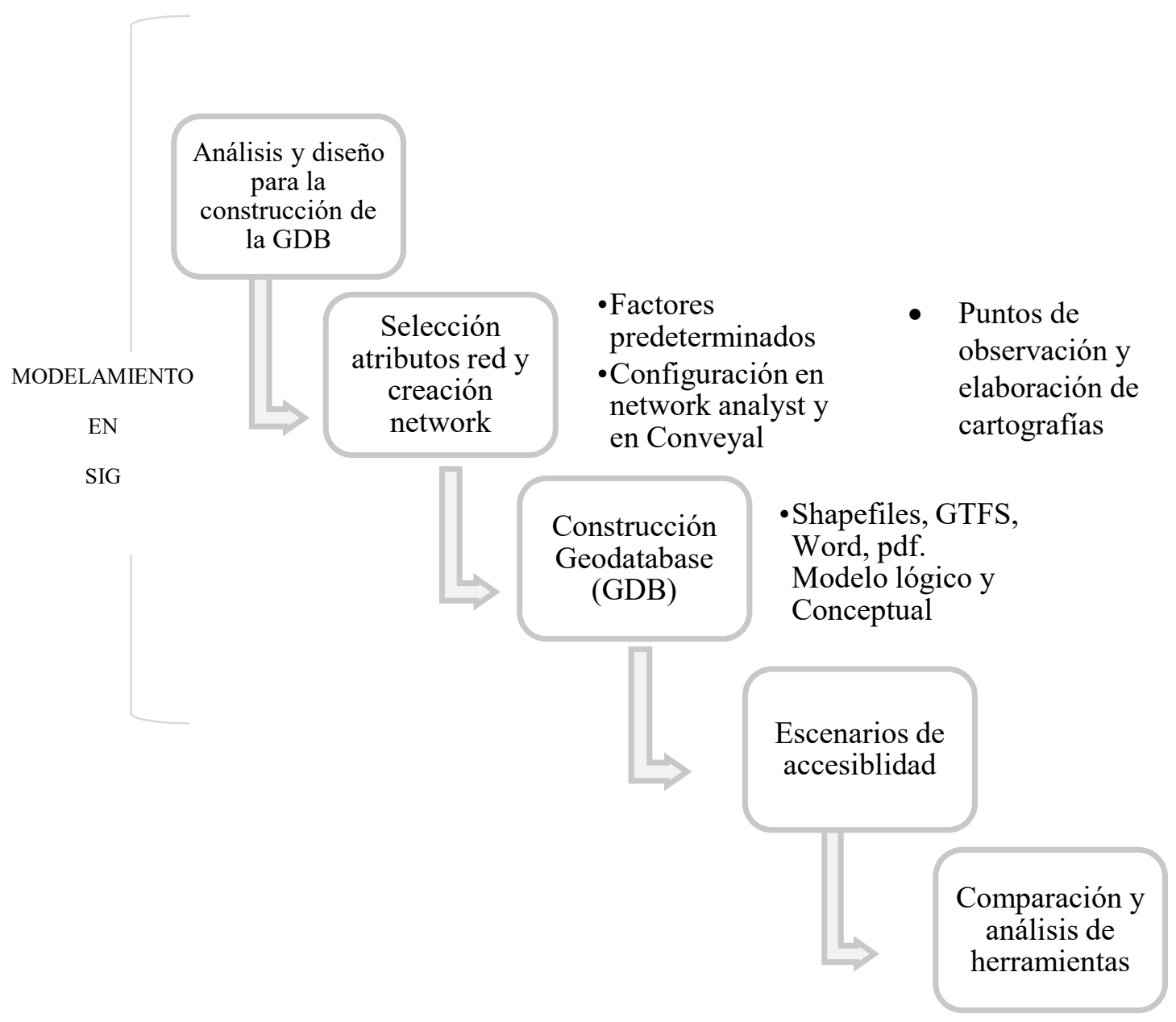

Fuente: Elaboración propia.

\section{Etapa 1: Análisis y diseño de la Base de Datos Geográfica (GDB)}

Como parte del proceso de construcción del GDB, lo primero que se necesita es entender que se está realizando un modelamiento de la realidad en un Sistema de Información Geográfica. Para facilitar esta abstracción se emplean tres modelos: Conceptual, Lógico y Físico, los cuales serán descritos a continuación: 


\section{-Modelo Conceptual}

¿Cuál es el problema que se intenta resolver?

Se pretende cuantificar los impactos de nuevas infraestructuras de transporte, asociado principalmente a los cambios en la accesibilidad de las personas a los equipamientos y servicios de las comunas del Área Metropolitana de Concepción, para ello se comparan dos escenarios (con/sin corredores de transporte público). Además, se pretende brindar al usuario un instrumento que le permita, de manera práctica y eficaz, llevar a cabo la valoración de los impactos en las zonas urbanas. Por otra parte, se cuenta con dos plataformas (ArcGis y CoAXs) que en la práctica realizan el mismo proceso, debido a esto, es de interés la comparación de los resultados para conocer la maniobrabilidad de los softwares y los valores obtenidos.

Lo primero, es realizar un análisis exploratorio de la información, para ello se ha seleccionado un set de datos geográficos que se encuentran descritos en la Tabla №3.

Tabla $N^{\circ}$ 3: Información base para ARCGIS y COAXS

\begin{tabular}{|l|l|l|l|l|}
\hline Nombre & Formato & $\begin{array}{l}\text { Entidad } \\
\text { Espacial }\end{array}$ & $\begin{array}{l}\text { Modelo de } \\
\text { datos }\end{array}$ & Atributos \\
\hline Puntos de muestra & Shapefile & Puntual & Vectorial & ID/COMUNA \\
\hline Centros de Salud & Shapefile & Puntual & Vectorial & $\begin{array}{l}\text { ID/TIPO/NOMBR } \\
\text { E }\end{array}$ \\
\hline Lugares de trabajo & Shapefile & Puntual & Vectorial & FOLIO/PERSONA \\
\hline $\begin{array}{l}\text { Establecimientos } \\
\text { educacionales }\end{array}$ & Shapefile & Puntual & Vectorial & RBD/NOMBRE \\
\hline Áreas verdes & Shapefile & Polígono & Vectorial & ID/ÁREA \\
\hline Ferias libres & Shapefile & Puntual & Vectorial & $\begin{array}{l}\text { CÓDIGO/NOMBR } \\
\text { E/DÍA/DIRECCIÓ } \\
\text { N }\end{array}$ \\
\hline
\end{tabular}




\begin{tabular}{|l|l|l|l|l|}
\hline Supermercados & Shapefile & Puntual & Vectorial & ID \\
\hline $\begin{array}{l}\text { General Transit Feed } \\
\text { Specification }\end{array}$ & GTFS & $\begin{array}{l}\text { Lineal/Puntu } \\
\text { al }\end{array}$ & & $\begin{array}{l}\text { ID/VELOCIDAD/ } \\
\text { NOMBRE }\end{array}$ \\
\hline Líneas transporte público & Shapefile & Lineal & Vectorial & $\begin{array}{l}\text { ID/NOMBRE/VEL } \\
\text { OCIDAD }\end{array}$ \\
\hline Red vial & Shapefile & Lineal & Vectorial & $\begin{array}{l}\text { TIPO/CLASE/PR } \\
\text { MC }\end{array}$ \\
\hline
\end{tabular}

Fuente: Elaboración propia.

Las fuentes de cada información se detallan en la Tabla $\mathrm{N}^{\circ} 4$.

Tabla $N^{\circ} 4$ : Información base para ARCGIS y COAXS

\begin{tabular}{|l|l|}
\hline Nombre del dato & Fuente \\
\hline Centros de Salud & $\begin{array}{l}\text { Departamento Estadísticas e Información de } \\
\text { Salud, 2018 }\end{array}$ \\
\hline Lugares de trabajo & Encuesta Origen-Destino/ SECTRA, 2017 \\
\hline Establecimientos educacionales & $\begin{array}{l}\text { Agencia Calidad de Educación/MINEDUC, } \\
2016\end{array}$ \\
\hline Áreas verdes & Basado en Plan Regulador Metropolitano, 2013 \\
\hline Ferias libres & Fondecyt N¹171113 \\
\hline Supermercados & Fondecyt N ${ }^{\circ} 1171113$ \\
\hline $\begin{array}{l}\text { General } \\
\text { Specification (GTFS) }\end{array}$ & Fobierno de Chile, 2016-2017 \\
\hline Líneas transporte público & A partir del GTFS \\
\hline Red vial & MINVU, 2013 \\
\hline
\end{tabular}

Fuente: Elaboración propia.

Centros de salud

Esta información proviene de los registros del Ministerio de Salud, específicamente del Sistema

Nacional de Servicios de Salud y Municipales y se encuentra disponible en la Infraestructura 
de Datos Espaciales de Chile (IDE Chile). La capa geográfica muestra establecimientos públicos de salud de niveles primario y secundario y su última actualización se realizó en junio de 2017.

Como centro de salud primaria se entiende el primer nivel de contacto de los ciudadanos con el sistema público. Brinda atenciones ambulatorias y son administrados principalmente por las municipalidades (Servicio de Salud, 2018).

El nivel de atención secundario corresponde a los establecimientos que brindan atención ambulatoria y sólo a pacientes que hayan sido derivados desde el nivel primario o tras consultar las Unidades de Emergencia, cuando el profesional de la salud ha determinado que requiere atención de mayor complejidad.

El nivel terciario está constituido por los establecimientos hospitalarios. En ellos se realizan actividades de alta complejidad, aunque también tienen funciones del nivel secundario.

Existen 90 centros de salud repartidos en el Área Metropolitana de Concepción y se concentran en la zona urbana tal como muestra la Figura $\mathrm{N}^{\circ} 12$. 
Figura $\mathrm{N}^{\circ}$ 12: Localización de centros de salud en el Área Metropolitana de Concepción

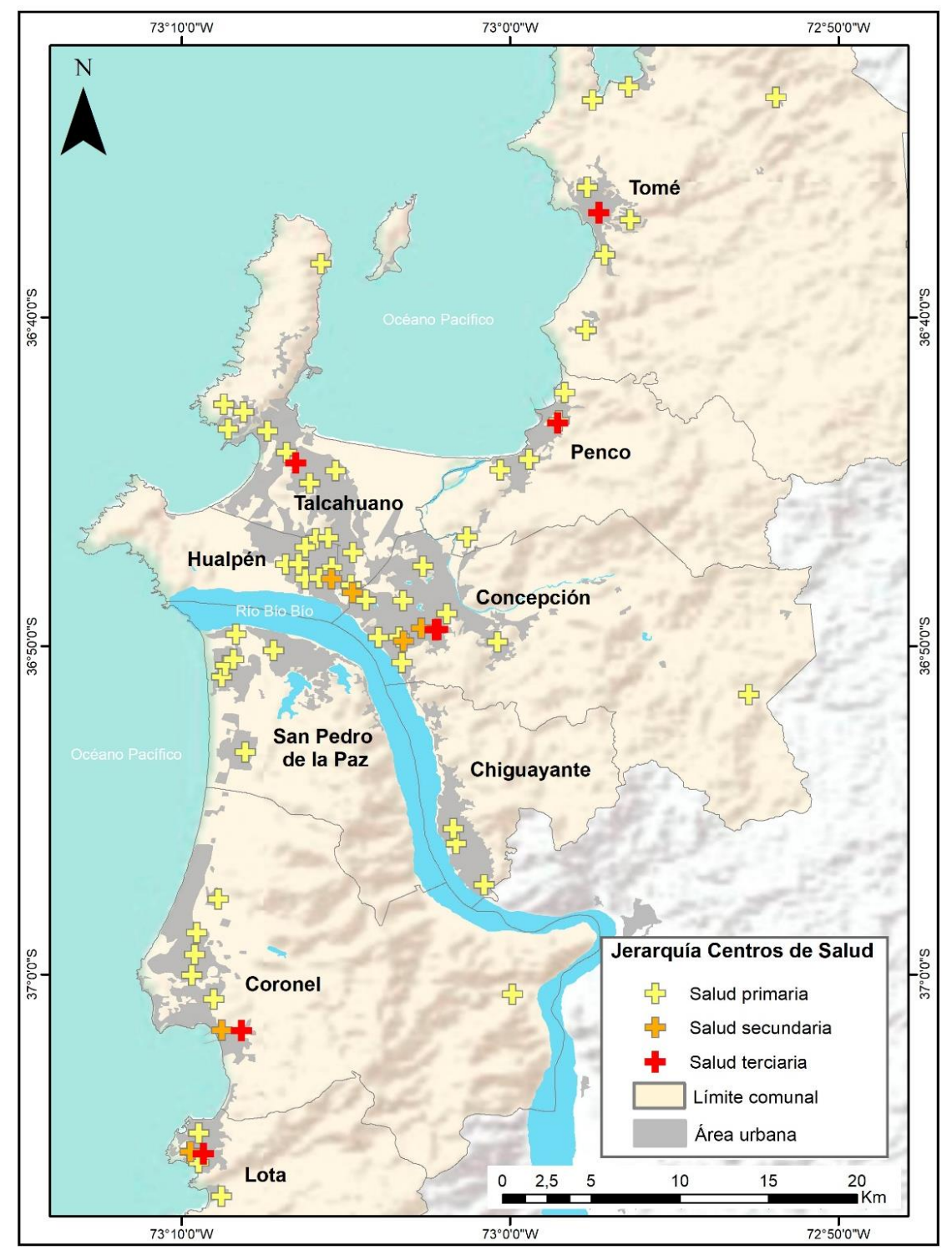

Fuente: Elaboración propia.

\section{Lugares de trabajo}

Se obtienen a partir de la Encuesta Origen Destino de viajes del año 2017. Esta encuesta de movilidad constituye la principal fuente de información utilizada en el proceso de planificación de los sistemas de transporte y está disponible a todo público. Disponible en el portal del Ministerio de Transporte.

Para elaborar la cobertura se utilizó la información disponible en la planilla con propósito "al trabajo" y se seleccionaron sólo los viajes con destino dentro del AMC y que fueron realizados durante la semana. 
Figura $\mathrm{N}^{\circ}$ 13: Localización de lugares de trabajo en el Área Metropolitana de Concepción

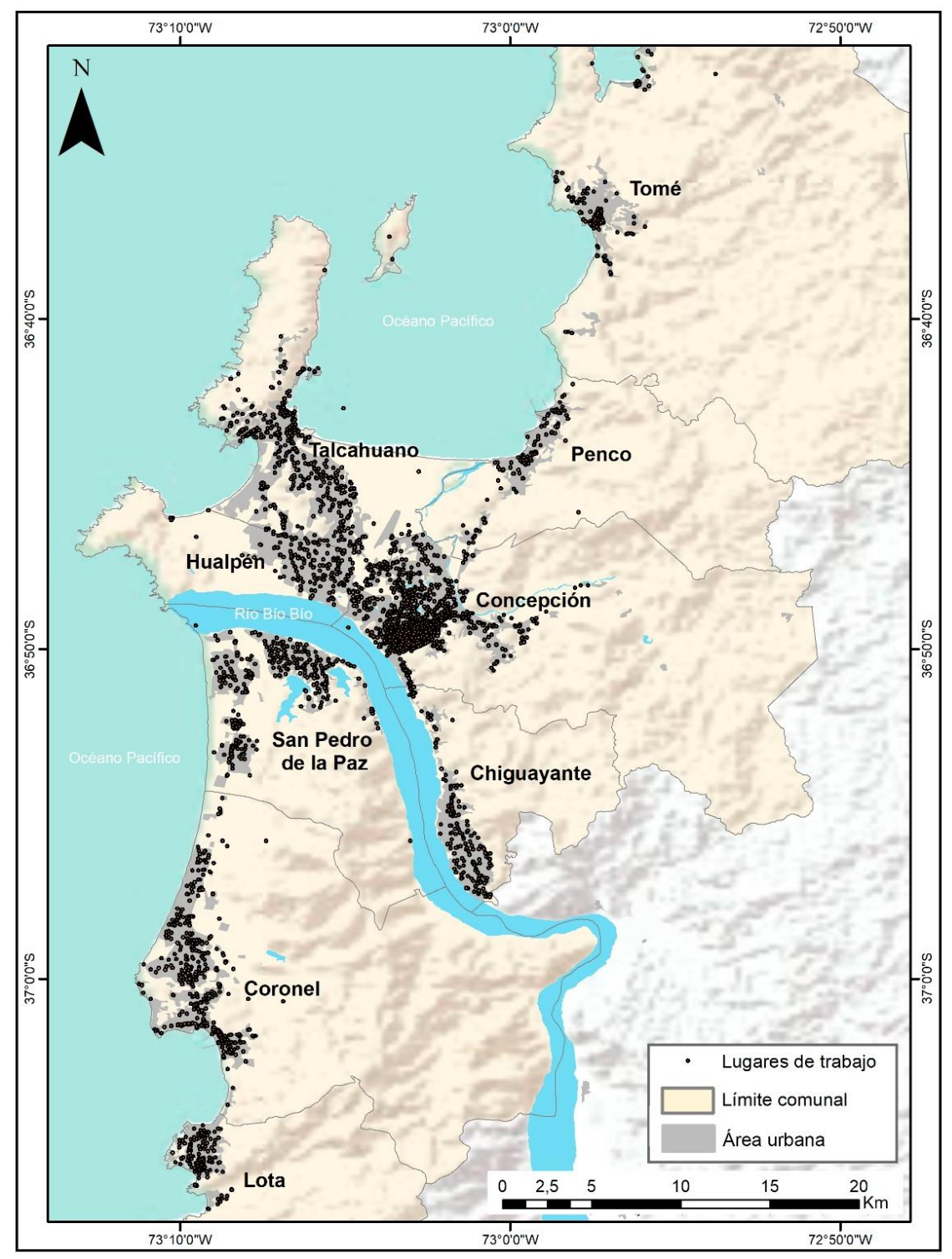

Fuente: Elaboración propia.

\section{Establecimientos educacionales}

Los centros educativos provienen de la base de datos del Directorio Oficial del año 2016, que depende del Ministerio de Educación. En esta capa de información se describen establecimientos educacionales según tipo de financiamiento, es decir, si es gratuito o pagado. En cuanto a este último punto, se han seleccionado aquellos colegios que cobran un arancel 
mensual menor a 40USD, con el objetivo de definir una educación accesible en términos monetarios equivalente al 7\% del salario mínimo nacional.

Para la georreferenciación se utilizó las coordenadas X e Y que poseía la tabla de datos y se localizaron 232 escuelas. Se observa que la mayor concentración de establecimientos educacionales se encuentra en los centros cívicos de cada comuna, mientras que sectores recientemente urbanizados no poseen acceso a educación escolar (Figura $\mathrm{N}^{\circ} 14$ ).

Figura $\mathrm{N}^{\circ}$ 14: Localización de Establecimientos Educacionales en el Área Metropolitana de Concepción.

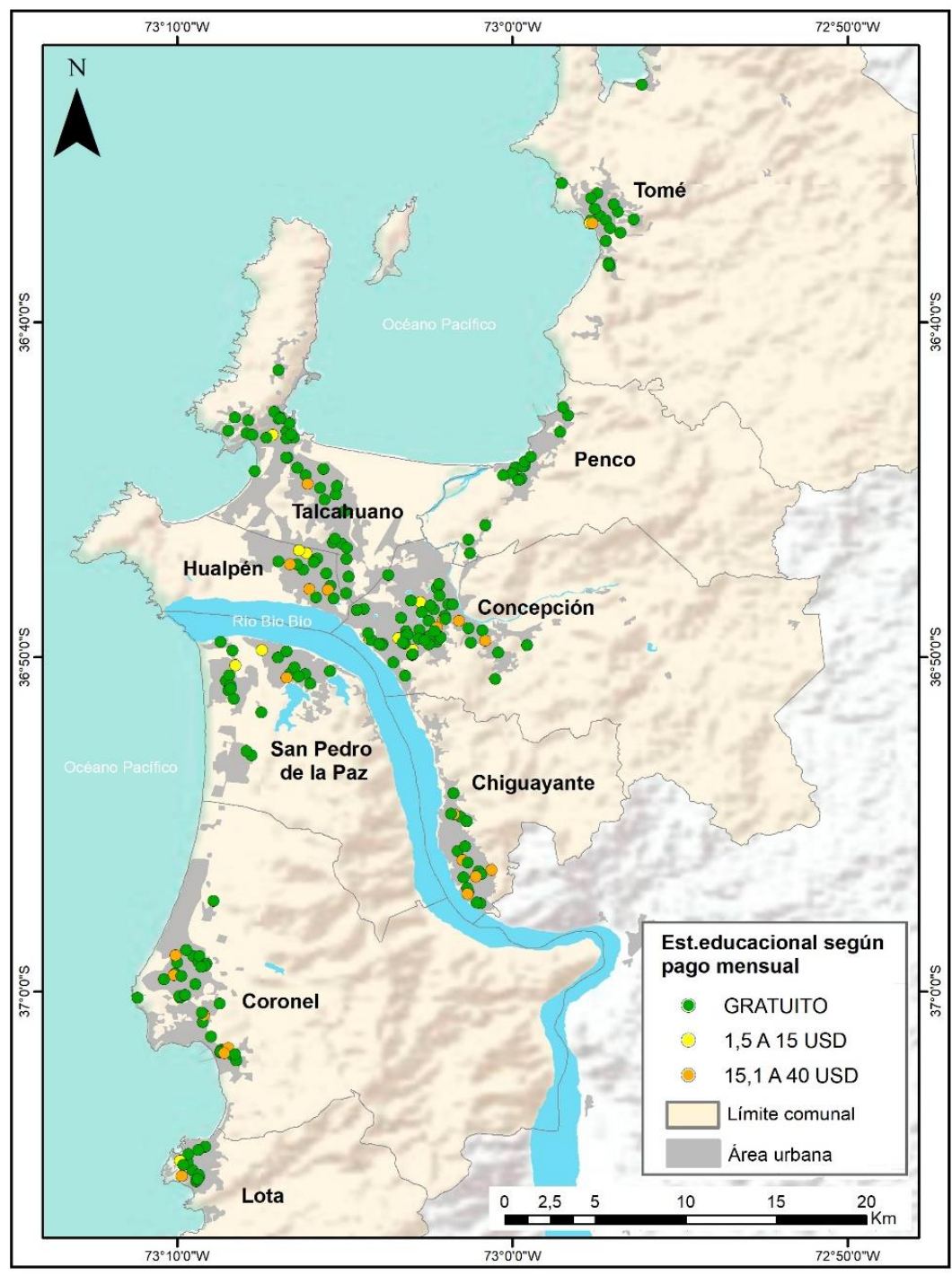

Fuente: Elaboración propia. 


\section{Ferias Libres y Supermercados}

Esta información fue elaborada a partir del proyecto Fondecyt $\mathrm{N}^{\circ} 1171113$ : Understanding the relationship between people's mobility and food patterns, and the role of attitudes and social networks. La capa geográfica contiene 42 ferias y 88 supermercados del año 2018, distribuidas en las comunas del Área Metropolitana de Concepción a excepción de Lota. Cada entidad describe el nombre, dirección y días de funcionamiento en el caso de las ferias.

Figura $\mathrm{N}^{\circ}$ 15: Localización de ferias libres y supermercados en el Área Metropolitana de Concepción

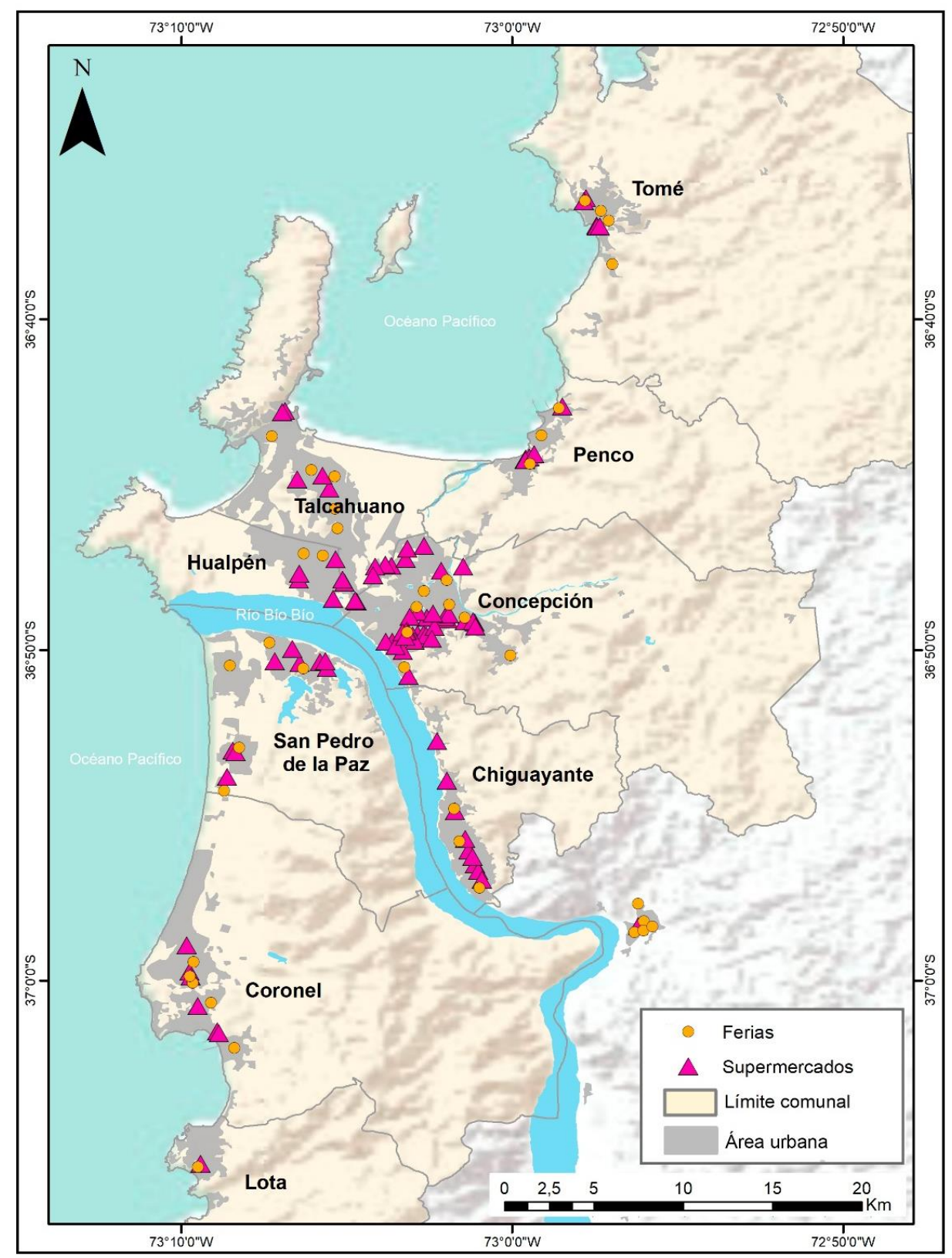

Fuente: Elaboración propia. 
Áreas verdes

Las superficies destinadas a áreas verdes fueron obtenidas a través del catastro realizado por el Ministerio de Vivienda y Urbanismo, las que posteriormente fueron procesadas por criterios de tamaño y clasificación, con el objetivo de seleccionar áreas social y ecológicamente funcionales (Cedeus, 2017). Es decir, se consideraron como áreas verdes aquellas con una superficie mayor a $5000 \mathrm{~m} 2$ y ancho mínimo de 10 metros y cuya tipología corresponda a "Plaza", "Plazoleta", "Plazuela"; "Parque”, "Bandejón”, y “Platabanda", "Jardín”.

De un total de 2500 polígonos sólo 169 cumplieron con los requisitos mencionados y se visualizan en la Figura $\mathrm{N}^{\circ} 16$.

Figura $N^{\circ}$ 16: Localización de áreas verdes en el Área Metropolitana de Concepción

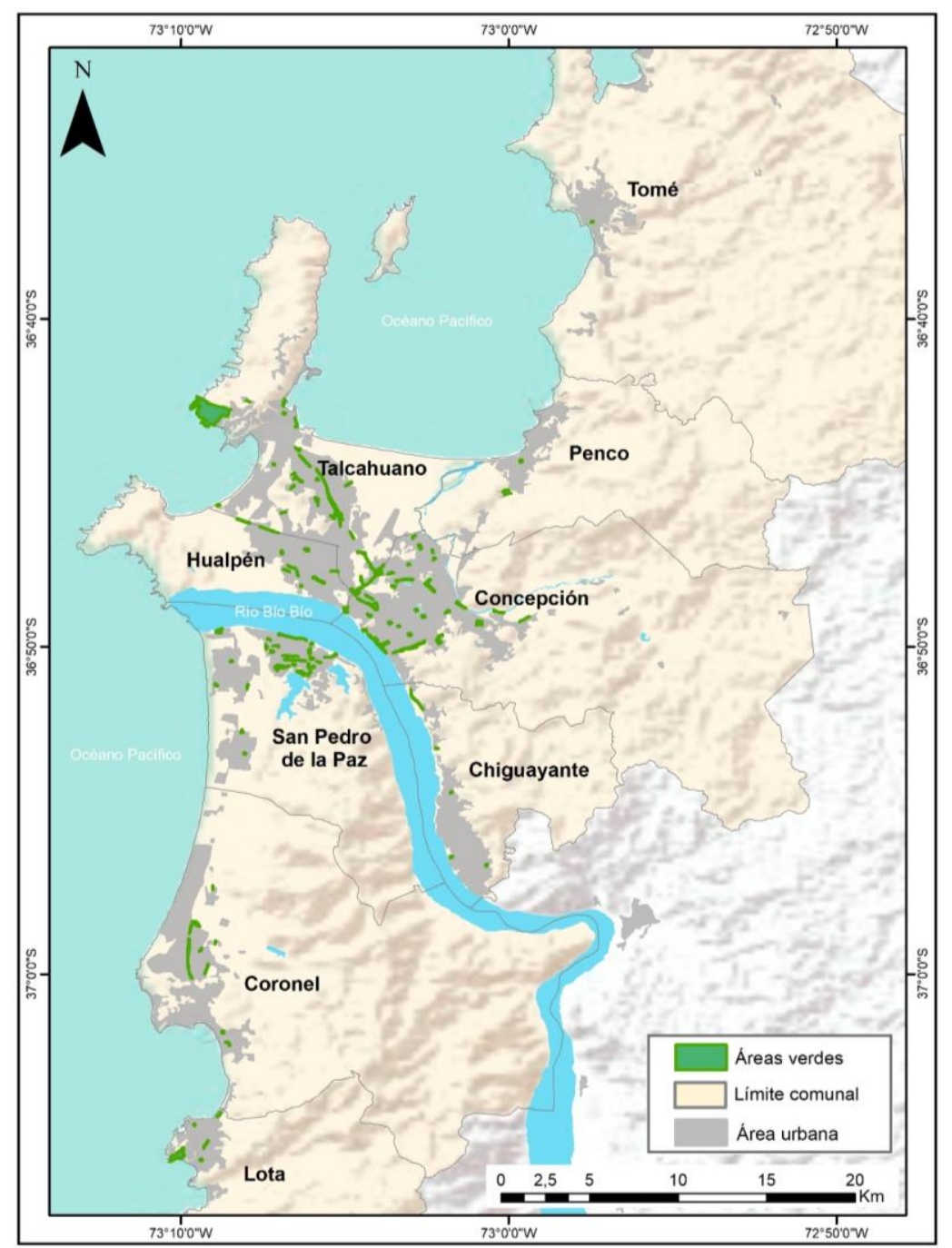

Fuente: Elaboración propia. 
GTFS - Lineas de transporte público

Esta información se encuentra disponible en el portal de datos públicos del Gobierno de Chile. Los GTFS (Especificación general de feeds de transporte público) son un formato de información común para los horarios de transporte público y con información geográfica asociada a ellos. Los "feeds" GTFS permiten que las empresas de transporte público publiquen sus datos de transporte y que los programadores escriban aplicaciones que consuman esos datos de manera interoperable (Google Transit, 2016).

Los GTFS pueden ser estáticos o en tiempo real. Son estáticos cuando la información no se modifica con frecuencia y son en tiempo real cuando la información varía en cosa de minutos como por ejemplo actualizaciones de trayectos, alertas y hasta posición del vehículo. Las actualizaciones en tiempo real mejoran notablemente la experiencia en el servicio de transporte público. Puede proporcionar información actualizada sobre los horarios actuales de llegada y salida permitiendo a los usuarios planificar sus viajes sin inconvenientes.

Un feed GTFS está compuesto por una serie de archivos de texto recopilados en un archivo ZIP. Cada archivo modela un aspecto específico de la información de transporte público: paradas, rutas, viajes y otros datos relacionados con los horarios. Estos archivos txt son: agency.txt, stops.txt, routes.txt, trips.txt, stop_times.txt, calendar.txt, calendar_dates.txt, fare_attributes.txt, fare_rules.txt, shapes.txt, frequencies.txt, transfers.txt, pathways.txt, levels.txt, feed_info.txt, translations.txt, attributions.txt. (Google Transit, 2021).

Estos formatos son compatibles con variadas aplicaciones, para elaborar un GTFS es necesario representar a una empresa de transporte público y registrarse en Google, posteriormente utilizar la aplicación Google Transit. 
Para convertir este formato a un shapefile se utiliza la herramienta "Display GTFS in ArcGis" para el posterior trabajo en Sistemas de Información Geográfica y se visualiza de la siguiente manera:

Figura $N^{\circ}$ 17: Líneas de transporte público

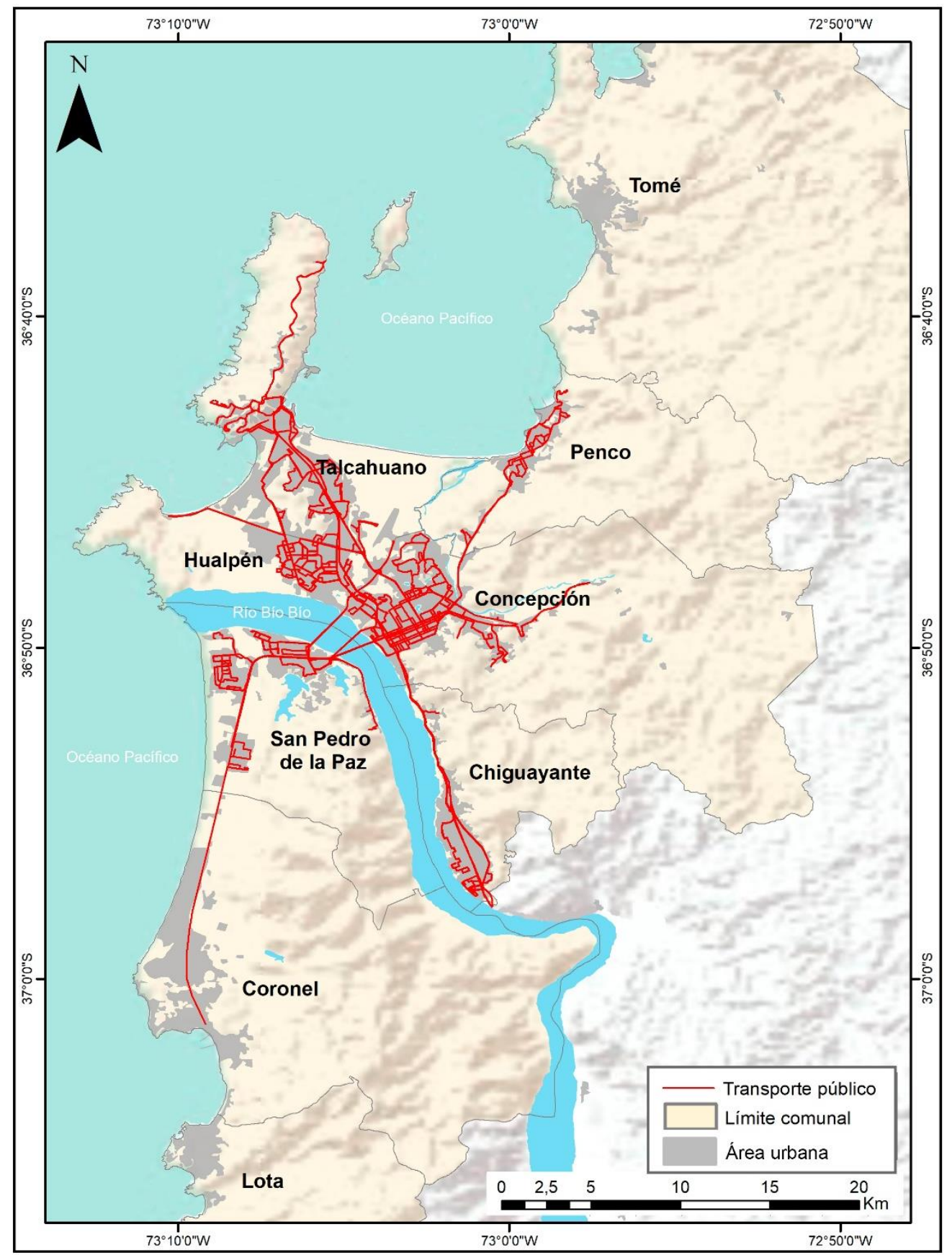

Fuente: Elaboración propia. 


\section{Puntos de muestra}

Son 63 puntos que serán utilizados para comparar la accesibilidad en ambas plataformas y cumplen los siguientes requisitos:

-Un punto en el centro cívico de cada comuna.

-Tres puntos en zonas de mayor densidad de población.

-Tres puntos en zonas de menos densidad de población.

Para modelar el problema geográfico en su etapa de menor abstracción, modelo conceptual, su representación es de la siguiente manera (Figura $\mathrm{N}^{\circ} 18$ ).

Figura $\mathrm{N}^{\circ} 18$ : Modelación del problema geográfico a resolver

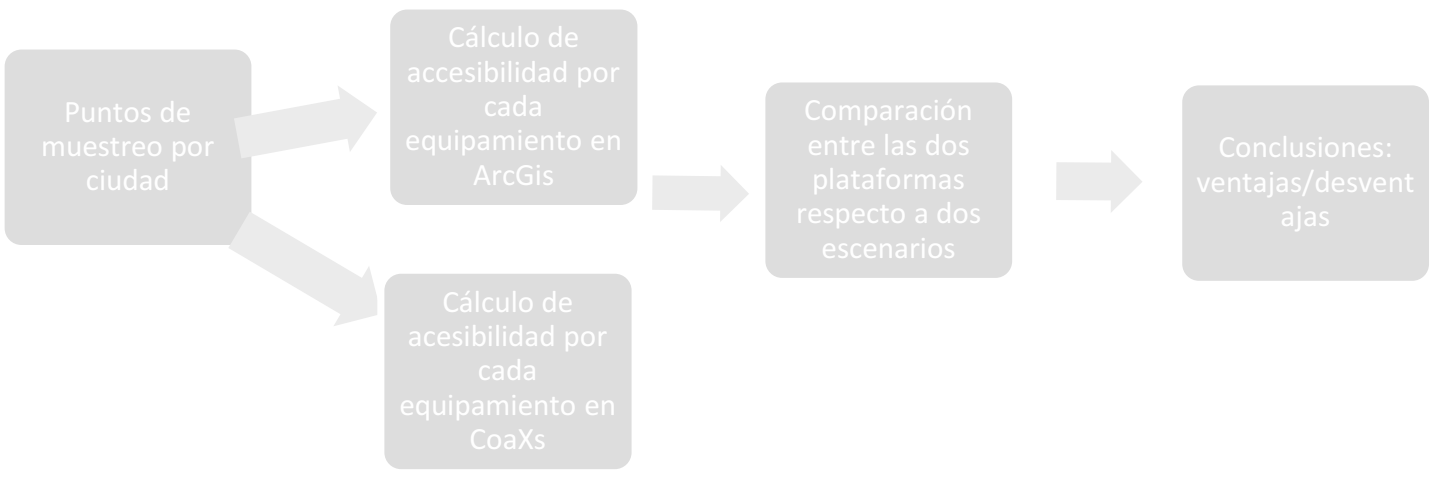

Fuente: Elaboración propia.

Posteriormente, se detallan las entidades y relaciones entre ellas, las cuales pueden observarse en el siguiente modelo conceptual (Figura $\mathrm{N}^{\circ} 19$ ) que según Costa (2002): “Es una herramienta útil tanto para ayudar al diseñador a reflejar los requisitos del mundo real, como para comunicarse con el usuario final sobre el modelo conceptual obtenido y, de este modo, se 
verifica si satisface sus requisitos." El modelo conceptual a utilizar en ArcGis muestra que a través de la entidad puntos de muestra se evaluará la situación con y sin la implementación de corredores de transporte público, para esto se generan dos tipos de escenarios representados a través de las isócronas. Posteriormente, estas áreas de influencia se relacionan o contienen una cierta cantidad de equipamientos o servicios, que se encuentran en el último nivel del modelo. Para CoAXs el modelo es mucho más complejo y no se cuenta con acceso a él.

Figura $\mathrm{N}^{\circ}$ 19: Modelo Conceptual inicial del proyecto

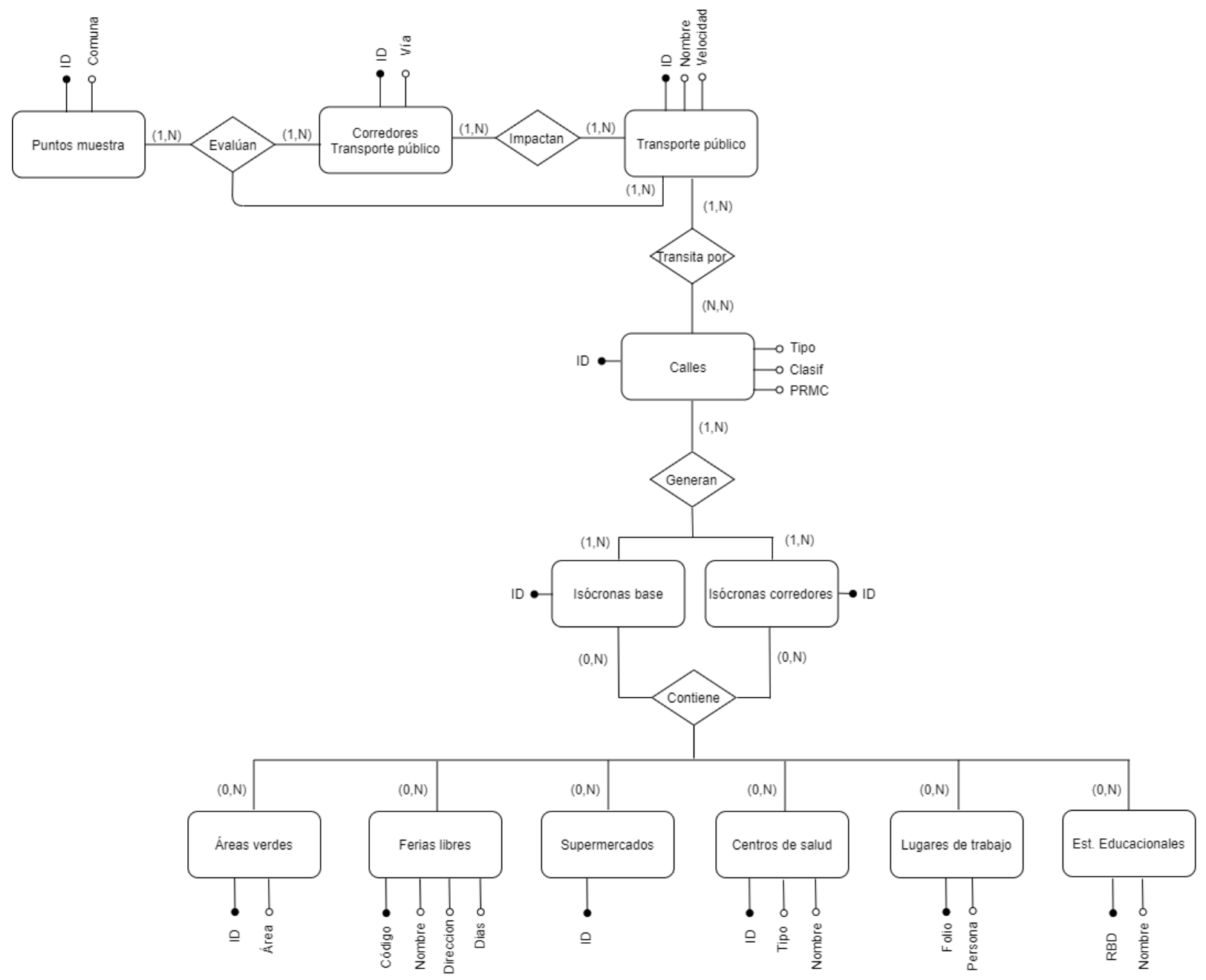

Fuente: Elaboración propia. 


\section{Etapa 2: Construcción Base de la GDB}

Para la construcción de la GDB, se debe dejar en claro cuál será el modelo lógico del problema geográfico (Figura $\mathrm{N}^{\circ} 20$ ). Esto involucra la estructura y las entidades a utilizar. El modelo lógico fue realizado con el software Diagrammer 10.1 compatible con ArcGis 10.2.

Figura $\mathrm{N}^{\circ} 20$ : Modelo Lógico resumido

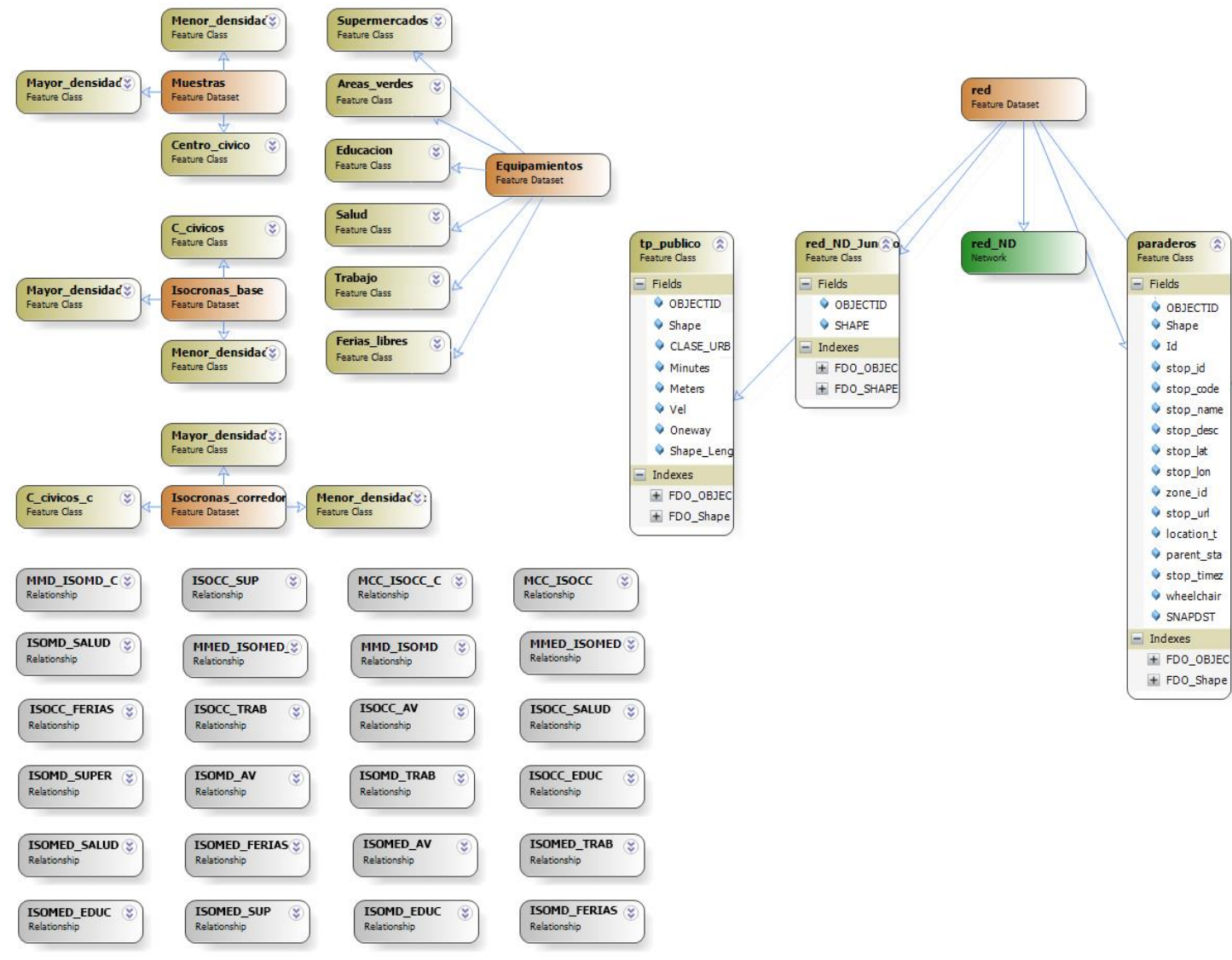

Fuente: Elaboración propia.

Para el trabajo en el software ArcGis se requiere de la elaboración de una base de datos geográfica (GBD) o base de datos mínima. Esta BD incluye información cuya riqueza y detalle otorgan al usuario la posibilidad real de emprender cualquier tarea o estudio a partir de ella (Ocaña et al., 2002). 
En ese sentido, el objetivo es contar con una base de datos básica que permita el cálculo de accesibilidad en Network Analyst y, por otro lado, también son necesarios en el back-end de CoAXs (Navas, 2017). Para esto se necesitó tres tipos de datos, primero la especificación general de los feeds de tránsito (GTFS) que posee el trazado de las líneas de transporte público, la red vial y por último un registro espacializado de las oportunidades a alcanzar, las cuales se describieron en la etapa anterior.

Es importante agregar que la información geográfica fue trabajada en el mismo Sistema de Referencia, es decir, Datum WGS84 con proyección cartográfica UTM huso 18 Sur, correspondiente al Área Metropolitana de Concepción y a una escala de 1:400.000.

Finalmente, el modelo físico resulta visible en una Geodatabase, compatible con un software de SIG y su vista sintetizada es la Figura $\mathrm{N}^{\circ} 21$.

Figura $\mathrm{N}^{\circ} 21$ : Modelo físico resumido

\begin{tabular}{|c|c|}
\hline Equipamientos & File Geodatabase Feature Dataset \\
\hline Isocronas_base & File Geodatabase Feature Dataset \\
\hline Isocronas_corredores & File Geodatabase Feature Dataset \\
\hline Muestras & File Geodatabase Feature Dataset \\
\hline pred & File Geodatabase Feature Dataset \\
\hline 봄ISOCC_ALM & File Geodatabase Relationship Class \\
\hline 望ISOCC_SUP & File Geodatabase Relationship Class \\
\hline 兒MCC_ISOCC & File Geodatabase Relationship Class \\
\hline 昆MCC_ISOCC_C & File Geodatabase Relationship Class \\
\hline 斯MMD_ISOMD & File Geodatabase Relationship Class \\
\hline 年MMD_ISOMD_C & File Geodatabase Relationship Class \\
\hline 兒MMED_ISOMED & File Geodatabase Relationship Class \\
\hline 诂MMED_ISOMED_C & File Geodatabase Relationship Class \\
\hline 兒ISOCC_AV & File Geodatabase Relationship Class \\
\hline 品ISOCC_EDUC & File Geodatabase Relationship Class \\
\hline 品ISOCC_FERIAS & File Geodatabase Relationship Class \\
\hline ISOCC_SALUD & File Geodatabase Relationship Class \\
\hline ISOCC_TRAB & File Geodatabase Relationship Class \\
\hline ISOMD_AV & File Geodatabase Relationship Class \\
\hline ISOMD_SUPER & File Geodatabase Relationship Class \\
\hline ISOMD_TRAB & File Geodatabase Relationship Class \\
\hline ISOMD_FERIAS & File Geodatabase Relationship Class \\
\hline ISOMD_SUPER & File Geodatabase Relationship Class \\
\hline ISOMED_EDUC & File Geodatabase Relationship Class \\
\hline ISOMED_SUP & File Geodatabase Relationship Class \\
\hline
\end{tabular}




\section{Etapa 3: Selección y descripción de atributos de la red y su creación en Network Analyst}

(ArcGis) - Conveyal (CoAXs).

\section{Atributos en ArcGis}

Los atributos de red son propiedades que controlan la navegación. Algunos ejemplos comunes son los atributos de coste que funcionan como impedancias en la red y los atributos de restricción que prohíben el trazado en ambas direcciones o una dirección, como carreteras de una sola dirección. ArcGIS Network Analyst analiza la clase de entidad de origen y busca campos comunes como Meters, Minutes y Oneway, estos mismos son utilizados para el desarrollo de esta tesis. Si encuentra estos campos, crea automáticamente los atributos de red correspondientes y les asigna los campos respectivos (ESRI, 2012).

Network Analyst es una extensión de ArcGis, es decir, un paquete adicional que permite modelar redes de transporte, redes de carreteras o peatonales y realizar análisis sobre ellas (ArcGis, 2021).

El algoritmo utilizado para el análisis de redes, ya sea para los solucionadores de ruta, instalación más cercana y matriz de coste Origen-Destino, se basan en el algoritmo llamado "Dijkstra" para buscar las rutas más cortas. Cada uno de estos solucionadores implementa dos tipos de algoritmos de búsqueda de ruta. El primer tipo es la trayectoria exacta más corta y el segundo es un solucionador de trayectorias jerárquicas para un mejor rendimiento. El algoritmo de Dijkstra resuelve un problema de trayectoria más corta en un gráfico sin dirección, no negativo, ponderado. Para utilizarlo dentro del contexto de los datos de transporte del mundo real, este algoritmo se ha modificado para respetar configuraciones de usuario tales como: restricciones unidireccionales, restricciones de giro, impedancia de cruces, barreras y restricciones de lado de calle, mientras se minimiza un atributo de coste especificado por el usuario. El rendimiento del algoritmo de Dijkstra se mejora aún más utilizando mejores estructuras de datos. Además, el algoritmo debe modelar las ubicaciones en cualquier punto a lo largo de un borde, no solo en los cruces. 
En el caso de la herramienta de áreas de servicio, utilizada para el cálculo de accesibilidad, en análisis de redes devuelve un subconjunto de características de borde conectadas que se encuentran dentro de una distancia de viaje o tiempo de viaje específico. Las áreas de viaje se crean ingresando los bordes en una estructura de datos de red irregular triangulada (TIN). La distancia de la red a lo largo de las líneas sirve como la altura de las ubicaciones dentro del TIN. Las ubicaciones no atravesadas por el área de servicio se colocan con un valor de altura mucho mayor. Se utiliza una rutina de generación de área con este TIN para extraer regiones que abarcan áreas entre los valores especificados como tiempo de viaje o distancia de viaje (ArcGis, 2021).

Para este caso, se elaboró una red multimodal que contiene los modos de caminata y transporte público junto a sus paradas. Las velocidades a utilizar son $4 \mathrm{~km} / \mathrm{h}$ para caminata y para transporte público se utiliza la reportada por el GTFS.

Sumado a esto, se debe agregar un campo de minutos y otro de longitud (calculado directamente en ArcGis), los cuales ayudarán a estimar la velocidad en cada arco de la red. Todos los archivos que conforman la red deben estar en un Feature Dataset, cuya configuración corresponde a los siguientes tres pasos:

1. Sistema de coordenadas

Figura $N^{\circ} 22$ : Selección del Sistema de Referencia UTM H18S.

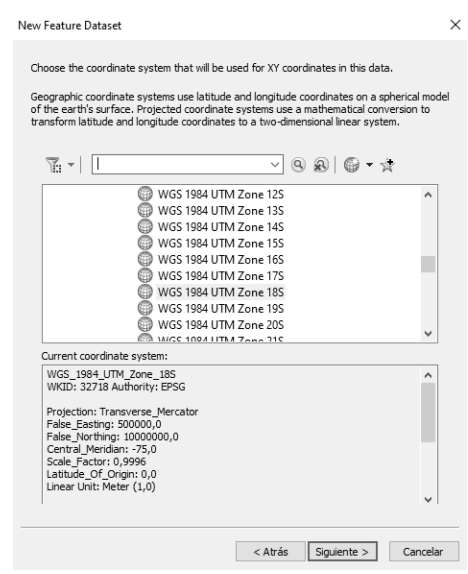


2. Sistema de referencia vertical (No utilizado en este trabajo)

Figura $\mathrm{N}^{\circ} 23$ : Selección sistema de referencia vertical

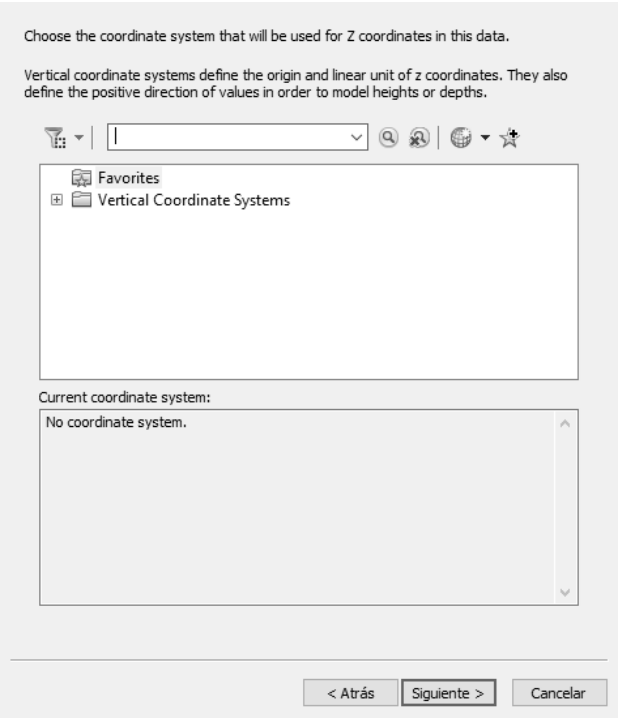

Fuente: Elaboración propia.

3. Tolerancias (Predefinidas automáticamente por el software)

Figura $N^{\circ} 24$ : Definición de la tolerancia

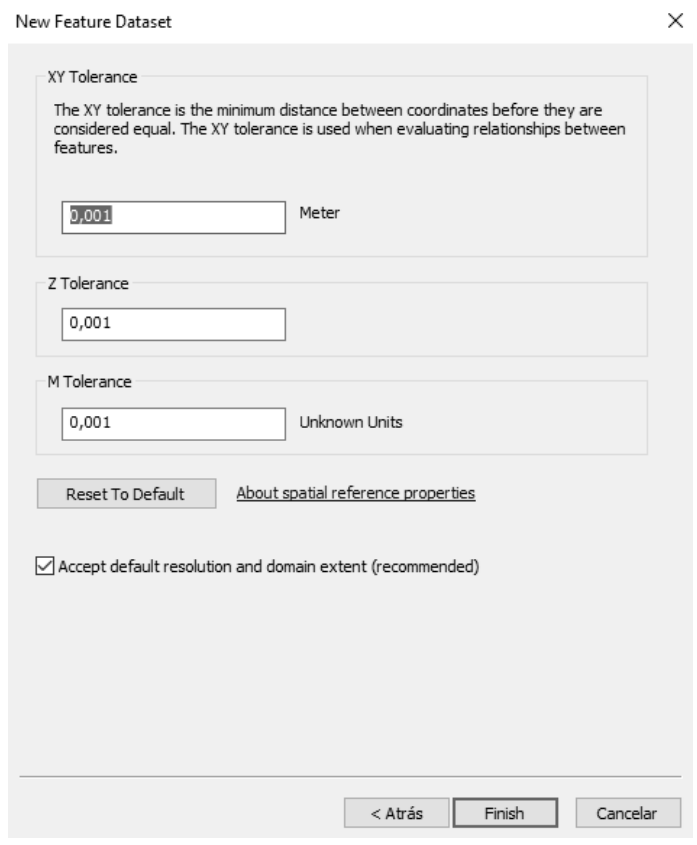

Fuente: Elaboración propia. 
Cuando los elementos que componen la red están dentro del Feature Dataset, es posible activar la opción Nuevo Network Dataset, resultando el contenido que se observa en la siguiente figura.

Figura $\mathrm{N}^{\circ} 25$ : Elementos del Feature Dataset para modelación de la red

\begin{tabular}{ll}
$\because$ paraderos & File Geodatabase Feature Class \\
$\square$ red_amc & File Geodatabase Feature Class \\
\hline red_ND & File Geodatabase Network Dataset \\
$\because$ red_ND_Junctions & File Geodatabase Feature Class \\
$\square$ tp_publico & File Geodatabase Feature Class
\end{tabular}

Fuente: Elaboración propia.

Es importante que la "Red AMC" y "TP Publico" estén corregidos topológicamente para un correcto procesamiento y conexión entre los distintos arcos y nodos.

Algunos errores básicos de topología o geometría de la red son los que se muestran a continuación, donde los arcos no están debidamente conectados o simplemente existe un error en la digitalización de la información, tal como se visualiza en la Figura $\mathrm{N}^{\circ} 26$.

Para el caso de esta red se corrigió utilizando las siguientes reglas topológicas: Must Not Overlap (que no haya superposición), Must Be Single Part (las líneas no debes estar cortadas en varias partes) y Must Not Have Pseudo Nodes (se conecta con otra línea en cada extremo).

Figura $\mathrm{N}^{\circ} 26$ : Ejemplos de errores en la geometría

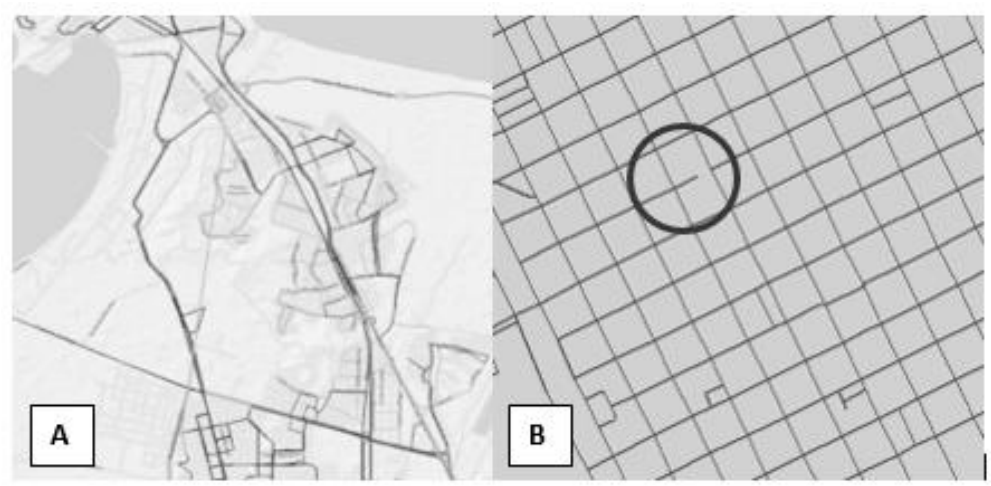

A: En color celeste representa el trazado de una ruta en línea recta por donde no existe red vial. B: Digitalización de la calle incompleta. 
Para el caso más específico de configuración del network, se estableció la conectividad entre la red de caminata y la red de transporte público a través de los puntos de paraderos (Figura $\mathrm{N}^{\circ} 27$ ), en otras palabras, una persona que transita caminando por la calle puede acceder al transporte público solo por medio de los paraderos.

Figura $\mathrm{N}^{\circ} 27$ : Conectividad de la red

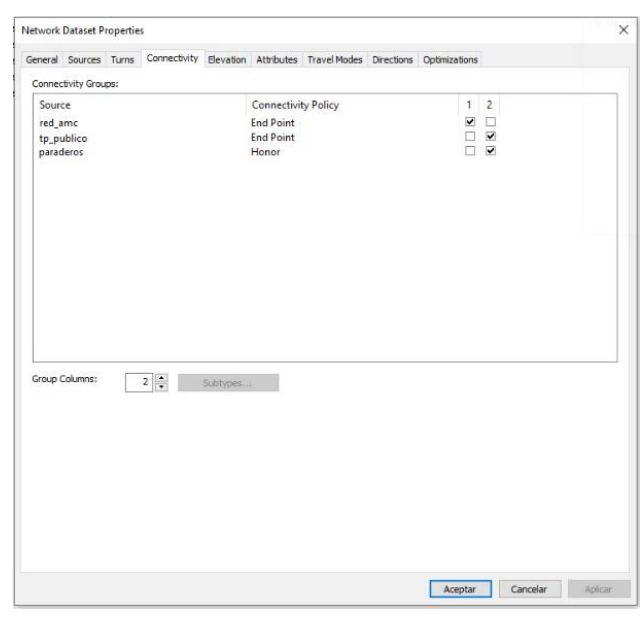

Fuente: Elaboración propia.

Posteriormente, se descarta la opción de utilizar elevación en la red y los atributos de la red son:

Tabla $\mathrm{N}^{\circ}$ 5: Atributos de la red

\begin{tabular}{|l|c|c|c|}
\hline \multicolumn{1}{|c|}{ Nombre } & Uso & Unidades & Tipo de dato \\
\hline Distancia & Cost & Meters & Double \\
\hline Minutos_pie & Cost & Minutes & Double \\
\hline Minutos_tp & Cost & Minutes & Double \\
\hline Minutos_pie_tp & Cost & Minutes & Double \\
\hline Oneway_tp & Restriction & Unknown & Boolean \\
\hline
\end{tabular}

Fuente: Elaboración propia.

\footnotetext{
${ }^{11}$ Según ArcGis, 2021, el atributo Cost significa que son atributos que se utilizan para medir y modelar las impedancias, como el tiempo de viaje (tiempo de tránsito por una calle).

El atributo Restriction significa que calles con ciertas características están completamente prohibidas, deben evitarse, aunque sea preferibles, esto sucede con el sentido de las calles para el caso de los buses.
} 
Finalmente, cada atributo tiene evaluadores que definen su dirección y el tipo de elemento, si es arco o nodo y también sus valores, es decir el campo asociado a la medición de cada atributo. Para el caso de los paraderos se agrega una penalidad de 0.15 al valor de medición del tiempo, es decir, un peatón tardará un poco más de tiempo asociado a la espera del transporte público que lo llevará a su destino.

Al utilizar la herramienta Network Analyst para calcular áreas de servicio, se debe determinar el área de influencia a partir de un punto. Se debe configurar el tiempo de viaje para generar la isócrona, en este caso son 30 minutos y luego seleccionar cuál es el punto de origen, para este estudio son las muestras correspondientes a centro cívico, centroides de manzanas censales con menor densidad poblacional y centroides de manzanas censales con mayor densidad poblacional, terminada esta configuración se obtienen las isócronas, como se muestran en la Figura $\mathrm{N}^{\circ} 28$. 
Figura $\mathrm{N}^{\circ} 28$ : Procedimientos Network Analyst
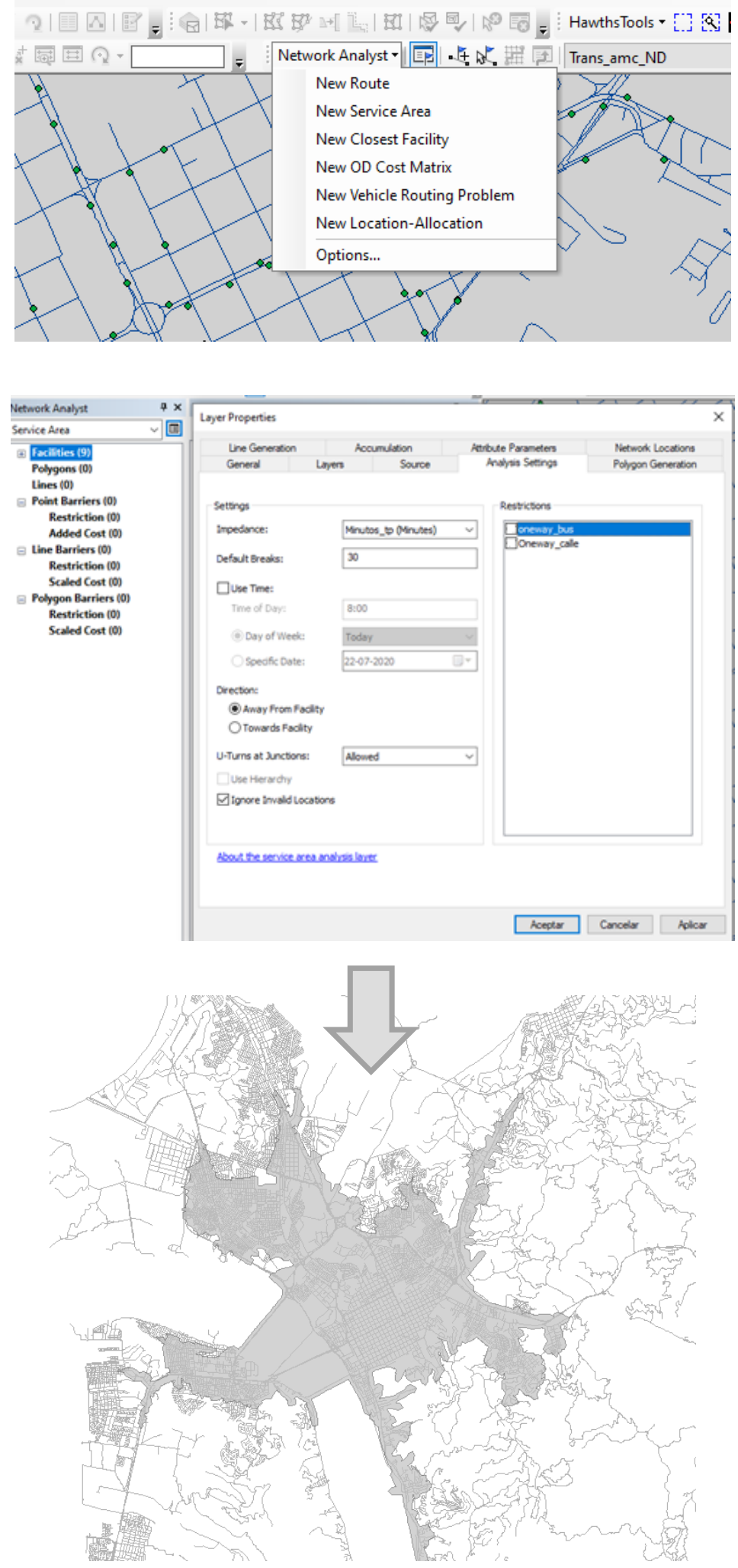

Fuente: Elaboración propia. 
Atributos en CoAXs

La plataforma CoAXs contiene dos interfaces "Front End" y "Back End", la primera es la parte que interactúa con los usuarios y el back-end es la parte que procesa todos los datos.

\section{-Conveyal: Back End}

Es una plataforma OpenSource que permite calibrar los distintos escenarios de accesibilidad que se mostrarán en CoAXs, para ello es necesario delimitar el área de estudio (formato pbf) y posteriormente cargar la información de rutas (GTFS) y oportunidades a alcanzar (Shapefiles de servicios/puntos de interés).

Además, permite el ajuste de las líneas de buses como frecuencia, velocidad, dirección de la vía, paradas y la configuración individual por tipo de escenario generado (Figura $\mathrm{N}^{\circ} 30$ ).

A continuación, se muestra parte de la interfaz Back End.

Figura $\mathrm{N}^{\circ} 29$ : Interfaz Conveyal

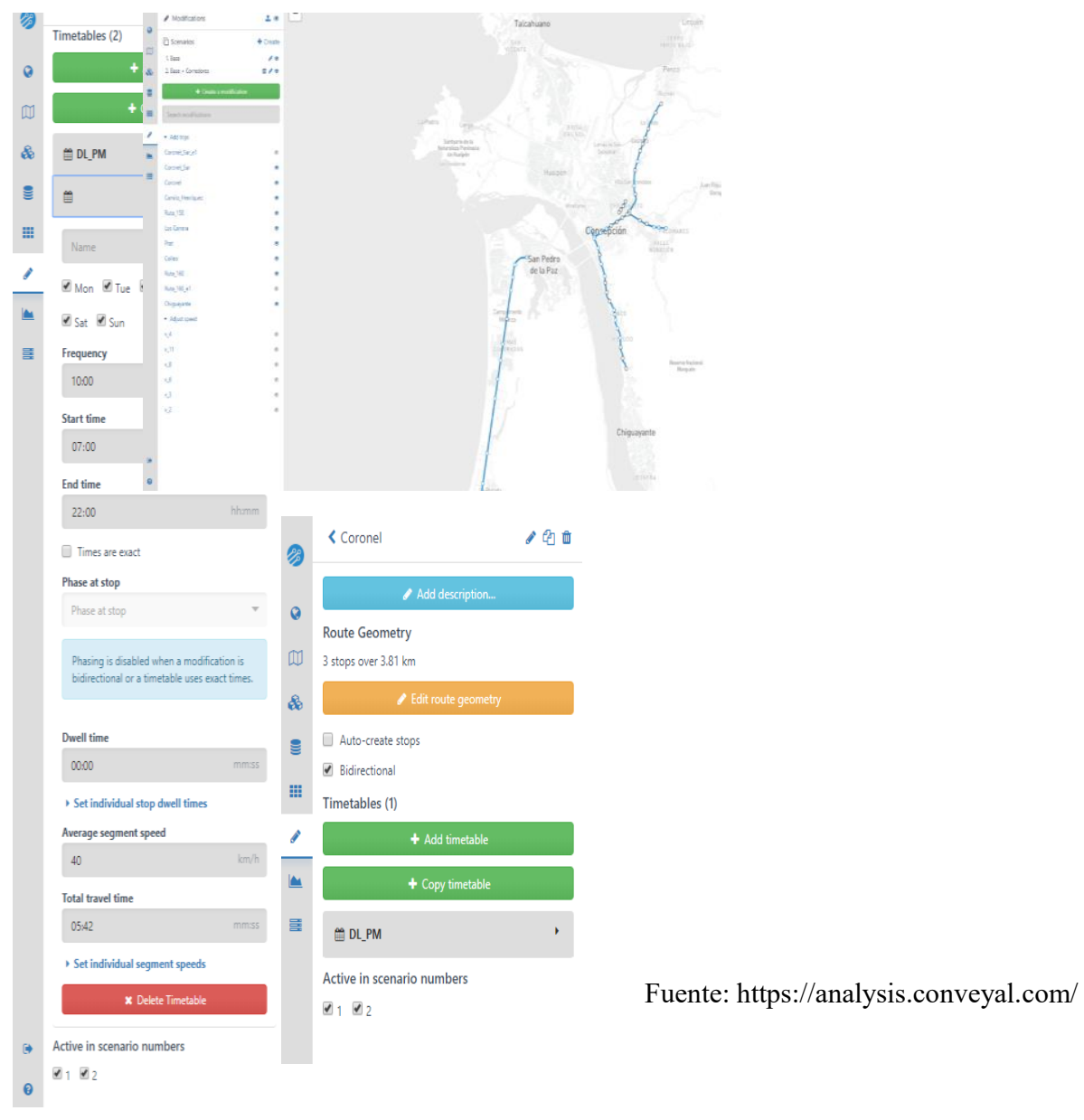




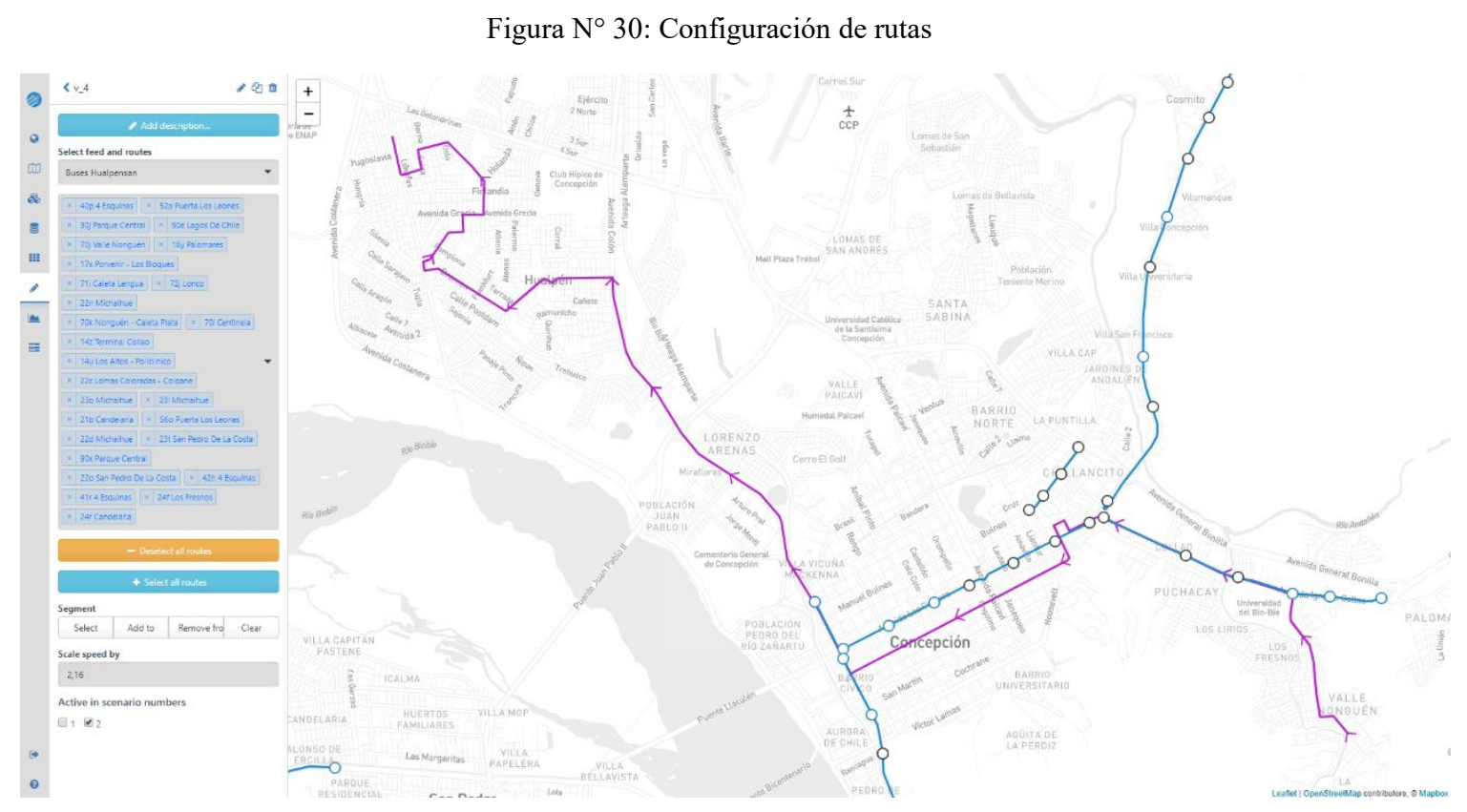

Fuente: https://analysis.conveyal.com/

En cuanto a la configuración individual de cada ruta, se ha mantenido la velocidad reportada en el GTFS y para escenarios futuros, se fija una velocidad estándar de $40 \mathrm{~km} / \mathrm{h}$ con dirección de doble sentido. Además, fue necesario verificar la ubicación de las paradas actuales y las por construir, en el caso de corredores a implementar se ubicaron puntos cada 300 metros, según lo informado por el Director de la Secretaría de Transporte en Concepción.

Para la frecuencia se adoptó un tiempo fijo de 10 minutos por línea de bus y para horario Punta Mañana se consideró el rango entre las 07:00 am y 08:30 am.

Por último, es posible visualizar el resultado de las isócronas e interactuar según la localización, esto mediante la ubicación de un ícono o pin espacial. Además, entrega estadísticas según la oportunidad seleccionada en función de los tiempos de viaje (Figura N³1). 
Figura $\mathrm{N}^{\circ} 31$ : Visualización de isócronas en Conveyal y estadísticas asociadas

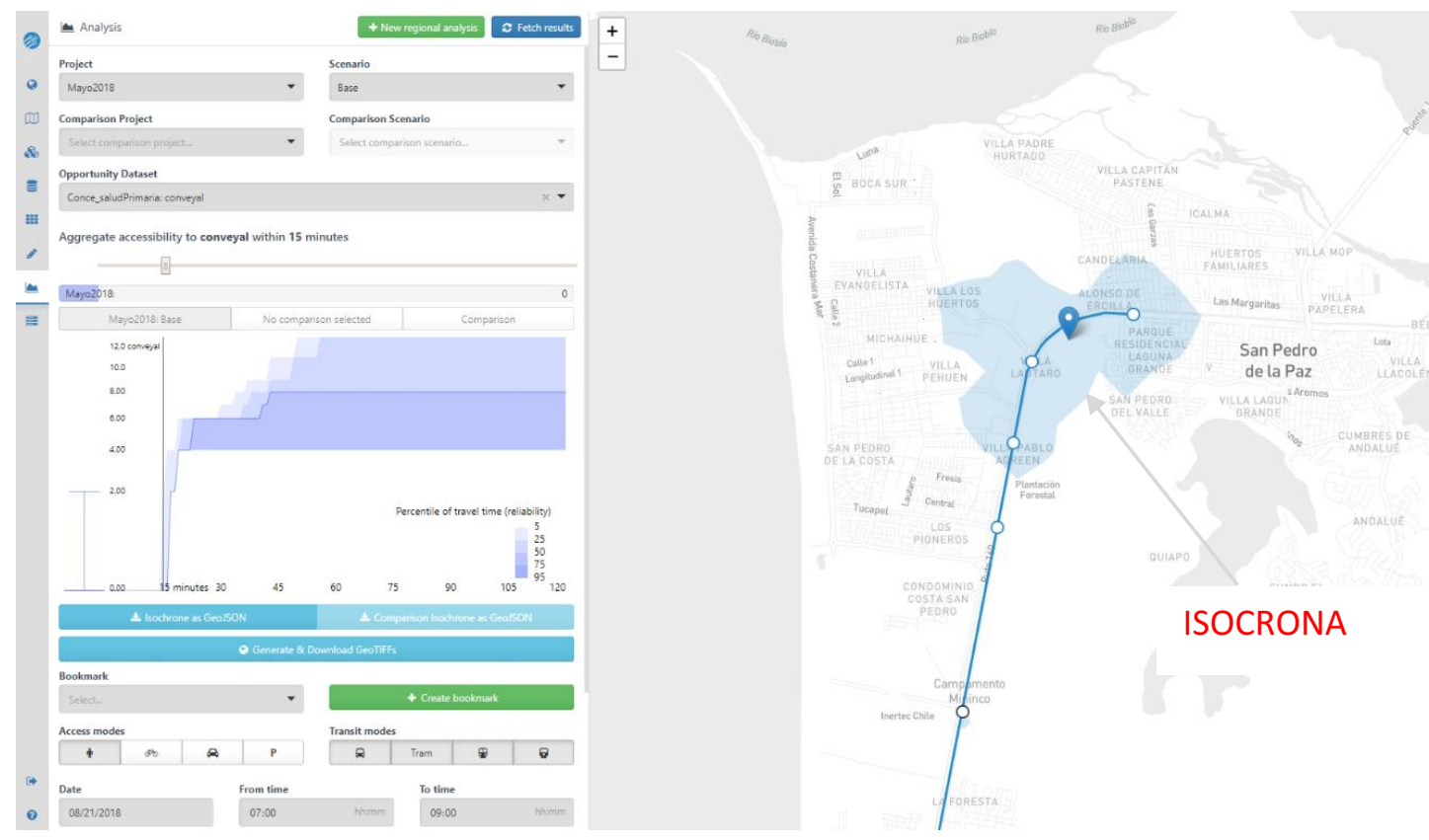

Fuente: https://analysis.conveyal.com/

-Front End: CoAXs

Esta es la interfaz para usuarios utilizada en los talleres que se han aplicado en distintas ciudades del mundo. Está diseñada para funcionar en una pantalla touch conectada a internet y las personas deben localizar el pin en el lugar donde desean conocer los cambios de accesibilidad. En el panel derecho se encuentran los servicios a los cuales se calculará la accesibilidad, el tiempo de viaje que generará la isócrona y la información que contrasta el escenario base con el futuro, que se detallan en el próximo apartado (barras azul y amarilla en la Figura $\mathrm{N}^{\circ} 32$ ). 
Figura $\mathrm{N}^{\circ} 32$ : Visualización de COAXS

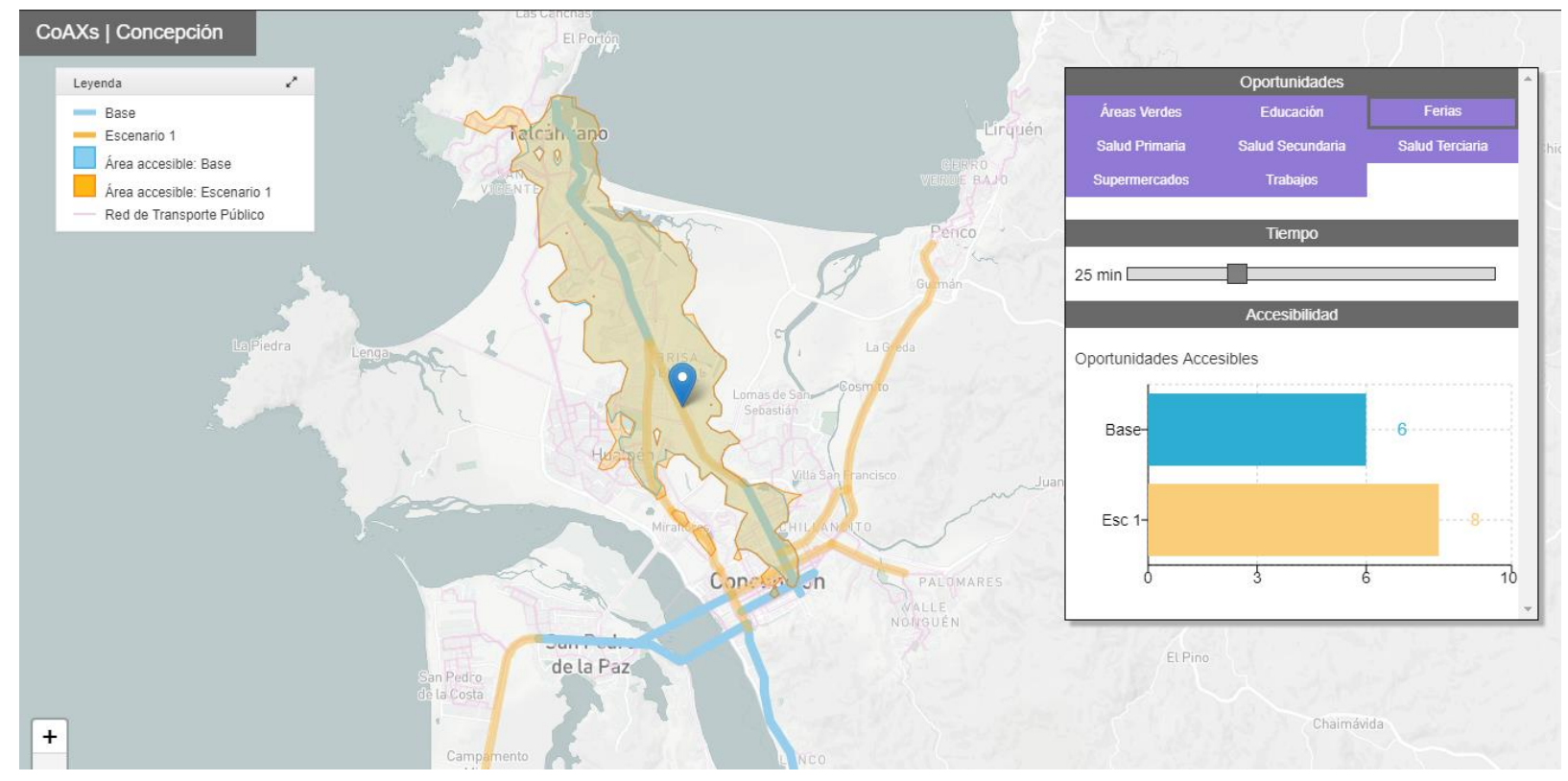

Fuente: https://coaxs-concepcion.herokuapp.com/

Etapa 4: Escenarios de accesibilidad según proyectos de Infraestructura de Transporte Público.

Tanto en ArcGis como en CoAXs se contrastaron dos escenarios, base y futuro, para ello se seleccionaron 14 proyectos de infraestructura de transporte correspondiente a vías exclusivas o corredores de transporte público en el Área Metropolitana de Concepción. La selección de estos proyectos se realizó mediante la consulta a expertos, principalmente de la Secretaría de Transporte Sur, debido a que son iniciativas que en su mayoría se encuentran en etapa de inversión o pre-inversión.

-Escenario base: Corredores de transporte ya en operación

Los corredores ya construidos son Paicaví, Pedro Aguirre Cerda, Coronel Tramo A y Tramo B, Chiguayante, Talcahuano-Hualpén, Calle O’Higgins (Figura N³3). 
-Escenario Futuro: Implementación de la red de corredores

Se consideran 14 corredores de transporte público distribuidos desde las comunas de Penco, al Norte, hasta Coronel situado al Sur del AMC, según información de Proyectos Viales del Gran Concepción. Algunos de ellos se encuentran en etapa de inversión, pre-inversión, sumado a los que ya están en operación (Figura N³3).

En la Tabla 5 se presenta el listado con las velocidades promedio de operación en horario Punta Mañana de corredores construidos y rutas en donde se implementarán los futuros corredores, con estas velocidades se trabajará en el escenario base.

El nuevo escenario se calibra según la velocidad estándar a la que debería circular la locomoción en el eje que es $40 \mathrm{~km} / \mathrm{h}$.

Tabla $\mathrm{N}^{\circ}$ 6: Velocidad de operación en ejes con y sin corredores de transporte público

Eje

Velocidad $(\mathbf{k m} / \mathbf{h})$

Horario Punta Mañana (PM)

$\begin{array}{lll}1 & \text { O'Higgins } & 19 \\ 2 & \text { Av. Los Carrera } & 22 \\ 3 & \text { Av. Prat } & 27 \\ 4 & \text { Av. Collao } & 19 \\ 5 & \text { Paicaví } & 20 \\ 6 & \text { Pedro de Valdivia (Chiguayante) } & 35 \\ 7 & \text { Av. Colón (Talcahuano-Hualpén) } & 36 \\ 8 & \text { Ruta 150 } & 62 \\ 9 & \text { Camino a Penco } & 34 \\ 10 & \text { Autopista Concepción-Talcahuano } & 46 \\ 11 & \text { Pedro Aguirre Cerda } & 27 \\ 12 & \text { Camilo Henríquez } & 31 \\ 13 & \text { Ruta 160 } & 55\end{array}$


Figura $\mathrm{N}^{\circ}$ 33: Proyectos de corredores de transporte público en el Área Metropolitana de Concepción

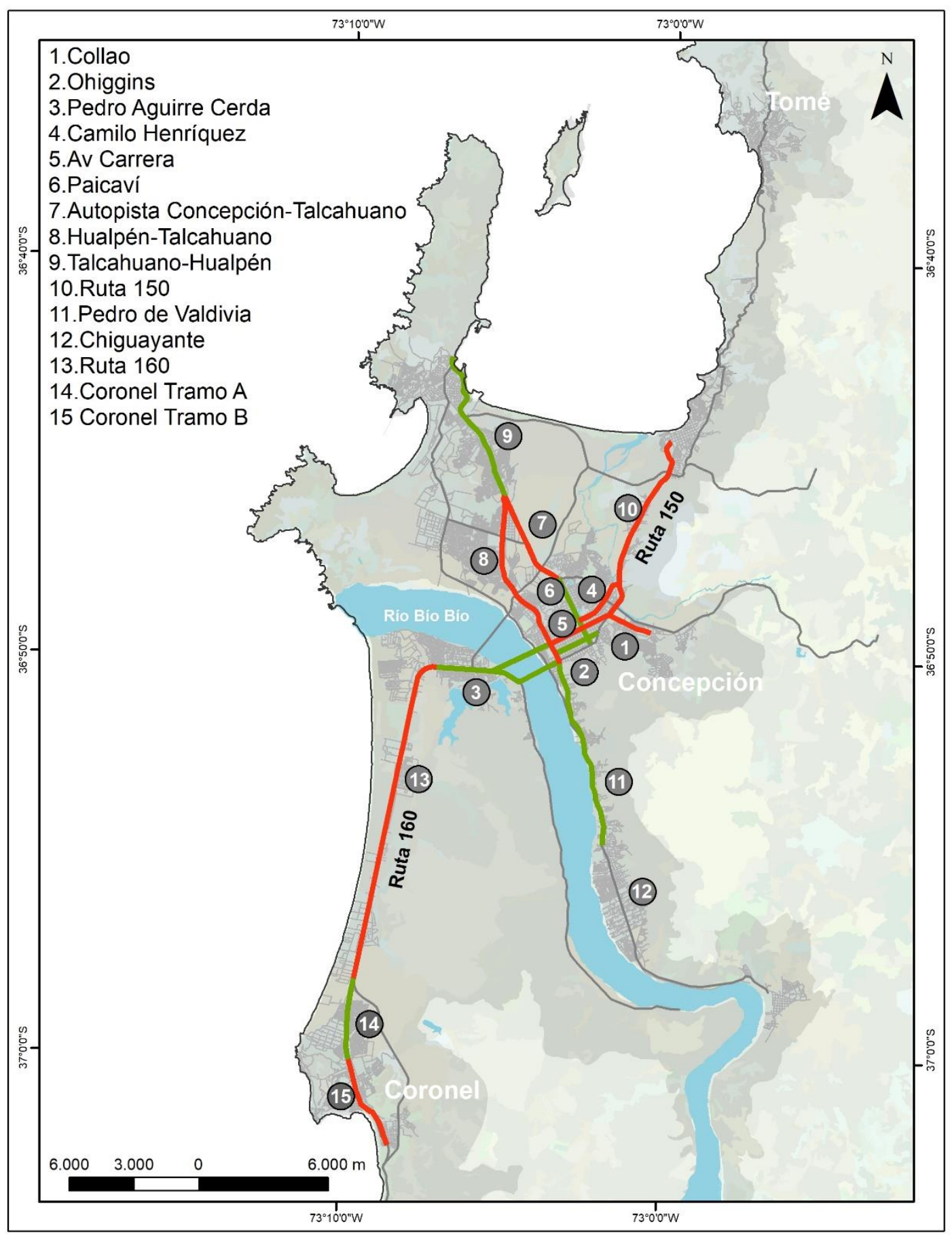

Fuente: SECTRA, 2018 


\section{Etapa 5: Comparación de escenarios y análisis de las herramientas}

Para realizar la comparación entre escenarios y plataformas se propuso un muestreo no probabilístico de 7 puntos por cada comuna del área de estudio, es decir 63 en total, estos puntos serán los mismos para cada uno de los programas.

Las características de los puntos a evaluar son los siguientes:

-Un punto en el centro cívico de cada comuna, debido a que en él se concentran los servicios, plaza de armas y municipio en la mayoría de los casos.

-Tres puntos en zonas de mayor densidad de población, corresponden principalmente a sectores altamente densificados como por ejemplo de viviendas sociales.

-Tres puntos en zonas de menos densidad de población, los cuales son zonas periféricas o al borde del límite urbano.

Cada uno de estos puntos entrega un isócronas, es decir un polígono con su área de influencia los que son intersectados con las oportunidades o servicios a nivel metropolitano. Este procedimiento se realiza en el SIG ArcGis y en la plataforma web, el formato de entrega de isócronas de CoAXs es Geojson (Figuras N³4 y N³5).

A modo de ejemplo, en la Figura $\mathrm{N}^{\circ} 32$, se observa el área de influencia para el escenario base (amarillo) y futuro (púrpura), mientras que los puntos verdes son ferias libres y el cuadro negro corresponde a los centros cívicos de las comunas. 
Figura $\mathrm{N}^{\circ}$ 34: Ejemplo de isócronas en ArcGis

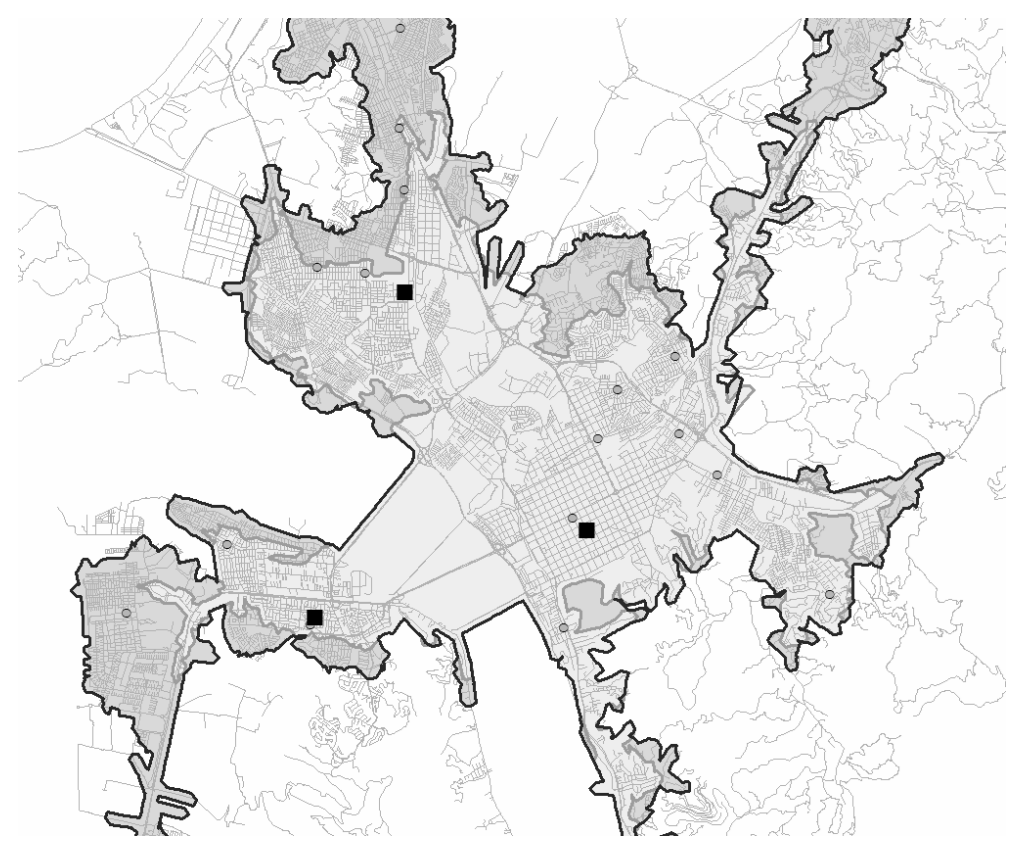

Fuente: Elaboración propia.

Figura $\mathrm{N}^{\circ}$ 35: Ejemplo de resultado en COAXS

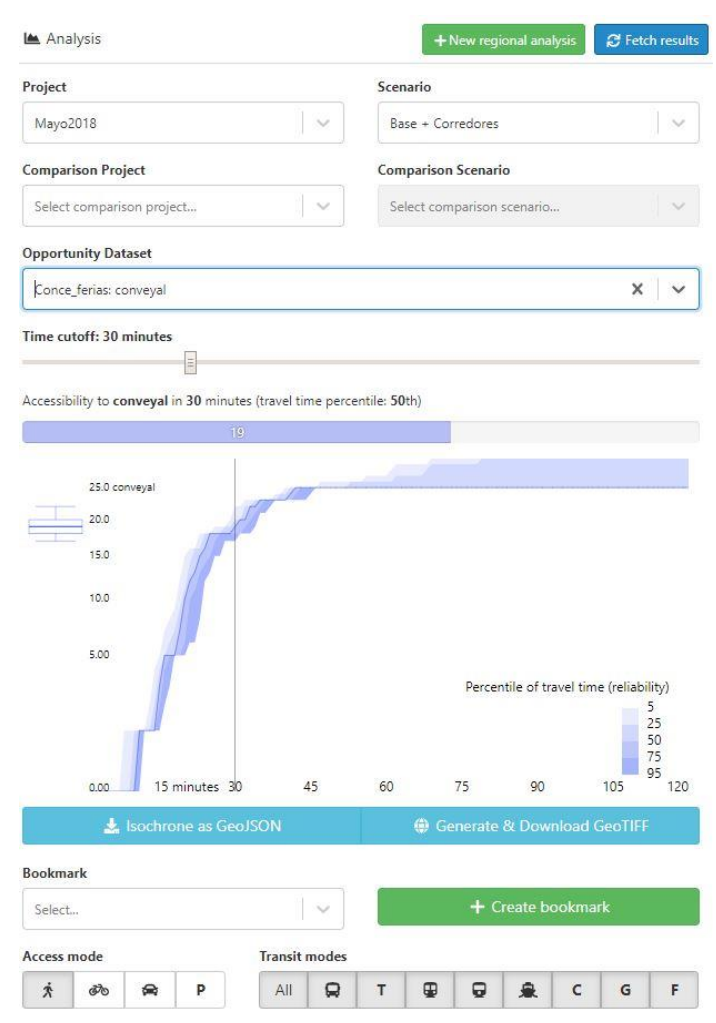

Fuente: Coaxs, 2019. 
Luego, se realizó una valoración cualitativa de cada software, con el fin de analizar las herramientas facilitadas por cada uno, basándose en la Norma ISO 9126, la cual evalúa la calidad interna/externa y el uso de un programa. En base a los trabajos de Camacho et al. (2012) y Alberto et al. (2006), quienes evalúan la calidad de distintos softwares según la norma ISO 9126, se determinó una escala cualitativa adaptada a variables lingüistas que en ambos casos se definieron como cuatro categorías denominados niveles de aceptación y que para este trabajo son: Bajo, Medio, Alto y Muy Alto, adicionalmente, sus puntajes varían desde 0 a 100 (Camacho et al., 2012) y poseen diferentes ponderaciones, ya sea para la calidad interna/externa como para la calidad en el uso.

-Bajo: en este nivel se encontrará el producto que haya obtenido una cota porcentual en el proceso de medición, que este entre 0 y 49 puntos.

- Medio: en este nivel de aceptación se encontrará el software que en su proceso de medición haya obtenido una cota porcentual que este entre el 50 y 69 puntos.

-Alto: el nivel alto de aceptación lo tendrá aquel producto que en el proceso de medición haya obtenido una cota entre el 70 y 89 puntos.

-Muy Alto: en el nivel más alto de aceptación se encontrará el software que en su proceso de medición haya obtenido una cota entre 90 y 100 puntos.

Posteriormente, se debe ponderar cada característica Interna/ Externa del software como también la calidad de uso (descritas en las Tablas $\mathrm{N}^{\circ} 7$ y N8). Para determinar estos valores, se utilizó el trabajo de Camacho et al. (2012) para la calidad Interna/Externa y Vivanco (2011) para las ponderaciones de la calidad de uso, este último autor evaluó la calidad del software utilizado en las casas de valores en la ciudad de Quito, Ecuador. 
Tabla $N^{\circ} 7$ : Evaluación de la calidad Interna/Externa del Software

\begin{tabular}{|c|c|c|c|c|}
\hline & \multicolumn{3}{|c|}{ PUNTAJE } & \multirow[b]{2}{*}{ Ponderación } \\
\hline \multirow[b]{2}{*}{ CARACTERÍSTICAS } & Medio & Alto & Muy Alto & \\
\hline & $50-69$ & $70-89$ & $90-100$ & \\
\hline FUNCIONALIDAD & \multicolumn{3}{|c|}{$\begin{array}{l}\text { La capacidad del software para proveer las funciones } \\
\text { que satisfacen las necesidades explícitas e implícitas } \\
\text { cuando el software se utiliza bajo condiciones } \\
\text { específicas. }\end{array}$} & 0.3 \\
\hline FIABILIDAD & \multicolumn{3}{|c|}{$\begin{array}{l}\text { La capacidad del software para mantener un nivel } \\
\text { especificado de funcionamiento cuando se está } \\
\text { utilizando bajo condiciones especificadas. }\end{array}$} & 0.11 \\
\hline USABILIDAD & \multicolumn{3}{|c|}{$\begin{array}{l}\text { La capacidad del software de ser entendido, } \\
\text { aprendido, usado y atractivo al usuario, cuando es } \\
\text { usado bajo las condiciones especificadas. }\end{array}$} & 0.3 \\
\hline EFICIENCIA & \multicolumn{3}{|c|}{$\begin{array}{l}\text { La capacidad del software para proveer un desempeño } \\
\text { apropiado, de acuerdo a la cantidad de recursos } \\
\text { utilizados y bajo las condiciones planteadas. }\end{array}$} & 0.03 \\
\hline $\begin{array}{l}\text { FACILIDAD DE } \\
\text { MANTENIMIENTO }\end{array}$ & \multicolumn{3}{|c|}{$\begin{array}{l}\text { Capacidad del software para ser modificado. Las } \\
\text { modificaciones pueden incluir correcciones, mejoras } \\
\text { o adaptación del software a cambios en el entorno, y } \\
\text { en requerimientos y especificaciones funcionales. }\end{array}$} & 0.25 \\
\hline PORTABILIDAD & \multicolumn{3}{|c|}{$\begin{array}{l}\text { La capacidad del software para ser trasladado de un } \\
\text { entorno a otro. }\end{array}$} & 0.01 \\
\hline
\end{tabular}

Fuente: Basado en Prats (2016) y Camacho et al. (2012). 
Para la calidad del uso del software, el proceso es similar pero las métricas son cuatro: efectividad, productividad, integridad y satisfacción.

\begin{tabular}{|c|c|c|c|c|c|}
\hline \multicolumn{6}{|c|}{ Tabla $N^{\circ} 8$} \\
\hline & Bajo & Medio & Alto & Muy Alto & \multirow[t]{2}{*}{ Ponderación } \\
\hline & $0-49$ & $50-69$ & $70-89$ & $90-100$ & \\
\hline EFECTIVIDAD & \multicolumn{4}{|c|}{$\begin{array}{l}\text { La capacidad del software para permitir a los } \\
\text { usuarios lograr las metas especificadas con } \\
\text { precisión y completitud en un contexto de uso } \\
\text { específico }\end{array}$} & 0.3 \\
\hline PRODUCTIVIDAD & \multicolumn{4}{|c|}{$\begin{array}{l}\text { La capacidad del software para permitir a los } \\
\text { usuarios emplear cantidades apropiadas de } \\
\text { recursos en relación a la efectividad lograda en un } \\
\text { contexto de uso específico }\end{array}$} & 0.2 \\
\hline INTEGRIDAD & \multicolumn{4}{|c|}{$\begin{array}{l}\text { La capacidad del software para lograr niveles } \\
\text { aceptables de riesgo de daño a las personas, } \\
\text { negocio, software, propiedad o entorno en un } \\
\text { contexto de uso específico }\end{array}$} & 0.2 \\
\hline SATISFACCIÓN & \multicolumn{4}{|c|}{$\begin{array}{l}\text { La capacidad del software para satisfacer a los } \\
\text { usuarios en un contexto de uso específico }\end{array}$} & 0.3 \\
\hline
\end{tabular}

Adicionalmente, se realizaron talleres con diferentes grupos de personas con el objetivo de testear la plataforma CoAXs como una herramienta que ayuda a la participación ciudadana. Se diseñaron tres instancias de participación, una en la ciudad de Penco, otra en Concepción y el último en Coronel. Las instancias se encuentran reflejadas en la Figura $\mathrm{N}^{\circ} 36$. 
Figura $\mathrm{N}^{\circ} 36$ : Set de fotografías de los talleres de testeo
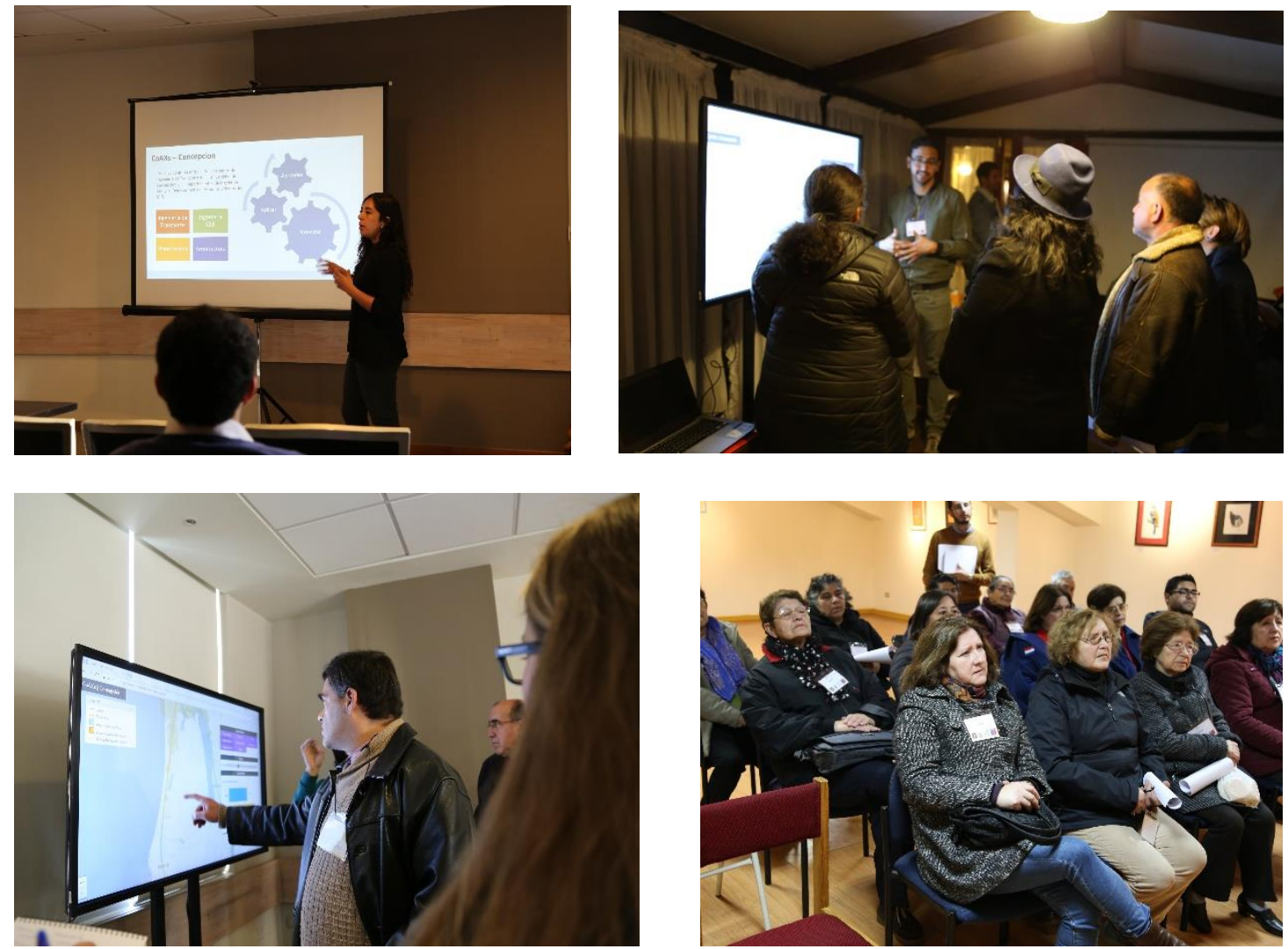

Fuente: Cedeus, 2018.

A partir de las opiniones e impresiones recolectadas se realizó una nube de palabras, que es una representación visual de un texto, las palabras que aparecen con mayor tamaño son aquellas que se repiten o mencionan con más frecuencia. Este ejercicio permite sintetizar de manera práctica los comentarios de las personas que participaron en los talleres.

Figura $\mathrm{N}^{\circ} 37$ : Ejemplos de una nube de palabras

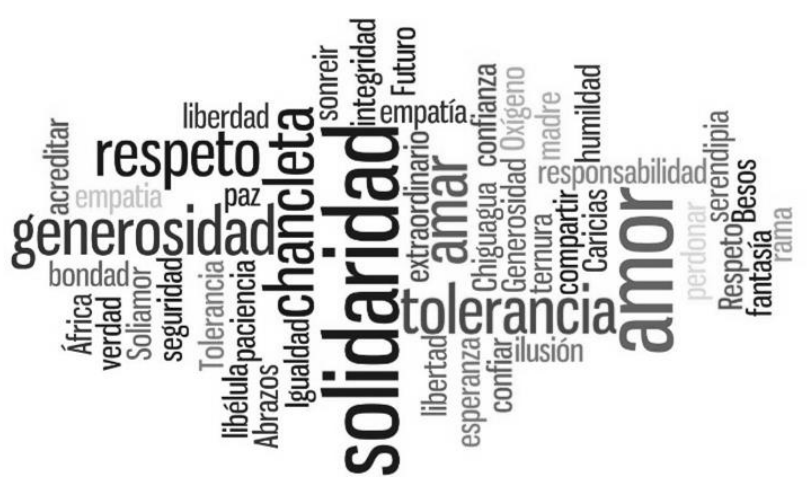

Fuente: Cecilia, F. (2011). 


\section{RESULTADOS}

A continuación, se muestran los principales resultados luego de realizar los procedimientos en ambos softwares (ArcGis y CoAXs) y contrastando la situación base versus la situación futura, es decir, con la implementación de nuevos corredores de transporte público.

\section{Situación base}

A nivel metropolitano, las 9 comunas analizadas tienen un acceso del $66 \%$ a los servicios básicos ${ }^{12}$ respecto a una situación futura según el software ArcGis. En la plataforma CoAXs, la misma operación arrojó valores que en algunos casos superan el 100\%, es decir, la situación base brinda mayor acceso que una situación futura.

En el caso específico de las comunas, se observa que aquellas con menor acceso son Chiguayante y Penco, no superando el 21\%, siendo más notorio en el acceso a la salud terciaria y secundaria. De forma contraria, las comunas que se acercan a una mejor cobertura, viajando en un tiempo 30 minutos y sin contar con la presencia de nuevos corredores, son: Hualpén, Tomé y Lota. Tanto para ArcGis como para CoAXs, ambos coinciden en una baja accesibilidad a algún tipo de servicio de salud, siendo este ítem el único en el cual hay un $0 \%$ de cobertura en algunas comunas, tales como: Chiguayante, Hualpén, Tomé y San Pedro de la Paz, promediando para el Área Metropolitana un 56\%. A pesar de esto, Tomé junto a Lota, al ser comunas de menor tamaño, presentan alta accesibilidad en la mayoría de sus servicios básicos sin la necesidad de la implementación de corredores, al contrario de Penco que, a pesar de estar próxima a Concepción, en términos de este ejercicio se encuentra menor conectada.

A nivel desagregado, se analizaron tres casos en el interior de las comunas, cuyos resultados son los siguientes:

\footnotetext{
${ }^{12}$ Se mencionan en el apartado de metodología: Áreas verdes, salud primaria, salud secundaria, salud terciaria, puestos de trabajo, establecimientos de salud, supermercados y ferias libres.
} 
1. Centro cívico: aquellas comunas con menor acceso desde el centro de la ciudad son Penco, Chiguayante y Talcahuano promediando un $25 \%$. Caso opuesto son Coronel, Lota y Tomé promediando 91\%.

2. Zonas con menor densidad poblacional: presentan baja accesibilidad las comunas de San Pedro de la Paz, Chiguayante y Penco con $32 \%$ y presentan una alta accesibilidad las comunas de Coronel, Tomé y Lota con $85 \%$

3. Zonas con mayor densidad poblacional: las comunas con menor acceso son Penco, San Pedro de la Paz y Hualpén con $60 \%$ y con mayor acceso son Tomé, Lota y Coronel con $95 \%$

\section{Situación futura}

En base a los cálculos realizados, resulta inesperado que en la plataforma CoAXs no se manifieste un gran incremento de acceso a servicios básicos en algunas comunas, al contrario de los resultados realizados en ArcGis.

A nivel de Área Metropolitana, el acceso aumentó en aproximadamente un $29 \%$ con la presencia de nuevos corredores de transporte público, según el software ArcGis. En el cálculo en CoAXs, se estima que, para zonas alejadas del centro de cada una de las ciudades, no hay beneficios directos de los nuevos proyectos, es decir, no hay incremento en los porcentajes de cobertura promedio, esto se observa en comunas como: Hualpén, San Pedro de la Paz, Talcahuano, asociado a que gran parte de sus trayectos cuentan con segmentos de corredores de transporte públicos.

Ahora bien, para zonas específicas el resultado es el siguiente:

4. Centro cívico: se observa un aumento promedio del $35,63 \%$ para todas las comunas, según ArcGis. Del mismo modo, hay un alza cercana al 14\% cuando se ejecuta bajo el software CoAXs. Las comunas que se ven más beneficiadas con la ejecución de corredores son Chiguayante, Penco y Talcahuano con un aumento superior al $60 \%$. La 
vereda opuesta nos presenta el caso de Lota y Tomé que no se ven beneficiadas ya que el incremento no es estadísticamente significativo.

5. Zonas con menor densidad poblacional: todas las comunas, salvo un par de excepciones, presentan un incremento superior al 40\%, destacando la situación de Chiguayante y Penco con resultados superiores al 60\%. Las comunas menos favorecidas, ya sea por estar más distante de Concepción o de su propio centro cívico, son Tomé y Lota con un $0 \%$ de incremento en el acceso a servicios, pero, además aparecen comunas como Coronel con un $18 \%$ y Concepción con $26 \%$.

6. Zonas con mayor densidad poblacional: San Pedro de la Paz y Penco son las comunas más beneficiadas en el caso de mayor densidad poblacional obteniendo un aumento de acceso del $48 \%$. Al contrario, comunas como Talcahuano y Tomé presenta un $0 \%$, mientras que Lota posee un $1 \%$ de incremento en el acceso a servicios desde el punto de vista matemática/geográfico. La comuna de Talcahuano, presenta un escenario muy llamativo, ya que si bien es cierto en el caso de sus zonas de menor población presentan un alza de acceso del 30,13\%, no ocurre lo mismo cuando se realiza el cálculo en zonas de mayor densidad poblacional.

En resumen, las comunas más beneficiadas con una futura implementación de corredores de transporte público son Chiguayante y Penco, comunas circundantes a Concepción y que un rango de 30 minutos en transporte público, podrían aumentar su acceso a diferentes puntos de interés localizados en comunas vecinas.

Tal como se muestra en la Figura $\mathrm{N}^{\circ} 33$, los mapas superiores representan la cobertura total a nivel metropolitano calculada en el software ArcGis para los tres tipos de muestras, mientras que las inferiores corresponden a los resultados de CoAXs. Las grandes diferencias se hacen evidentes en comunas como Coronel, Tomé y Lota, dado principalmente porque el escenario futuro contempla la construcción de corredores hasta las entradas de esas ciudades, al menos en el caso de Tomé y Lota. Para el caso de Coronel, ya cuenta una sección de corredor de 
transporte, por lo que extender los tramos en una ruta que ya posee condiciones de alta velocidad, no beneficia a la población.

Por otra parte, urbanizaciones con patrones lineales como Chiguayante o Talcahuano son un claro ejemplo de que la implementación de corredores podría funcionar de manera efectiva.

$\mathrm{Al}$ observar Concepción, sus cambios son poco perceptibles, pero se centran principalmente en sectores de condiciones socioeconómicas media-alta como Lomas de San Sebastián y Barrio Norte, que podrían acceder a un mayor porcentaje de servicios a Concepción Centro, pero también a comunas vecinas como Talcahuano.

Las diferencias cuantitativas de acceso a servicios se enseñan en los gráficos 2 y 3 , cuyos datos presentan una tendencia al alza con pendiente positiva, es decir, a mayor acceso a servicios en una situación base, se entiende que su situación futura se beneficiará en mayor cantidad. Esto impacta negativamente en comunas en estado de vulnerabilidad como Lota o Coronel, debido a que no hubo un cambio y sus valores de acceso se mantuvieron bajos, esto se observa en la esquina inferior izquierda de ambos gráficos, mostrando una densa cantidad de puntos. Los casos atípicos se detallan en el cuadro rojo y son disímiles entre ArcGis y CoAXs. Para ArcGis, significa que comunas pasaron de tener una situación base mala/regular a una situación futura con un incremento significativamente positivo en el acceso a servicios, esto se refleja en las zonas favorecidas de la Figura $\mathrm{N}^{\circ} 38$ A y B. En cambio, en CoAXs los casos atípicos corresponden a comunas donde su situación base no cambió o simplemente aumentó en bajo porcentaje como en casos de Talcahuano, Tomé o Coronel, cuyo espacialización se encuentra en la Figura $\mathrm{N}^{\circ} 39$ y demarcada en cuadrantes de color rojo. 
Gráfico $\mathrm{N}^{\circ}$ 2: Número de servicios alcanzados entre la situación base y la situación futura, software ARCGIS

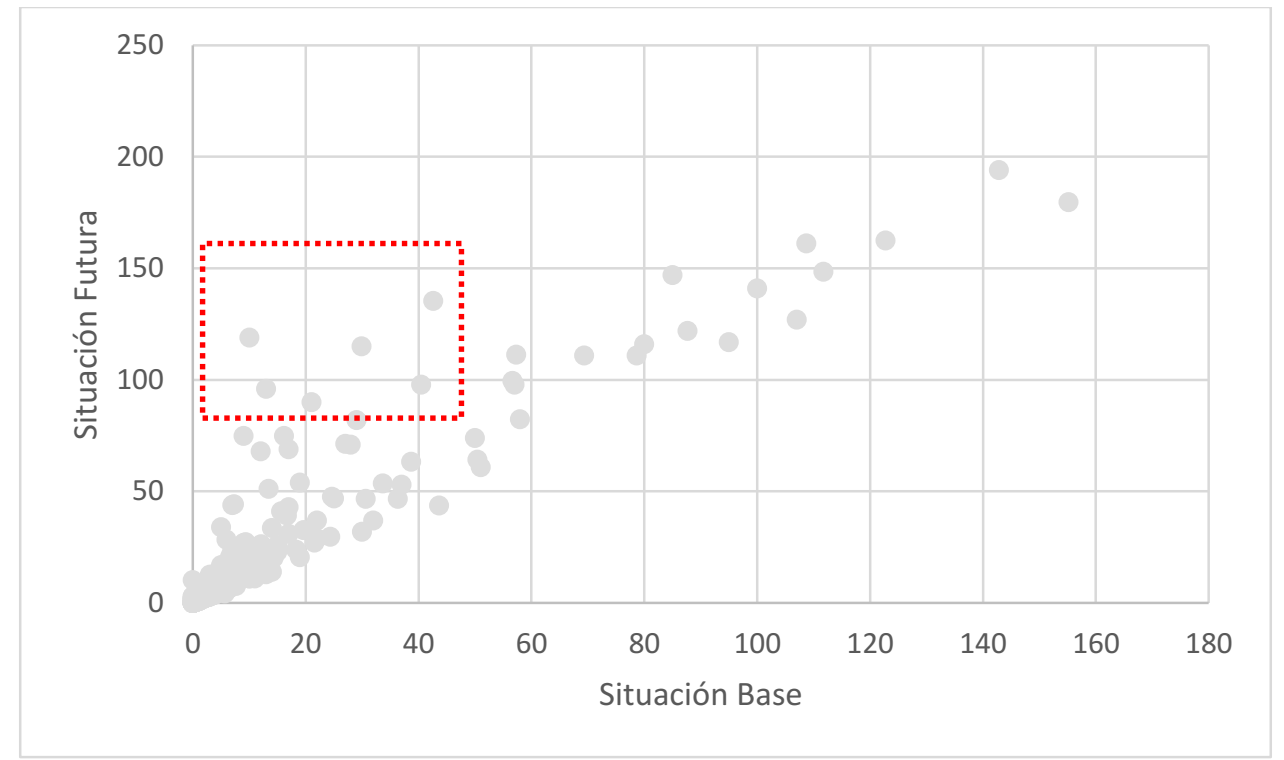

Fuente: Elaboración propia. 
Figura $\mathrm{N}^{\circ}$ 38: Comparación entre escenario base y futuro con ArcGis

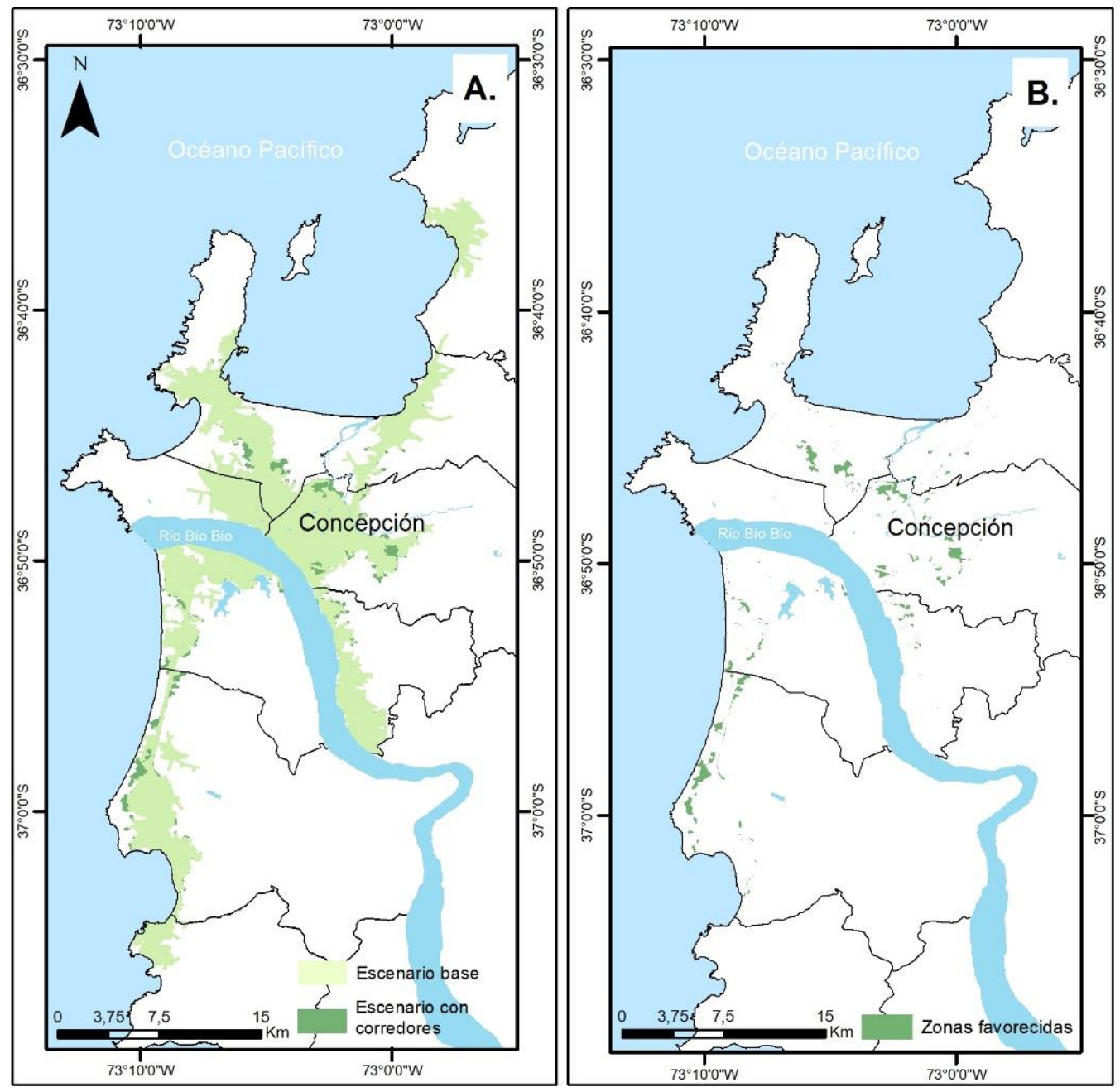

La Figura A contiene los escenarios base y futuro con corredores de transporte público.

La Figura B contiene la diferencia positiva entre ambos escenarios.

Fuente: Elaboración propia. 
Gráfico $\mathrm{N}^{\circ}$ 3: Número de servicios alcanzados entre la situación base y la situación futura, Plataforma COAXS

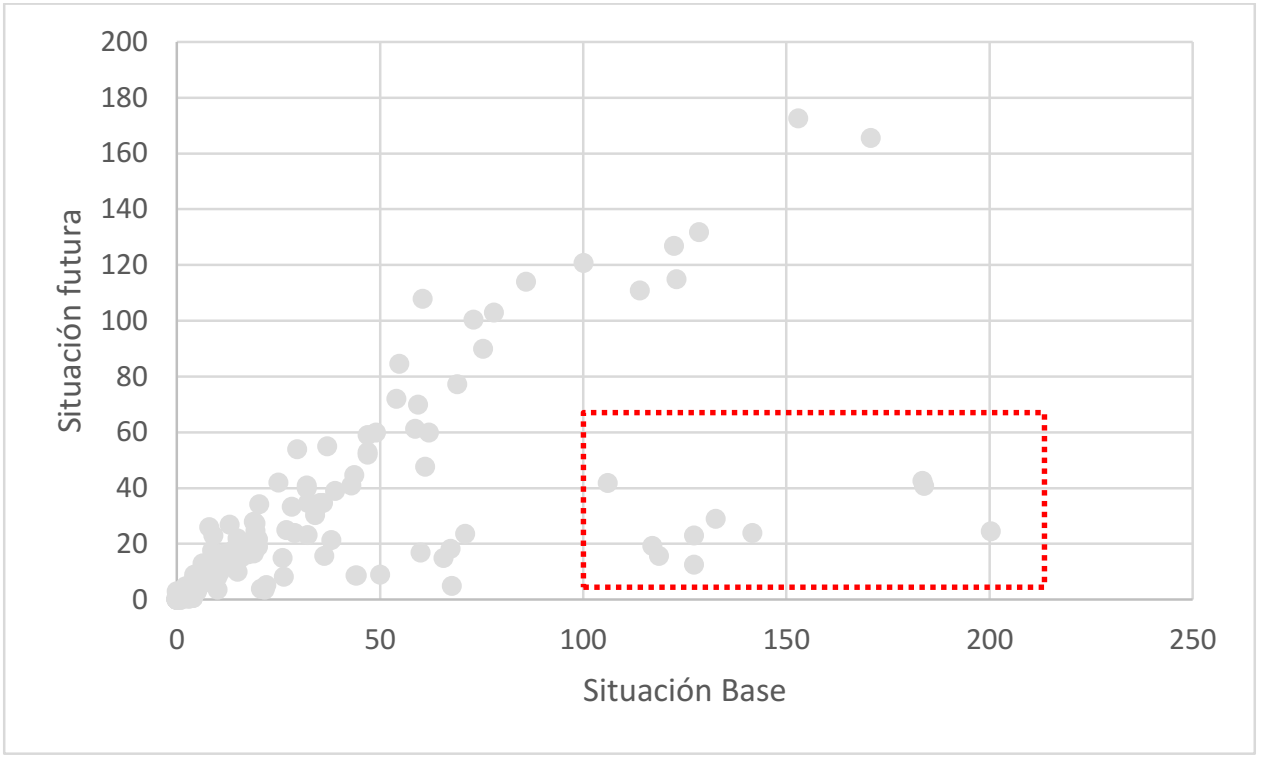

Fuente: Elaboración propia. 
Figura $\mathrm{N}^{\circ} 39$ : Comparación de escenario base y futuro con CoAXs

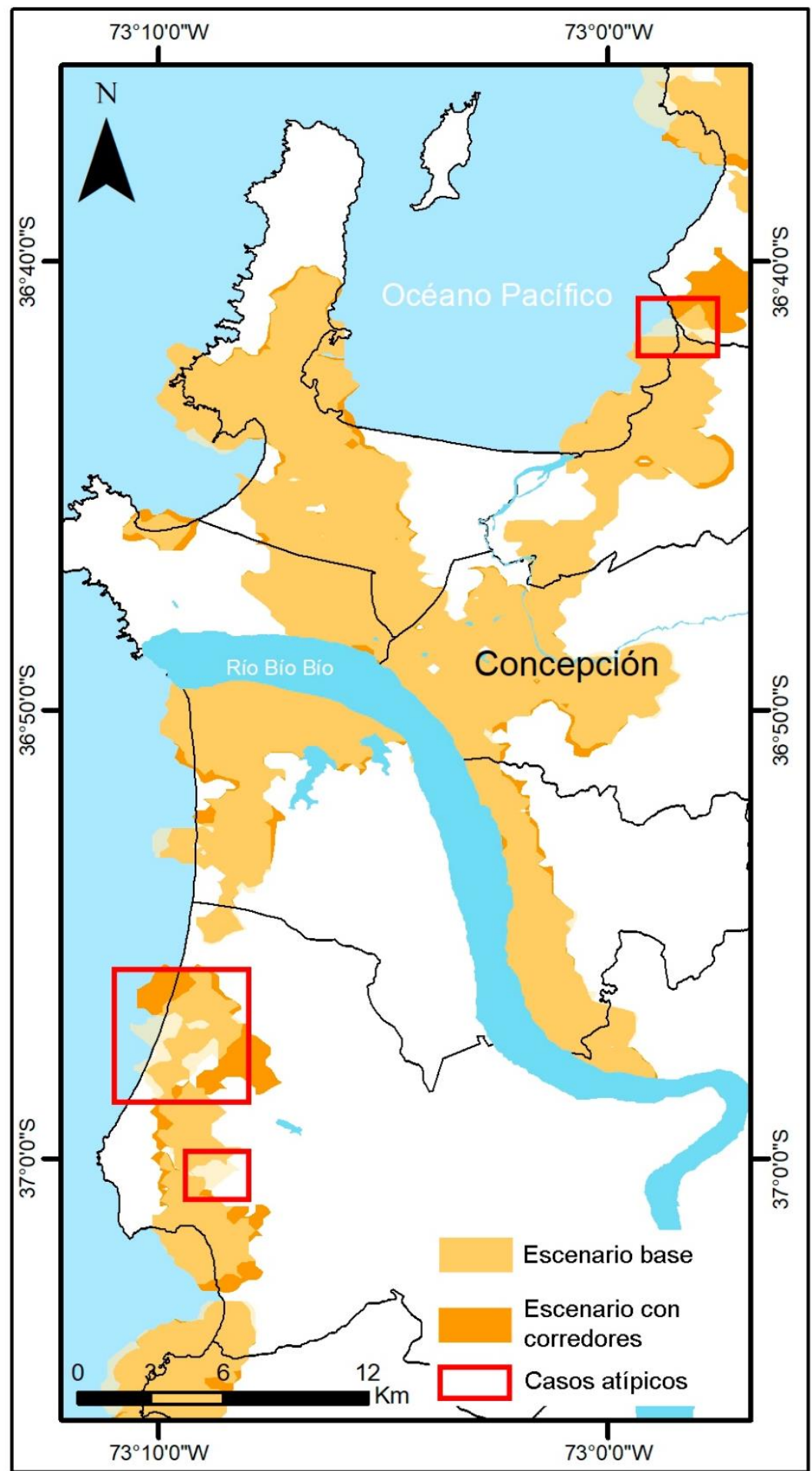

Fuente: Elaboración propia. 
Figura $\mathrm{N}^{\circ}$ 40: Resultados para el escenario futuro. A y $\mathrm{D}$ representan a Centro cívicos, $\mathrm{B}$ y $\mathrm{E}$ zonas con menor densidad poblacional y $\mathrm{C}$ y $\mathrm{F}$ zonas con mayor densidad poblacional.
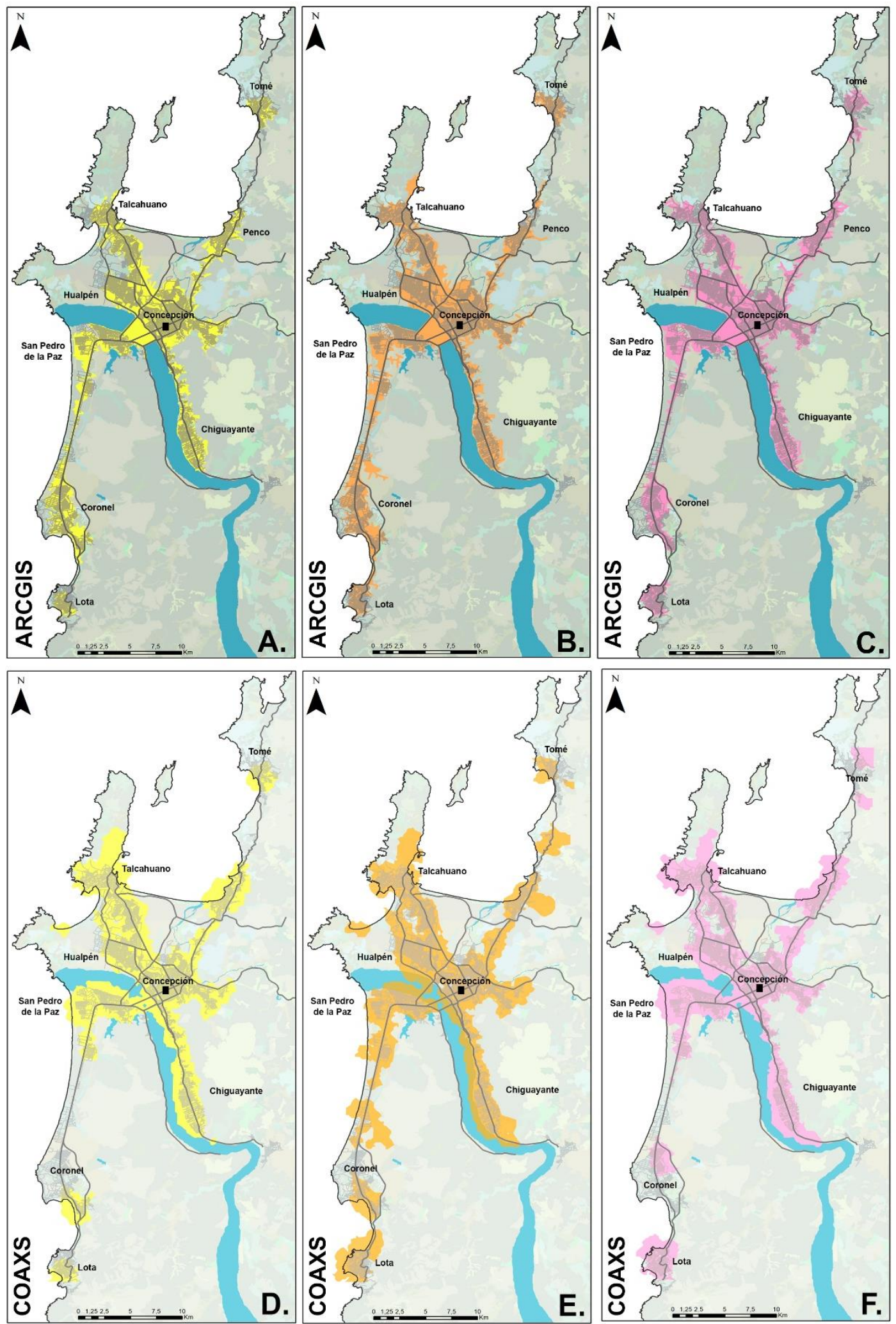

Fuente: Elaboración propia. 


\section{Comparación entre software ARCGIS y COAXS}

Ambos softwares entregaron datos muy dispares, siendo ArcGis el que presenta parámetros matemáticos más acertados en el acceso de población a servicios básicos. CoAXs, al ser una plataforma online, es probable que presente información desactualizada o no completamente exacta generando una volatilidad de los datos, cuyos parámetros de porcentajes deberían estar entre 0 a 100\% como se aprecia en gráfico 4, para el caso de los centros cívicos. Por otro lado, ArcGis logra representar la realidad de mejor manera a pesar de depender de los datos recolectados de forma manual para cada procedimiento.

En el Gráfico $\mathrm{N}^{\circ} 4$, los contrastes entre escenarios son razonables tanto en ArcGis como CoAXs, ya que la situación base fluctúa entre 0 a $83 \%$ y su situación futura se incrementa hasta un 35\% de acceso a servicios. El problema se evidencia cuando se trabaja con zonas distantes de los centros urbanos o periféricas (Gráfico $\mathrm{N}^{\circ} 5$ ), ya sea zonas con menor o mayor densidad poblacional, allí los datos escapan de manera notoria en CoAXs generando escenarios donde la situación base es increíblemente mejor que la futura.

Esto podría explicarse desde la perspectiva de la geometría de los datos, CoAXs se basa en archivo GTFS que fue revisado en un SIG de escritorio, allí se evidenciaron variadas falencias desde el punto de vista topológico, es decir, falta de conexión entre calles, rutas mal digitalizadas por mencionar algunos errores. Para el caso de ArcGis, se corrigió la red vial siguiendo la geometría arco-nodo, para evitar este problema.

Si bien se corrigieron los trazados de las nuevas rutas en CoAXs y contiene muchas más opciones de configuración para asemejarla realidad, queda la duda de la fiabilidad de sus datos base, provistos por los GTFS.

De manera visual, en la Figura $\mathrm{N}^{\circ} 40$ se pueden observar dichas incoherencias en la información cuando hay polígonos aislados sin una aparente conexión con rutas como en las subfiguras E y 
F. En cambio, A, B y C muestran una continuidad en la forma del dato, asemejándose más a una posible realidad.

Gráfico $\mathrm{N}^{\circ}$ 4: Histograma de resultados por software para el caso de Centros Cívicos

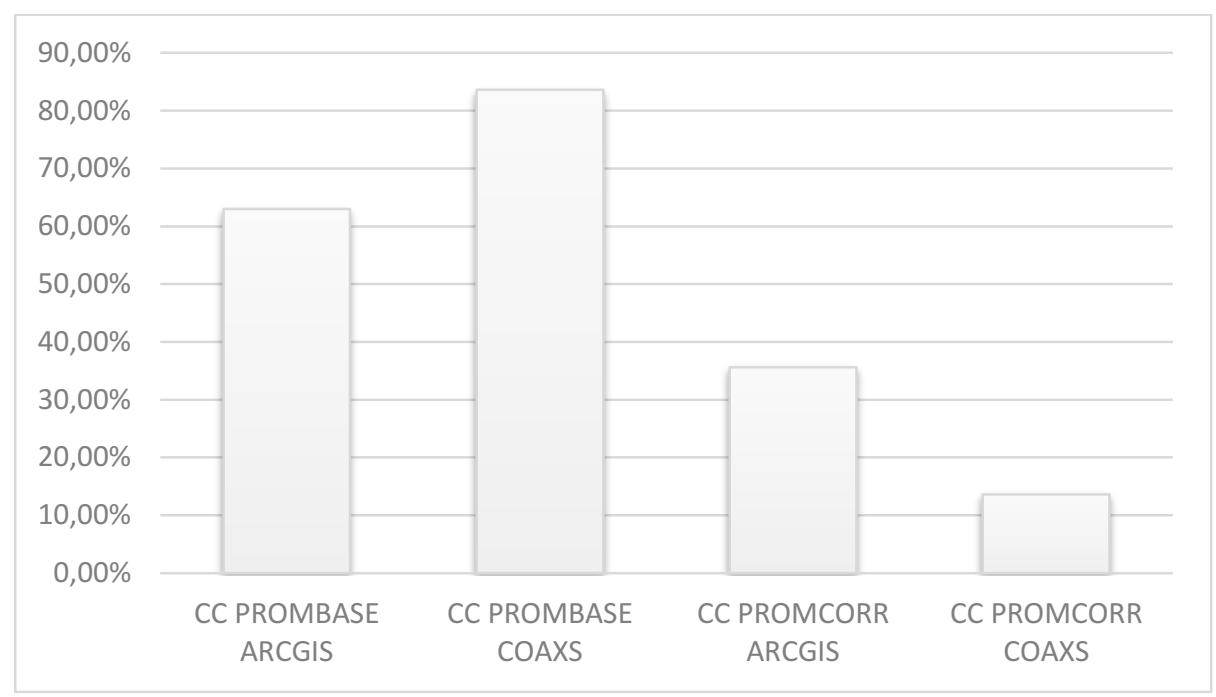

Fuente: Elaboración propia

Gráfico $\mathrm{N}^{\circ}$ 5: Histograma de resultados por software para el caso de zonas con menor y mayor densidad poblacional

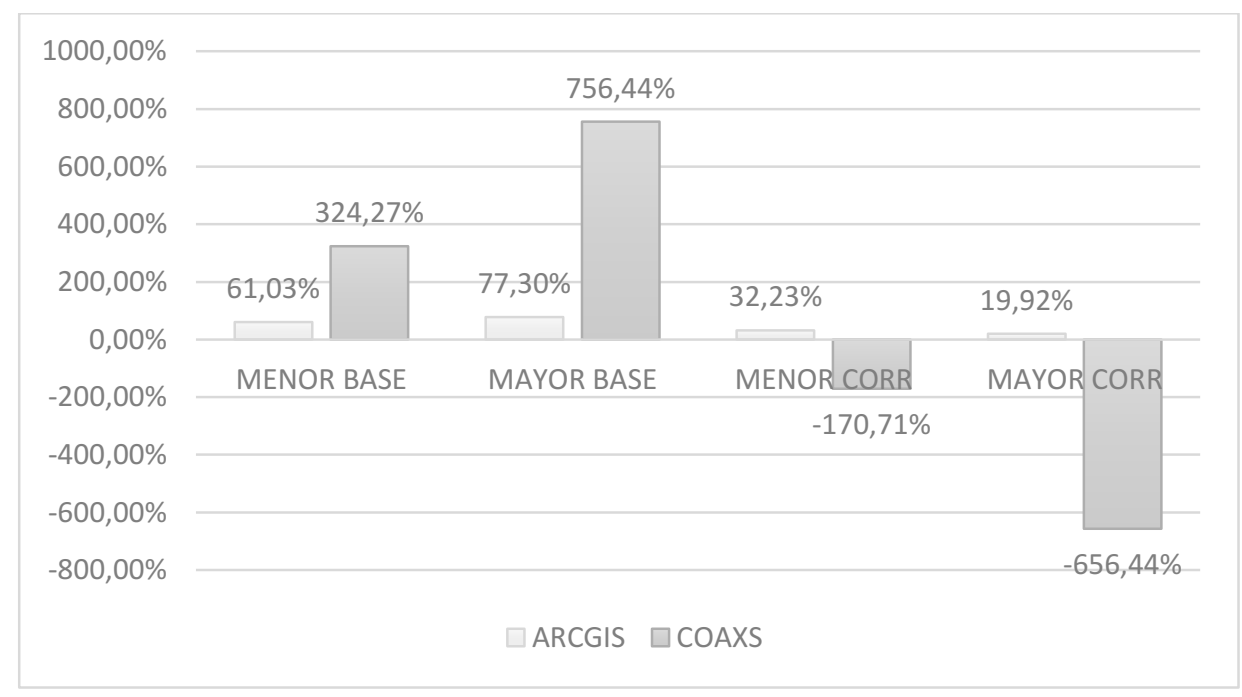

Fuente: Elaboración propia.

Respecto a la evaluación cualitativa de los softwares, se realizó una puntuación de cada uno respecto al tipo de calidad, tal como se presenta en la tabla $\mathrm{N}^{\circ} 9$. En calidad Interna/Externa las mayores debilidades de ambos programas radican en el mantenimiento y portabilidad, ya que 
los datos necesitan constante actualización y es más dificultoso si se deben realizar funciones de programación, requiriendo más especialistas y hardwares con más recursos computacionales. Para el caso de ArcGis, la portabilidad juega en contra, debido a la adquisición de licencias o suscripciones, alcanzando un costo elevado dependiendo de su versión. En calidad de uso, se debe tener la experiencia interactuando con ambas plataformas, por esta misma razón, CoAXs es mucho más amigable que ArcGis, y el motivo es su origen, ya que se plantea desde un inicio como una plataforma participativa, con el objetivo de que todo tipo de personas logre comprender los impactos del transporte público. Su punto negativo son los errores en la estimación de los servicios, que como se mencionó anteriormente, posee falencias debido a la geometría de la información espacial.

Para resumir, se visualizan pequeñas ventajas y desventajas en ambos programas que podrían mejorarse con el tiempo, ya sea optando por un software libre para mostrar información o mejorando los datos de entrada para obtener resultados más confiables y no generar confusión en el usuario.

Tabla ํㅜㄹ: Evaluación de la calidad de los softwares

\begin{tabular}{|l|c|c|c|c|}
\cline { 2 - 5 } \multicolumn{1}{c|}{} & ArcGis & Ponderación & CoAXs & Ponderación \\
\hline Calidad Interna/Externa & & & & \\
\hline Funcionalidad & 75 & 22.5 & 60 & 18 \\
\hline Fiabilidad & 75 & 8.25 & 40 & 4.4 \\
\hline Usabilidad & 90 & 27 & 95 & 28.5 \\
\hline Eficiencia & 70 & 2.1 & 50 & 1.5 \\
\hline Facilidad de mantenimiento & 50 & 12.5 & 10 & 2.5 \\
\hline Portabilidad & 20 & 0.2 & 80 & 0.8 \\
\hline & Total & 72.55 & Total & 55.7 \\
\hline Calidad de uso & & & & \\
\hline Efectividad & 90 & 27 & 45 & 13.5 \\
\hline Productividad & 49 & 9.8 & 65 & 13 \\
\hline Integridad & 90 & 18 & 95 & 19 \\
\hline Satisfacción & 49 & 14.7 & 85 & 25.5 \\
\hline & Total & 69.5 & Total & 71 \\
\hline
\end{tabular}

Fuente: Elaboración propia basada en ISO 9126. 
En relación a los talleres realizados, se procesaron las transcripciones de las actividades resultando una nube de palabras donde se destacan principalmente conceptos como: herramienta para entender la realidad, ver información, interesante, participación, proyecto, etc. Esto quiere decir que la evaluación de las personas fue primordialmente positiva, enfocándose como una herramienta que beneficia el entendimiento de los proyectos.

Figura $\mathrm{N}^{\circ} 41$ : Nube de palabras a partir de los talleres

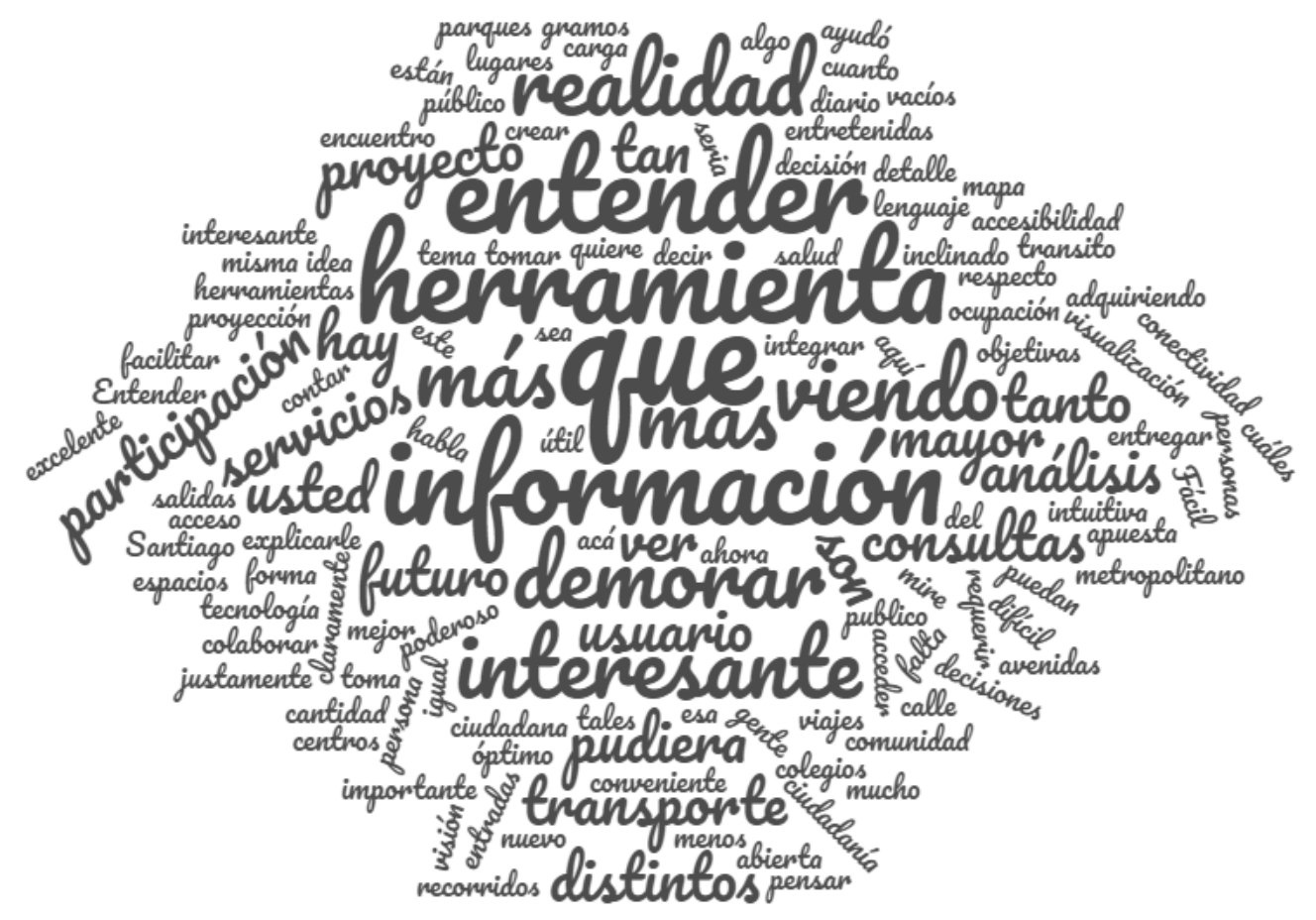

Fuente: Elaboración propia. 


\section{CONCLUSIONES}

Las plataformas para visualizar información geográfica son diversas, dependiendo de la temática y forma en la que se desea mostrar el contenido. Para este caso de estudio se comparó el desarrollo de dos sistemas SIG, uno web y otro de escritorio. Los resultados indican diferencias notorias, tanto en la información que se muestra como en la creación de cada una las plataformas, asociados principalmente a sus orígenes y capacidades diferentes.

Desde el punto de vista de los datos, la configuración en un entorno web es más amigable (basado en métricas de valoración subjetiva por parte del usuario) y con mayores parámetros para simular la realidad, sin embargo, requiere de un especialista calificado que diseñe de manera correcta el "Back-End", si esta interfaz se encuentra mal elaborada desde un principio, los resultados a mostrar no serán los correctos. Es decir, debe existir una coherencia entre la cara visible de la plataforma "Front-End" y el procesamiento detrás o "Back-End". Esto es lo que sucede con CoAXs, ya que las isócronas resultantes presentaron fallos, en el caso de los sectores periféricos de la ciudad, esto se debe probablemente a un dato incorrecto de entrada como a la falta de un detector de errores que permita automáticamente diagnosticar la calidad de la información de salida. En ese sentido, ArcGis consta con herramientas para comprobar un óptimo funcionamiento de la geometría de la red (topología), con este primer paso los resultados entregados ya serán más acertados. Continuando con la configuración, el software de escritorio permite añadir parámetros similares a CoAXs permitiendo una mejor calidad y precisión de los datos de salida. Cabe aclarar que las variables utilizadas en esta tesis son menores a las trabajadas en CoAXs, no obstante, funcionan de manera correcta y con mayor precisión al compararlo con la plataforma web.

En cuanto a la interacción software-usuario, sin duda un mapa interactivo facilita la comprensión de los impactos en el transporte público, más aún si se trabaja con distintos grupos de población como tomadores de decisiones o público general. Los talleres participativos así lo demuestran, destacando en mayor medida conceptos relacionados a la fácil comprensión de las 
herramientas. Caso contrario, ArcGis, en esta oportunidad sólo presenta mapas estáticos que no permiten entender la magnitud de los cambios en términos de accesibilidad a nivel individual.

Evidentemente, cualquiera de estas dos formas de representar los impactos en la cotidianidad de las personas, ya es un desafío para las actuales estrategias de evaluar proyectos de infraestructura de transporte. Ya que, temáticas como accesibilidad, no son abordados desde la perspectiva espacial.

Respecto a la interrogante de implementar nuevos corredores de transporte público, el acceso a servicios tuvo un 29\% de variación positiva en el Área Metropolitana de Concepción (software ArcGis), demostrando que la construcción de corredores es beneficiosa porque se registra un aumento del acceso total de servicios por parte de la población. En relación a esta misma situación futura, el porcentaje de población favorecida, ya sea de personas localizadas en el centro de las ciudades como en lugares distantes o periféricos, promedian 768.755 habitantes (86\% de la población total del AMC) y en comparación a la situación base, el aumento es de aproximadamente $10 \%$ de población.

Al visualizar la rápida expansión urbana de ciudades como San Pedro de la Paz, Hualpén o Penco (asociadas fuertemente a ciudades dormitorio) a largo plazo más personas deberán acceder a sus fuentes laborales o servicios localizados en el centro, puesto que, las estructuras urbanas de las ciudades chilenas tienden al monocentrismo. Así lo confirman los datos de la Encuesta Origen-Destino ${ }^{13}$, donde la mayor concentración de viajes se encuentran en Concepción y en segundo lugar Talcahuano, comunas vecinas.

Por otro lado, asumiendo también la realidad actual de Concepción y sus comunas aledañas, los tiempos de viaje dependen principalmente de los operadores de los buses y es complejo fiscalizar el cumplimiento de las velocidades normadas en todos los tramos de sus rutas. Es así,

13 Es una encuesta que permite conocer los viajes en el Gran Concepción. http://www.sectra.gob.cl/prensa/prensa070.htm 
como en comunas periféricas como Coronel o Lota se acusa una falta de regulación. Por ejemplo, los microbuses pueden llegar a transitar más allá de la velocidad permitida y presentan constantes accidentes (según se menciona en la prensa local ${ }^{14}$ ) con tal de llevar a más pasajeros, ya que más pasajeros se traduce en mayores ganancias. La construcción de nuevos corredores, fomentaría el uso del transporte público y permitiría un orden tanto de las pistas en que transitan los buses como en la regulación de sus velocidades, las cuales podrían disminuir eventualmente, pero garantizaría mayor seguridad a la ciudadanía, ya sea por la construcción de nuevos paraderos como por los cruces habilitados para acceder a estas infraestructuras.

Finalmente, se rescata la importancia de evaluar la calidad de los softwares con metodologías derivadas de procesos cualitativos, con métricas que se encuentras ya definidas y normadas, así se asegura la calificación de la mayor cantidad de aspectos posibles. Esta evaluación es un insumo primordial para técnicos que elaboran aplicaciones como también a la hora de que una organización pretenda adquirir un software, esto permite conocer la opinión de los usuarios que utilizan las plataformas y si les son realmente de utilidad para sus funciones.

Por otra parte, con estos ejercicios se pretende visibilizar la valiosa opinión de la población en los procesos de desarrollo de los proyectos, porque territorialmente generan impactos ya sea positivos o negativos en su calidad de vida, por esta razón crear nuevas herramientas como las mencionadas podría ser útil para pasar de una participación ciudadana simbólica a una participación real.

\footnotetext{
${ }^{14}$ Algunas noticias recopiladas en diarios locales:

https://sabes.cl/2019/04/24/mujer-muere-tras-impacto-de-automovil-con-micro-en-coronel/

https://terminaldebuses.wordpress.com/2010/05/05/fuertes-criticas-a-locomocion-lota-concepcion-trasaccidente-en-que-murieron-3-pasajeros/

http://espaciosfm.cl/una-mujer-lesionada-dejo-el-choque-de-una-micro-con-un-auto-en-la-ruta-160/

https://www.facebook.com/radioelcarbon/posts/1744070135632734/
} 


\section{BIBLIOGRAFÍA}

Abad, P.; Bernabé, M. A. Rodríguez, A. (2012). Compartir: la solución está en las Infraestructuras de Datos Espaciales. En Bernabé-Poveda, M.A. \& López-Vázquez, C.M., (editores) Fundamentos de las Infraestructuras de Datos Espaciales. Madrid, UPM-Press, Serie Científica, pp. 41-53.

Ahola, T., Virrantaus, K., Krisp, J. \& Hunter, G. (2007) A spatio-temporal populationmodel to support risk assessment and damage analysis for decision making. International Journal of Geographical Information Science No 8, 935-953 pp.

ArcGis (2021). ¿Qué es la extensión network analyst?. Disponible en: https://desktop.arcgis.com/es/arcmap/latest/extensions/network-analyst/what-is-networkanalyst-.htm.

Arnstein, S. R. (1969). A Ladder Of Citizen Participation, Journal of the American Planning Association, 35: 4, pp.216-224.

Ávila, M. (1996) “Aplicación de los Sistemas de información geográfica al tráfico urbano en un sector de Santa Fe de Bogotá". Departamento de Ingeniería Civil, Universidad de los Andes. Bogotá. Colombia. Recuperado el 25 de Octubre de 2007 de http:/gis.esri.com/library/ userconf/latinproc95/uniande2.pdf

Bernabé-Poveda, M. \& López-Vásquez, C. (2012). Fundamentos de las Infraestructuras de Datos Espaciales. Universidad Politécnica de Madrid. UPM Press. España

Baedeker, S. \& Lindenau, M. (2013). Why is Participation a Challenge in Sustainable Urban Mobility Planning? CHALLENGE, 2013.

Banco Interamericano de Desarrollo, BID (2017). ¿Cuál es el futuro del transporte público?. Moviliblog. Ideas de transporte y movilidad para América Latina y el Caribe. Disponible en: https://blogs.iadb.org/moviliblog/2017/12/11/futuro-del-transporte-publico/

Banco Mundial, (2020). Desarrollo Urbano. Disponible en: https://www.bancomundial.org/es/topic/urbandevelopment/overview 
Ballari et al. (2014). Tendencias en infraestructuras de datos espaciales en el contexto Latinoamericano. MASKANA, I+D+ingeniería. $\quad 177 \mathrm{p}-184 \mathrm{p} . \quad$ Vol 5. http://dspace.ucuenca.edu.ec/handle/123456789/21364

Bavoux, J.-J., Beaucire, F., Chapelon, L. \& Zembri, P. (2009). Géographie des transports. Paris, France: Armand Colin.

Bosque Sendra, J. \& Moreno Jiménez, A. (coords.) (2004): Sistemas de Información Geográfica y localización de instalaciones y equipamientos, RA-MA, Madrid. España.

Bosque Sendra, J.; Gómez Delgado, M.; Palm Rojas, F. (2006). Un nuevo modelo para localizar instalaciones no deseables: ventajas derivadas de la integración de modelos de localizaciónasignación y SIG Cuadernos Geográficos, Universidad de Granada Granada, España, núm. 39, pp. 53-68.

Buzai, G. \& Baxendale, C. (2006). Análisis socioespacial con Sistemas de Información Geográfica. Editorial Buenos Aires.

Buzai, G. (2008). Sistemas de Información Geográfica y cartografía temática. Métodos y técnicas para el trabajo en el aula. Buenos Aires, 128 pp.

Buzai, G. (2011). Modelos de localización-asignación aplicados a servicios públicos urbanos: análisis espacial de Centros de Atención Primaria de Salud (CAPS) en la ciudad de Luján, Argentina. Cuadernos de Geografía. Revista Colombiana. Vol. 20, № 2, p. 111 - 123.

Buzai, G \& Baxendale, C. (2015). Análisis socioespacial con sistemas de información geográfica. Marco conceptual basado en la teoría de la geografía. Memoria XIV Conferencia Iberoamericana de Sistemas de Información Geográfica Parte II. 391-408 pp.

Buzai, G. (2016). La Geografía como ciencia espacial. Bases conceptuales de la investigación astronómica vigentes en la Geografía Cuantitativa. Revista Universitario de Geografía, Vol. 25, 11-30 pp. 
Camacho, A.; Annichiarico, F. \& Jarava, J. (2012). Evaluación de la calidad del sistema de información SICAD bajo la norma ISO 9126. Monografía para optar al título de Especialista en Auditoria de Sistemas de Información. Corporación Universitaria de la Costa. Barranquilla. Colombia.

Cecilia, F. (2011), Nuestra nube de palabras, disponible en: https://www.abuelohara.com/2011/06/nuestra-nube-de-palabras-save-children.html

Celemín, J. (2009). Autocorrelación espacial e indicadores locales de asociación espacial: Importancia, estructura y aplicación. Revista Universitaria de Geografía, 18(1), 11-31. Disponible en: http://www.scielo.org.ar/scielo.php?script=sci_arttext\&pid=S1852$42652009000100002 \& \operatorname{lng}=$ es\&tlng=es.

Comisión Económica América Latina y El Caribe, CEPAL (2009). Preparación y evaluación de proyectos de inversión pública. Disponible en: https://www.cepal.org/cgibin/getprod.asp?xml=/ilpes/noticias/paginas/8/37218/P37218.xml\&xsl=/ilpes/tpl/p18f.xsl\&ba $\mathrm{se}=/$ ilpes/tpl/top-bottom.xsl

Corporación de Estudios Sociales y Educación (2001). Participación ciudadana en la Gestión Pública. Boletín del programa de pobreza y políticas sociales del Sur, Temas Sociales N 42.

Ellis, F. 2001. Gis self-learning tool. Universidad Alcalá de Henares, Departamento de Geomática. https:/geogra.uah.es/patxi/gisweb/GISModule/GIST_Raster.htm

Eluru, V. Khakour, A. El-Geneidy. (2012). Travel mode choice and transit route choice behaviour in Montreal: insights from McGill University members commute patterns. Public Transport, Vol. 4, 129-149 pp.

Encuesta Origen Destino, SECTRA (2017). Base de datos Hogares.

Escobar, D.; García, F. \& Tolosa, R. (2013). Accesibilidad Territorial a nivel regional. 1 ${ }^{\text {a }}$ Edición, Universidad Nacional de Colombia. Facultad de Ingeniería y Arquitectura, Manizales, Colombia

Fotheringham, S. \& Rogerson, P. (2007). GIS and spatial analytical problems. International Journal of Geographical Information System. Vol 7.3 - 19 pp. 
García Palomares, J. (2008). Los desplazamientos al trabajo en la comunidad de Madrid. Madrid.

Geurs, K.T \& Van Wee, B. (2004). Accessibility evaluation of land-use and transport strategies: review and research directions. Journal of Transport Geography. Vol, $\mathrm{N}^{\circ} 12$, pp.127-140. Disponible en: https://doi.org/10.1016/j.jtrangeo.2003.10.005

Geurs, K. T., Boon, W., \& Van Wee, B. (2009). Social impacts of transport: literature review and state-of-the-practice transport appraisal in the Netherlands and the United Kingdom. Transport reviews, Vol. 29(1), pp. 69-90.

Google Transit (2021). Descripción de los GTFS. Disponible en: https://developers.google.com/transit/gtfs?hl=es.

Goodchild, M. (1999). Geographic Information System. Progress in Human Geography 15, 2. 194-200 pp. University of California. USA.

Gómez, L (2007). Interoperabilidad en los Sistemas de Información Documental (SID): la información debe fluir. Revista Códice. Vol 3 N¹: 23-29. Disponible en: https://core.ac.uk/download/pdf/290487285.pdf

Gutiérrez Puebla, J. \& Gould, M. (2009). Reseña "SIG: Sistemas de Información Geográfica. Vol. 14, $\mathrm{N}^{\circ} 1.151-154 \mathrm{pp}$.

Gutiérrez Puebla, J.; Salas, M. \& García, P. (2016). Big (Geo) Data en ciencias sociales: retos y oportunidades. Revista de estudios Andaluces. Vol. 33; 1-23 pp.

Guerra, G. \& Fernando, A. (2009). Reseña "SIG: Sistemas de Información Geográfica" de Javier Gutiérrez Puebla y Michael Gould Geoenseñanza, vol. 14, núm. 1, enero-junio, 2009, pp. 151-154.

Hart, R. (1992). Childrens Participation from tokenism to citzenship. UNICEF Innocenti Research Centre. 
INE-Instituto Nacional de Estadísticas (2017): XIX Censo Nacional de población y VIII de vivienda, Gobierno de Chile. Disponible en: www.ine.cl.

Jäppinen, T. Toivonen, \& M. Salonen (2013). Modelling the potential effect of shared bicycles on public transport travel times in Greater Helsinki: An open data approach Applied Geography, Vol. 43, 13-24 pp.

Jaramillo

C. Murillo

$\mathrm{J}$.

(2006).

Análisis

de

accesibilidad vial para el área metropolitana de Santiago de Cali, Colombia), Santiago de Cali, Valle del Cauca, Colombia.

Jones, E. (1979). La geografía social. En Geografía pasado y futuro. Fondo de cultura económica de México. 424 pp.

Karst, t.; Boon, W. \& Van Wee, B. (2009). Social impacts of transport: literature review and state-of-the-practice transport appraisal in the Netherlands and the United Kingdom. Journal Transport reviews. Vol 29, 69-90 pp.

Lei, R.L. \& Church (2010). Mapping transit-based access: integrating GIS, routes and schedules. International Journal of Geographical Information Science, Vol. 24, 283-304 pp.

Liu \& Zhu, (2004). Accessibility analyst: an integrated GIS tool for accessibility analysis in urban transportation planning. Environment and Planning B: Planning and Design,Vol. $31,105-124 \mathrm{pp}$.

López,V.; Bosque,J. Delgado, M. 2008: Flexibilidad de los SIG para asistir a la toma de decisiones espaciales. Actas del XI Coloquio Ibérico de Geografía, Alcalá de Henares.

López, R. (2005). Cálculo de rutas óptimas mediante SIF en el territorio de la ciudad Celtibérica de Segeda. Propuesta metodológica. SALDVIE N5, pp 95-111.

Malczewski, J. 1999. Gis and multicriteria decision analysis. University of Western Ontario. Martin, H. Jordan, P. \& Roderick (2008). Taking the bus: Incorporating public transport timetable data into health care accessibility modelling. Environment and Planning A, Vol. 40, 2510-2525 pp. 
Manizales, Colombia. Universidad Nacional de Colombia. Editorial Blanecolor. ISBN: 978958-761-277-6

Ministerio de Desarrollo Social, Gobierno de Chile, MDS (2016). Metodología de formulación y evaluación de proyectos de vialidad local. Disponible en: http://www.senado.cl/site/presupuesto/2017/cumplimiento/Glosas\%202017/primera_subcomi sion/21\%20Des.\%20Social/ORD.\%201208\%20Subs.\%20Ev.\%20Social\%202017/Metodologi a\%20Vialidad\%20Local.pdf

Ministerio de Planificación MIDEPLAN, (2015). Metodología General de Preparación y Evaluación de Proyectos. Disponible: http://sitio.gorebiobio.cl/wpcontent/uploads/2015/05/Metodologia_general.pdf

Mejías Vera, M.A., Herrera Lorenzo, N., Vera Galván, J.R. y Pérez Pérez, M. (2010): Diseño de un modelo de datos de redes para el transporte multimodal. En: Ojeda, J., Pita, M.F. y Vallejo, I. (Eds.), Tecnologías de la Información Geográfica: La Información Geográfica al servicio de los ciudadanos. Secretariado de Publicaciones de la Universidad de Sevilla. Sevilla. Pp. 511-521. ISBN: 978-84-472-1294-1.

Ministerio de Transporte y Telecomunicaciones, (2013). Resultados Diálogos Ciudadanos para la Política Nacional de Transporte. http://www.mtt.gob.cl/wpcontent/uploads/2013/05/Resultados-Dialogos-Ciudadanos.pdf.

Moniruzzaman \& A. Páez (2012). Accessibility to transit, by transit, and mode share: application of a logistic model with spatial filters. Journal of Transport Geography, Vol. 24, 198-205 pp.

Moliner, F., (2005). Informáticos Generalitat Valenciana. Editorial MAD. España

Morales, C. (2013). Participación ciudadana en proyectos de transporte público. Disponible en: https://ransvial.wordpress.com/2013/11/03/participacion-ciudadana-en-los-proyectos-detransporte-publico-parte-i/ 
Morales, S (¿???). Fundamentos SIG Teledetección Disponible en: https://www.ucursos.cl/ciencias/2013/2/CS06025/1/material_docente/o/783273

Moreno Jiménez, A. (2000). Localización de la población y servicios de farmacia. En Población y Espacio para la comunidad de Madrid. Análisis y aplicaciones a nivel microgeográfico. Disponible en: www.comadrid.es/iestadis.

Moreno Jímenez, A. (2007). Sistemas y Análisis de la Información Geográfica. Cuadernos Geográficos, Vol.39. 231-233 pp.

Opazo, Sergio; Garay, Eduardo; Muñoz, René; López-Saldaña, Gerardo; Aguilar, R, \& Radic, S. (2014). Desarrollo de una plataforma web SIG para el monitoreo dinámico de pastizales en Magallanes. Anales Instituto Patagonia (Chile), vol. 42, nº 2, pp. 39-51.

Organización para la Cooperación y el Desarrollo Económico OCDE, (2002). Impact of transport infraestrcuture investment on regional development. Paris: OCDE Publicationes.

O'Sullivan, A. Morrison \& J. (2000). Using desktop GIS for the investigation of accessibility by public transport: an isochrone approach. International Journal of Geographical Information Science, Vol. 14, 85-104 pp.

Oviedo, D., Bocarejo, J. (2011). Desarrollo de una metodología de estimación de accesibilidad como herramienta de evaluación de políticas de transporte en países en desarrollo: estudio de caso de la ciudad de Bogotá, Colombia.

Páez, A., Scott, D.M. y Morency, C. (2012). Measuring accessibility: positive and normative implementations of various accessibility indicators. Journal of Transport Geography, vol. 25, pp. 141-153. DOI 10.1016/j.jtrangeo.2012.03.016.

Parras, M \& Gómez, E. (2015) Tiempo de viaje en transporte público. Aproximación conceptual y metodológica para su medicion en la ciudad de Resistencia. Revista Transporte y Territorio. Vol. 13. 66-79 pp.

Peipins, S. Graham, R. Young, B. Lewis, S. Foster, B. \& Flanagan, A. (2011). Time and distance barriers to mammography facilities in the Atlanta metropolitan área. Journal of community health, Vol. 36, 675-683 pp. 
Prats,

C. (2016).

Informática.

Disponible

en:

https://sites.google.com/site/informaticamcprats/iso-9126

Programa de las Naciones Unidas para el Desarrollo (PNUD). 2018. Objetivos de Desarrollo Sotenible. Disponible en: http://www.undp.org/content/undp/es/home/sustainabledevelopment-goals.html

Ramírez, L. (2006). La accesibilidad y la movilidad espacial: Posible tratamiento mediante SIG. Cuadernos de Ideas. Migración interna, movilidad espacial y reconfiguraciones territoriales. Serie Sociedad. Vol $\quad N^{\circ} 2 . \quad$ Disponible http://hum.unne.edu.ar/investigacion/geografia/labtig/publicaciones/public23.pdf

Ramírez, L. (2008). Modelado espacial de la accesibilidad de la población a los centros de salud en el Área Metropolitana del Gran Resistencia - Chaco (Argentina). Congreso Internacional de Cartografía Santiago de Chile.

Ruíz, G.; Peña, A.; Castro, C.; Alaguna, A.; Areiza, L. \& Rincón, R. (2006). Modelo de Evaluación de calidad de software basado en lógica difusa, aplicada a métricas de usabilidad de acuerdo con la norma ISO/IEC 9126. Revista Avances en Sistemas e Informática. Universidad Nacional de Colombia. Vol. 3, N², 25-29 pp. Disponible en: https://www.redalyc.org/pdf/1331/133114988005.pdf.

Secretaría de Planificación de Transporte SECTRA, (2013). Manual de Evaluación Social de Proyectos de Vialidad Urbana. MDS-Sectra. Disponible en: http://www.sectra.gob.cl/metodologias/mespivu.htm

Serna - Uran, C.; García-Castrillón, J. \& Flórez-Londoño, O. (2016). Análisis de rutas de transporte de pasajeros mediante la herramienta Network Analyst de ArcGis. Caso aplicado en la ciudad de Medellín. Ingenierías USBMed. Vol. 7, N².

Shekar, S \& Xiong, H., (2008) Encyclopedia of GIS, Springer, Boston. 
Sterling, J. (2017). The history and importance of web mapping. College of Earth and Mineral ciences. The Pennsylvania State University. Disponible en: https://www.eeducation.psu.edu/geog585/node/643

Stallman, R. (2011). Free software foundation. Disponible en: www.fsf.org.

Sinha, K. \& Labi, S. (2007). Transportation Decision Making: Principles of Project Evaluation and Programming. Editorial John Wiley \&Sons. Inc.ISBN:978047174732. DOI:10. $1002 / 97804701680731$

Stewart, F. \& Zegras, C. (2016). CoAXs: A Collaborative Accessibility-based Stakeholder Engagement System for communicating transport impacts. Research in Transportation Economics. Vol 59. Pp.423-433. Disponible en: https://doi.org/10.1016/j.retrec.2016.07.016

Torrego, F. (1986). Geografía de los transportes. Anales de Geografía de la Universidad Complutense. Vol. 6.

Vivanco, A. (2011). Evaluación de calidad de sistema integrado para casas de valores SICAV de la bolsa de valores de Quito utilizando la norma ISO/IEC 14598. Proyecto previo a la obtención del título de Ingeniero en Sistemas de Informáticos y Computación. Escuela Politécnica Nacional. Ecuador.

Vaccaro, L. (2011). Análisis de la accesibilidad desde la perspectiva de la movilidad. Hacia el entendimiento de la desigualdad socio-territorial en casos de estudio de las comunas de Conchalí y Huechuraba. Memoria para optar al Título Profesional de Geógrafo. Universidad de Chile.

Wefering, F.; Rupprecht, S.; Bührmann, S.; Böhler-Baedeker, S.; Rupperchet Consult \& Forschung und Beratung GmbH (2014). Guidelines. Developing and implementing a sustainable urban mobility plan. Disponible en: http://www.eltis.org/sites/default/files/guidelines-developing-and-implementing-asump_final_web_jan2014b.pdf 